\title{
Avian haemosporidian parasites of accipitriform raptors
}

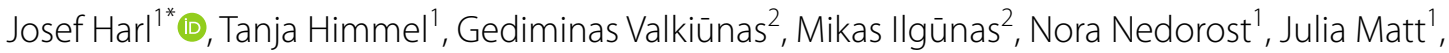 \\ Anna Kübber-Heiss ${ }^{3}$, Amer Alic $^{4}$, Cornelia Konicek $^{5}$ and Herbert Weissenböck ${ }^{1}$
}

\begin{abstract}
Background: The order Accipitriformes comprises the largest group of birds of prey with 260 species in four families. So far, 21 haemosporidian parasite species have been described from or reported to occur in accipitriform birds. Only five of these parasite species have been characterized molecular genetically. The first part of this study involved molecular genetic screening of accipitriform raptors from Austria and Bosnia-Herzegovina and the first chromogenic in situ hybridization approach targeting parasites in this host group. The aim of the second part of this study was to summarize the CytB sequence data of haemosporidian parasites from accipitriform raptors and to visualize the geographic and host distribution of the lineages.
\end{abstract}

Methods: Blood and tissue samples of 183 accipitriform raptors from Austria and Bosnia-Herzegovina were screened for Plasmodium, Haemoproteus and Leucocytozoon parasites by nested PCR, and tissue samples of 23 PCR-positive birds were subjected to chromogenic in situ hybridization using genus-specific probes targeting the parasites' 185 rRNAs. All published CytB sequence data from accipitriform raptors were analysed, phylogenetic trees were calculated, and DNA haplotype network analyses were performed with sequences from clades featuring multiple lineages detected in this host group.

Results: Of the 183 raptors from Austria and Bosnia-Herzegovina screened by PCR and sequencing, 80 individuals (44\%) were infected with haemosporidian parasites. Among the 39 CytB lineages detected, 18 were found for the first time in the present study. The chromogenic in situ hybridization revealed exo-erythrocytic tissue stages of Leucocytozoon parasites belonging to the Leucocytozoon toddi species group in the kidneys of 14 infected birds. The total number of CytB lineages recorded in accipitriform birds worldwide was 57 for Leucocytozoon, 25 for Plasmodium, and 21 for Haemoproteus.

Conclusion: The analysis of the DNA haplotype networks allowed identifying numerous distinct groups of lineages, which have not yet been linked to morphospecies, and many of them likely belong to yet undescribed parasite species. Tissue stages of Leucocytozoon parasites developing in accipitriform raptors were discovered and described. The majority of Leucocytozoon and Haemoproteus lineages are specific to this host group, but most Plasmodium lineages were found in birds of other orders. This might indicate local transmission from birds kept at the same facilities (raptor rescue centres and zoos), likely resulting in abortive infections. To clarify the taxonomic and systematic problems, combined morphological and molecular genetic analyses on a wider range of accipitriform host species are needed.

*Correspondence: josef.harl@vetmeduni.ac.at

${ }^{1}$ Institute of Pathology, Department of Pathobiology, University of Veterinary Medicine Vienna, Veterinaerplatz 1, 1210 Vienna, Austria

Full list of author information is available at the end of the article

\section{Background}

The order Haemosporida (phylum Apicomplexa) includes several genera of single-celled eukaryotic parasites, which infect vertebrate hosts and are transmitted by blood-sucking dipteran vectors. Haemosporidian 
parasites feature complex life cycles and undergo multiple developmental stages in both the vertebrate hosts and dipteran vectors. The infection of tissue and blood cells can seriously affect the host's health, potentially leading to the damage of organs $[1,2]$, anaemia, dyspnoea, and death [3]. Birds feature the largest diversity of haemosporidian parasites with more than 250 species classified into the genera Plasmodium, Haemoproteus, Leucocytozoon, and Fallisia [4]. Traditionally, haemosporidian parasite species were characterized based on the morphology of blood stages, an approach, which is limited by the low number of morphological features, particularly in species of Leucocytozoon and Akiba. The introduction of molecular genetics opened new possibilities to characterize the diversity of avian haemosporidians. DNA barcoding assays were developed two decades ago and a 478 base pair (bp) section of the mitochondrial Cytochrome B $(C y t B)$ was established as the main reference sequence for the identification of haemosporidian lineages [5, 6]. Bensch et al. [7] developed the MalAvi database (http://130.235.244. 92/Malavi/), which uses a standardized nomenclature to assign unique names to $C y t B$ lineages of avian haemosporidians and summarizes data on hosts, localities and references of most recorded lineages, providing an important source of information for the haemosporidian research community. The MalAvi database currently features a collection of about 4,000 unique $C y t B$ lineages recorded in over 35,000 birds. Only 279 records originate from accipitriform raptors (Accipitriformes), two-thirds of which were published in the following eight publications: Pérez-Rodríguez et al. [8], Sehgal et al. [9], Jasper et al. [10], Huang et al. [11], Hanel et al. [12], Poharkar et al. [13], Krone et al. [14], and Ciloglu et al. [15]. Avian raptors are under-represented in haemosporidian studies because they have low population densities and are usually not caught in mist nets like many passeriform birds. Moreover, many raptor species are protected by conservation laws and, therefore, are rarely, if at all, used in experimental studies. As a result, many aspects of haemosporidioses in accipitriform raptors are poorly studied, particularly the tissue stages, which develop in the organs.

The bird order Accipitriformes represents the largest group of birds of prey with 260 species in four families, compared to Strigiformes with 234 species in two families, and Falconiformes with 66 species in one family. Within the order Accipitriformes, the family Accipitridae is most diverse with 250 species in 69 genera including hawks, eagles, kites and others; the family Cathartidae includes nine species of New World vultures in six genera; the monotypic family Sagittariidae features only the secretary bird Sagittarius serpentarius; the osprey
Pandion haliaetus is the only two species of the family Pandionidae (http://datazone.birdlife.org/).

The number of haemosporidian parasites described from accipitriform hosts is low with 10 Leucocytozoon, five Haemoproteus, and three Plasmodium species (Table 1). Plasmodium circumflexum (type host: Turdus pilaris), Plasmodium fallax (type host: Strix woodfordii), and Plasmodium forresteri (type host: Strix woodfordii) are included in the table because morphologically indistinguishable parasites were reported to be common in accipitriform raptors [3]. Plasmodium alloelongatum and Plasmodium buteonis are listed in the table but the former name is likely a synonym of Plasmodium elongatum. Blood stages of $P$. buteonis should be re-examined because this name was considered a species inquirenda in the latest taxonomic review [16]. All 10 Leucocytozoon species belong to the Leucocytozoon toddi group, whose species exclusively infect accipitriform raptors. However, most of these species were synonymized with $L$. toddi because their blood stages and host cells possess similar characters and could not always be reliably delimitated by their morphological features [17-20]. The status of the current synonyms may be changed when more information on the parasites' life cycles and DNA sequences are available. Studies analysing both mitochondrial and nuclear genes of Haemoproteus spp. and Leucocytozoon spp. found that closely related lineages, differing in one or a few bp in the $C y t B$, were strictly associated with unique alleles for the nuclear loci, thus supporting the presence of a high number of cryptic species [9, 21, 22].

The present study consists of two parts. The first represents a molecular screening approach for which 183 accipitriform raptors of 16 species from Austria and Bosnia-Herzegovina (B.-H.) were screened for avian haemosporidians by PCR and sequencing the standard $C y t B$ barcode region. The present study not only included the most diverse sample of accipitriform raptors in Europe, but it also represents the first molecular genetic approach targeting haemosporidian parasites in the organs of infected raptors by chromogenic in situ hybridization (CISH). This study aimed at investigating the diversity of haemosporidian lineages in accipitriform raptors from Central Europe, examining blood and tissue stages in the hosts' organs by CISH, and identifying potential pathological effects of exo-erythrocytic development (tissue merogony) in this host group.

The second part of the study aims at analysing the geographic and host distribution of haemosporidian parasite lineages in accipitriform raptors worldwide. It follows the approach of [4], who summarized information on avian haemosporidian parasites of the family Turdidae. Other records were gathered from NCBI GenBank, MalAvi database and related publications. Phylogenetic clades 
Table 1 Haemosporidian parasite species described from or reported commonly in accipitriform birds

\begin{tabular}{|c|c|c|c|}
\hline Parasite species & Authors & Type host (bold) and additional hosts & Type locality \\
\hline Haemoproteus buteonis & Wingstrand, 1947 & $\begin{array}{l}\text { Buteo buteo, (Accipiter cooperii, Accipiter nisus, Aquila } \\
\text { nipalensis Buteo platypterus, Buteo rufinus, Circus aerugino- } \\
\text { sus, Pernis apivorus, Pernis ptilorhynchus) }\end{array}$ & Sweden \\
\hline $\begin{array}{l}\text { Haemoproteus catharti } \\
\text { hCATAUR01 }\end{array}$ & Greiner et al. 2011 & Cathartes aura & South Carolina (USA) \\
\hline $\begin{array}{l}\text { Haemoproteus elani } \\
\text { hBUBT1 }\end{array}$ & Mello, 1935 & $\begin{array}{l}\text { Elanus caeruleus, (Accipiter cooperii, Accipiter gentilis, } \\
\text { Accipiter melanoleucus, Accipiter nisus, Accipiter striatus, } \\
\text { Aegypius tracheliotus, Aquila rapax, Buteo jamaicensis, } \\
\text { Buteo lagopus, Buteo lineatus, Circaetus gallicus, Gyps } \\
\text { africanus, Hieraaetus fasciatus) }\end{array}$ & Goa (western India) \\
\hline Haemoproteus janovyi & Greiner and Mundy, 1979 & $\begin{array}{l}\text { Gyps africanus, (Melierax canorus, Necrosyrtes monachus, } \\
\text { Torgos tracheliotus, Trigonoceps occipitalis) }\end{array}$ & Northwest Zimbabwe \\
\hline Haemoproteus nisi & Peirce and Marquiss, 1983 & $\begin{array}{l}\text { Accipiter nisus, (Accipiter cooperi, Accipiter soloensis, } \\
\text { Accipiter striatus, Accipiter tachiro, Accipiter trivirgatus, } \\
\text { Accipiter virgatus, Aquila clanga, Aquila wahlbergi, Butastur } \\
\text { indicus, Buteo buteo, Buteo jamaicensis, Circus aeruginosus, } \\
\text { Circus cyaneus, Circus macrourus, Circus pygargus, Melierax } \\
\text { metabates, Milvus migrans) }\end{array}$ & Scotland (UK) \\
\hline Leucocytozoon audieri & Laveran and Nattan-Larrier, 1911 & Haliaeetus vocifer & Congo \\
\hline Leucocytozoon bacelari & Tendeiro, 1947 & Kaupifalco monogrammicus & Guinea Bissau \\
\hline Leucocytozoon beaurepairei & Travassos Santos Diaz, 1954 & Sagittarius serpentarius & Mozambique \\
\hline $\begin{array}{l}\text { Leucocytozoon buteonis } \\
\text { IBUBT2, IBUTJAM10, IBUTREG01 }\end{array}$ & Coatney and Roudabush, 1937 & $\begin{array}{l}\text { Buteo jamaicensis, (Buteo buteo, Buteo regalis, Buteo } \\
\text { lineatus) }\end{array}$ & Nebraska (USA) \\
\hline Leucocytozoon circaeti & Sergent and Fabiani, 1922 & Circaetus gallicus & Algeria \\
\hline Leucocytozoon franchini & França, 1927 & Circus macrourus ('albanella pallida') & Italy \\
\hline Leucocytozoon martyi & Commes, 1918 & Accipiter badius sphenurus & Mali \\
\hline $\begin{array}{l}\text { Leucocytozoon mathisi } \\
\text { IACCOP01, IACNI04 }\end{array}$ & França, 1912 & Accipiter nisus, (Accipiter cooperii) & Portugal \\
\hline Leucocytozoon muratovi & Subkhonov, 1980 & Circus aeruginosus & Tajikistan \\
\hline Leucocytozoon toddi & Sambon, 1908 & $\begin{array}{l}\text { Kaupifalco monogrammicus, (numerous birds of the } \\
\text { Accipitriformes) }\end{array}$ & Congo \\
\hline $\begin{array}{l}\text { Plasmodium circumflexum } \\
\text { pTURDUS1, pBT7 }\end{array}$ & Kikuth, 1931 & $\begin{array}{l}\text { Turdus pilaris, (Passeriformes, Accipitriformes, Anseri- } \\
\text { formes, Columbiformes, Coraciiformes, Charadriiformes, } \\
\text { Falconiformes, Strigiformes, Galliformes, and some } \\
\text { others) }\end{array}$ & Germany \\
\hline Plasmodium fallax & Schwetz, 1930 & $\begin{array}{l}\text { Strix woodfordii, (Accipiter nisus, Aquila rapax, Aquila } \\
\text { wahlbergi, Gyps africanus) }\end{array}$ & Belgian Congo \\
\hline Plasmodium forresteri & Telford, Nayar, Foster \& Knight, 1997 & $\begin{array}{l}\text { Strix varia, (Buteo jamaicensis, Buteo lineatus, Buteo } \\
\text { platypterus, Haliaeetus leucocephalus) }\end{array}$ & Georgia (USA) \\
\hline Plasmodium accipiteris & Paperna, Yosef \& Landau & Accipiter brevipes & Eilat (Israel) \\
\hline Plasmodium alloelongatum* & Paperna, Yosef \& Landau & Accipiter brevipes & Eilat (Israel) \\
\hline Plasmodium buteonis* & Paperna, Yosef \& Landau & Buteo buteo & Eilat (Israel) \\
\hline
\end{tabular}

Haemosporidian parasite species described from or reported commonly in accipitriform birds based on morphological blood stage records. If $C y t B$ lineages were linked to morphospecies, the MalAvi lineage name is indicated following the species name. The names of type hosts are written in bold letters, additional hosts are reported in brackets

*These two names are likely invalid according to [16]

containing multiple $C y t B$ lineages detected in accipitriform raptors were identified and DNA haplotype networks were calculated to visualize their geographic and host distribution. Moreover, information on morphologically but not yet molecular genetically characterized parasite species is discussed. This approach was selected to estimate the potential number of haemosporidian parasite species in this host group, identify lineages, which potentially belong to yet unrecognized parasite species, and create a basis for comparing $C y t B$ data with taxonomic information pre-dating the molecular genetic era. 


\section{Methods}

\section{Molecular screening of accipitriform raptors from Austria and Bosnia-Herzegovina Sample preparation}

For the present study, blood and tissue samples from 183 individual accipitriform raptors of 16 species were collected in Austria and B.-H. The samples collected by different institutions originated from the following host species: Accipiter gentilis (11 individuals), Accipiter nisus (25), Aquila chrysaetos (1), Aquila heliaca (10), Buteo buteo (75), Buteo lagopus (1), Buteo sp. (5), Circus aeruginosus (22), Circus cyaneus (4), Clanga pomarina (2), Gypaetus barbatus (2), Gyps fulvus (2), Haliaeetus albicilla (12), Haliaeetus leucocephalus (1), Milvus milvus (8), Pandion haliaetus (1), and Pernis apivorus (1).

The Research Institute of Wildlife Ecology (Department of Interdisciplinary Life Sciences, Vetmeduni Vienna) provided frozen and formalin-fixed paraffinembedded (FFPE) tissue samples of 112 birds collected between 2009 and 2018 in Austria (mostly Lower Austria, Upper Austria and Burgenland). Paraffin blocks of individual birds contained tissues of the heart, lung, liver, and spleen and in most cases also brain, spleen, skeletal muscle, and intestines. Blood samples were taken from 58 living birds received for treatment at the service unit for birds and reptiles of the clinic for small animal internal medicine (Department for Companion Animals and Horses, Vetmeduni Vienna) between 2015 and 2016. The clinical records showed that more than half of the birds suffered from traumatic injuries (e.g., bird strikes) and neurological problems. Blood counts, tests for other pathogens, and thorough examinations were performed only in a few cases, therefore, this information is not provided here. The blood was taken by puncturing the brachial vein using heparinized microcapillaries to transfer blood drops to high-grade filter papers Whatman ${ }^{\mathrm{TM}}$ 903 (GE Healthcare, Buckinghamshire, UK). Frozen tissue samples (liver and lung) of 11 birds were collected by the Department of Pathology at the Sarajevo Faculty of Veterinary Medicine (University of Sarajevo, B.-H.) between 2017 and 2018. Twelve birds, which died after treatment at the service unit for birds and reptiles (Vetmeduni Vienna), were dissected at the Institute of Pathology (Department of Pathobiology, Vetmeduni Vienna) and tissue samples were taken from the heart, lung, liver, spleen, kidney, brain, skeletal muscle, and gastrointestinal tract. For histology, tissue samples were fixed in formalin and embedded in paraffin. For molecular analyses, liver, spleen and brain samples were frozen and stored at $-80{ }^{\circ} \mathrm{C}$ until further use. All FFPE tissue blocks, frozen tissue samples, blood films, and blood spots are stored in the pathological collections of either the Research Institute of Wildlife Ecology (Vetmeduni Vienna), the
Institute of Pathology (Vetmeduni Vienna), or the Department of Pathology at the Sarajevo Faculty of Veterinary Medicine.

\section{DNA extraction, $P C R s$, and sequence analyses}

The DNA of all samples was extracted either from tissue (liver and spleen) or blood spots using the DNeasy Blood \& Tissue Kit (QIAGEN, Venlo, The Netherlands) by following the manufacturer's protocol for isolation of DNA from tissue samples. Two $100 \mu \mathrm{l}$ eluates were made from the same column in the last centrifugation step, the first at $8000 \mathrm{rpm}$ and the second at 13,000 rpm. The DNA samples (second eluate) of all 183 individuals were screened for the presence of avian haemosporidians using the nested PCR protocol established by [6], which allows the amplification of $478 / 476$ bp sections of the mitochondrial CytB gene in Plasmodium, Haemoproteus and Leucocytozoon parasites. The primers HaemNFI (5'-CAT ATA TTA AGA GAA NTA TGG AG-3') and HaemNR3 (5'-ATA GAA AGAT AAG AAA TAC CAT $\left.\mathrm{TC}-3^{\prime}\right)$ were used in the first PCR. In the nested PCRs, the primers HaemF $\left(5^{\prime}\right.$-ATG GTG CTT TCG ATA TAT GCA TG-3') and HaemR2 (5'-GCA TTA TCT GGA TGT GAT AAT GGT-3') were used to amplify a 478 bp section in Plasmodium spp. and Haemoproteus spp., and HaemFL (5'-ATG GTG TTT TAG ATA CTT ACA TT-3') and HaemR2L (5'-CAT TAT CTG GAT GAG ATA ATG GIG C-3') were used to amplify a 476 bp section in Leucocytozoon spp. The nested PCR assay by [6] does not allow amplification of the $C y t B$ in parasites of the $L$. todd $i$ group. In particular, the forward primer of the first PCR, HaemNFI, shows a two bp mismatch at the 3'-end compared to L. toddi group sequences (AG vs GC), and the nested reverse primer HaemR2L, used for amplification of the CytB in Leucocytozoon parasites, features a two bp mismatch at the 3'-end (GC [complement] vs CT, TT, or AT). Therefore, all samples were screened also using the nested PCR protocol established by [23], which allows the amplification of a $528 \mathrm{bp}$ fragment specifically of parasites in this group. The primers CytB_L2_F (5'-GAG AGT TAT GGG CTG GAT GGT-3') and CytB_L2_R (5'TAG AAA GCC AAG AAA TAC CAT TCT G-3') were used in the first PCR, and the primers CytB_L2_nF (5'GCT GGA TGG TGT TTT AGA TAY ATG C-3') and CytB_L2_nR (5'-CCA TTC TGG AAC AAT ATG TAA AGG TG-3') were used in the nested PCR.

All PCRs were performed using the GoTaq ${ }^{\circledR}$ G2 Flexi DNA Polymerase (Promega, Madison, WI, USA). They were conducted in $25 \mu \mathrm{l}$ volumes containing $14.375 \mu \mathrm{l}$ nuclease-free water, $5 \mu \mathrm{l} 5 \mathrm{X}$ Green GoTaq Flexi Buffer, $2 \mu \mathrm{l} \mathrm{MgCl}_{2}$ solution (25 mM), $0.5 \mu \mathrm{l}$ nucleotide mix (10 mM), $0.125 \mu \mathrm{l}$ GoTaq G2 Flexi DNA Polymerase $(5 \mu / \mu \mathrm{l})$, each $1 \mu \mathrm{l}$ forward and reverse primer $(10 \mathrm{mM})$, 
and $1 \mu \mathrm{l}$ of DNA template. The PCRs started with an initial denaturation for $2 \mathrm{~min}$ at $94{ }^{\circ} \mathrm{C}$, followed by 35 cycles with $30 \mathrm{~s}$ at $94{ }^{\circ} \mathrm{C}, 30 \mathrm{~s}$ at the respective annealing temperatures $\left(50{ }^{\circ} \mathrm{C}\right.$ : HaemNFI/ HaemNR3, HaemF/ HaemR2, and HaemFL/HaemR2L; $55{ }^{\circ} \mathrm{C}$ : CytB_L2_F/ CytB_L2_F and CytB_L2_nF/ CytB_L2_nR), 1 min at $72{ }^{\circ} \mathrm{C}$, and a final extension for $10 \mathrm{~min}$ at $72{ }^{\circ} \mathrm{C}$. Each $1 \mu \mathrm{l}$ of the first PCR product was used as a template in the nested PCRs. Negative and positive controls (previously confirmed by sequencing) were included in all PCRs. The PCR products were visualized on $1 \%$ agarose gels stained with MIDORI ${ }^{\text {Green }}$ Advance DNA/RNA stain (Nippon Genetics Europe, Düren, Germany). All positive products from the nested PCRs were sent to Microsynth Austria (Vienna, Austria) for purification and sequencing in both directions using the respective PCR primers. The forward and reverse sequences were aligned with Bioedit v. 7.0.5.3 [24], and the electropherograms were carefully checked for double peaks to identify mixed infections. The positions featuring double peaks in both the forward and reverse sequences were coded with the corresponding ambiguity codes. Then these sequences were unphased both manually and with DnaSP v.6.12.3 [25] based on an alignment containing all sequences generated for the present study. To confirm their identity and compare their similarity with already published data, the sequences were subjected to BLAST searches on NCBI GenBank and the avian malaria database MalAvi [7]. $C y t B$ sequences of new lineages and information on hosts and geographic origin were added to the MalAvi database, and all sequences were also uploaded onto NCBI GenBank (accession numbers OL598427-OL598534).

\section{Chromogenic in situ hybridization}

Chromogenic in situ hybridization (CISH) was performed on tissue samples of 33 PCR-positive birds of which paraffin blocks were available. For detecting haemosporidian parasite stages in tissue sections of these birds, 1-2 $\mu \mathrm{m}$ histological sections were prepared, one of which was stained with haematoxylin and eosin (HE), and the remaining were subjected to CISH. CISH was performed by following previously established protocols and using (sub)genus-specific probes, which target the $18 S$ ribosomal RNAs of parasites from the genera Plasmodium, Haemoproteus, and Leucocytozoon [2, 23]. Specifically, the following probes were used: Plas18S (5'TTT AAT AAC TCG TTA TAT ATA TCA GTG TAG CAC-3') for detecting Plasmodium spp., Haemo18S_1 (5'-GCT AAC CGT AGT TAT AGT CGC CAT CTC-3') for Haemoproteus parasites of the subgenus Parahaemoproteus, Leuco18S_1 (5'-TAG GAC TCC CCA CTT GTC TTT TTC TTGA-3') for Leucocytozoon parasites of the subgenus Leucocytozoon, and Ltod18S (5'-GCT AAC
CGT AGT TAT AGT CGC CAT CTC-3') for targeting parasites of the $L$. toddi species group. In cases of mixed infections, several tissue sections were separately incubated with all relevant probes. All HE-stained sections and in situ hybridized sections were examined at 50x$1000 \times$ magnification using an Olympus BX51 microscope (Olympus Europa, Hamburg, Germany) equipped with an Olympus DP71 camera for microphotography. Images were adjusted for brightness and contrast and assembled in Adobe Photoshop CC 2021 (Adobe, San José, CA, USA).

\section{Diversity of haemosporidian CytB lineages in accipitriform raptors worldwide Collection of CytB data from GenBank and MalAvi databases} The second part of the present study provides a summary of data on avian haemosporidian parasite lineages of accipitriform raptors worldwide. For a previous study on haemosporidian parasites in birds of the family Turdidae [4], the first author $(\mathrm{JH})$ collected all haemosporidian $C y t B$ sequences and related information available on NCBI GenBank. This dataset was used to identify clades featuring similar lineages by sorting the sequences with MAFFT v.7 [26], manually inspecting the alignments using Bioedit v.7.0.8.0 [24], and performing Maximum Likelihood (ML) analyses on the W-IQ-TREE web server (http://iqtree.cibiv.univie.ac.at/; [27]), as described in [4]. New data published to February 2021 were added to this data set. To incorporate information from the MalAvi database (http://130.235.244.92/Malavi/; [7]), the 'host and sites table' was mined for all data originating from accipitriform hosts (currently classified wrongly as Falconiformes in the MalAvi database). This information was then added to a Microsoft Excel spreadsheet containing the GenBank data and the new sequence data generated for the present study. Based on the combined data from NCBI GenBank and the MalAvi database, the authors evaluated all sequence data originating from accipitriform hosts, identified those clades featuring multiple haemosporidian parasite lineages detected in accipitriform hosts, and extracted information on all lineages contained within these clades (including data on nonaccipitriform birds) from the MalAvi database.

\section{Phylogenetic analysis of genus clades and Leucocytozoon toddi group}

A phylogenetic tree was calculated with lineages belonging to the $L$. todd $i$ species group, the most diverse group of haemosporidian parasites in accipitriform raptors. The alignment contained all $L$. toddi group lineages covering the full 478 bp $C y t B$ fragment of the DNA barcode region, 48 lineages in total (including 16 new ones detected in the present study). To conform to the alignments used for the 
DNA haplotype networks, the first and last two bp of the alignment were trimmed prior to the phylogenetic analyses. This was done with all alignments analysed for the present study because the end parts of many published sequences were not curated thoroughly and contained some obvious errors. The sequence of Leucocytozoon californicus lCIAE02 (accession number EF607287) was used as an outgroup. A ML bootstrap consensus tree (1,000 replicates) was calculated using the W-IQ-TREE web server (http://iqtree.cibiv.univie.ac.at/; [27]), applying the model TIM2 + G4, which was suggested as best fit for the data set in the model test according to the Bayesian inference criterion (BIC). A Bayesian Inference (BI) tree was calculated with MrBayes v.3.2.2 [28]. Applying the model GTR $+\mathrm{G}$, the BI analysis was run for $5^{10}$ generations (2 runs with 4 chains, one of which was heated), sampling every thousandth tree. The first $25 \%$ of the trees were discarded as burn-in and a majority rule consensus tree was calculated from the remaining 3,750 trees. The tree was visualized with Figtree v.1.4.4 (http://tree.bio.ed. ac.uk/software/figtree/; Andrew Rambaut) and finalized with Adobe Illustrator CC v.2015 (Adobe Inc., San José, CA, USA). Phylogenetic trees were also calculated for the Plasmodium, Haemoproteus and other Leucocytozoon lineages, including related lineages from other bird hosts contained in the DNA haplotype networks. BI and ML trees were calculated using the same settings as for the sequences of the $L$. toddi species group but with varying substitution models. The models used for the ML analyses were $\mathrm{TIM} 2+\mathrm{G} 4+\mathrm{I}$ (BI: GTR $+\mathrm{G}+\mathrm{I})$ for Plasmodium and Haemoproteus, and TIM2 + G4 (BI: GTR + G) for Leucocytozoon.

\section{DNA haplotype networks}

DNA haplotype networks were calculated for clades featuring multiple lineages of haemosporidian parasites from accipitriform birds. For each $C y t B$ lineage contained in the networks, information on the number of hosts and their geographic origin were obtained from NCBI GenBank, the MalAvi 'host and sites table', and the respective publications. All GenBank sequences, which contained ambiguous characters, obvious sequencing errors, or which did not cover the 474 bp CytB section used in the analysis were removed from the alignments. There were several cases in which lineage names and related information were reported only to the MalAvi database, but sequences were not submitted to NCBI GenBank. Although a quality check could not be performed for these data, they were still included to obtain a more comprehensive picture. The sequences of a few lineages, which were deposited only in NCBI GenBank but not published in research studies, were also included because they featured valuable information. Analyses were performed with the sequence data of nine Leucocytozoon clades, eight of which belong to the L. toddi species group, three Plasmodium clades, and four Haemoproteus clades. The DNA haplotype network analyses were performed following the procedure of [4]: (1) The alignments were trimmed to $474 \mathrm{bp}$ by removing the first and last two base pairs of the full 478 bp barcode section because particularly the end parts of many published sequences were not curated thoroughly and contained some obvious errors; (2) Median-Joining haplotype networks were calculated with Network 10.2.0.0 (Fluxus Technology Ltd, Suffolk, UK) applying the default settings; (3) Using Network Publisher v.2.1.2.5 (Fluxus Technology Ltd), the networks were graphically arranged and information on the host species and geographic regions was added. For each network, two visual representations were prepared, the first showing the host distribution of the lineages, the second showing the geographic distribution according to the United Nations Geoscheme; and, (4) The networks were finalized with Adobe Illustrator CC v.2015 (Adobe Inc., San José, CA, USA).

\section{Results \\ Molecular study on accipitriform raptors from Austria and Bosnia-Herzegovina \\ Diversity and infection rates of haemosporidian parasite lineages}

For this part of the study, samples of 183 accipitriform raptors of 16 species were screened for the presence of avian haemosporidians. In total, 80 individuals (44\%) featured haemosporidian infections, of which 49 were mono-infections, 27 double infections, and four triple infections (Table 2). Infections with parasites of the $L$. toddi species group were most common with 60 birds either being infected with one (43 individuals) or two lineages (16). The most common lineage was IBUBT2 (27), followed by lBUTBUT03 (13), lBUTBUT07 (6), ICIAE03 (4), IMILVUS01 (4), IACNI04 (3), IMILANS04 (2), IBUTBUT08 (2), lACCGEN01 (1), and lACNI1 (1). Apart from the novel lineages 1BUTBUT07 and 1BUTBUT08, nine additional new $L$. toddi group lineages were found in one bird each: ICLAPOM02, ICLAPOM03, IBUTBUT13, ICIAE04, ICIAE05, IBUTBUT11, IBUTBUT12, IBUTBUT09, and 1BUTBUT10. Leucocytozoon sp. ICIAE02 was detected in four individuals of Circus aeruginosus, whereby one individual featured a double infection with Leucocytozoon sp. ICIAE06. Leucocytozoon sp. IMILVUS2 was found in each one individual of Buteo buteo and Buteo lagopus, and Leucocytozoon sp. 1ASOT06 in each one individual of Buteo buteo and Circus aeruginosus. Plasmodium circumflexum was by far the most common Plasmodium parasite with 11 individuals being infected with the lineage pTURDUS1, two with $\mathrm{pBT} 7$, and one 
Table 2 Haemosporidian CytB lineages found in accipitriform raptors from Austria and Bosnia-Herzegovina

\begin{tabular}{|c|c|c|c|c|c|}
\hline Host species & $\mathrm{n}$ tested & $\mathrm{n}$ infected & Plasmodium & Haemoproteus & Leucocytozoon \\
\hline Accipiter gentilis & 11 & 5 & P. matutinum pLINN1 (1) & - & $\begin{array}{l}\text { L. buteonis IBUBT2 (1), L. sp. IBUTBUT03 (2), L. sp. IAC- } \\
\text { CGEN01 (1) }\end{array}$ \\
\hline Accipiter nisus & 25 & 12 & P. circumflexum pTURDUS1 (3) & - & $\begin{array}{l}\text { L. sp. IACNI03 (1), L. sp. IACNI05 (1), L. mathisi IACNI04 (2), } \\
\text { L. sp. IACNI1 (1), L. sp. IACNI06 (1), L. sp. IACNI07 (1), L. sp. } \\
\text { IMILANSO4 (2) }\end{array}$ \\
\hline Aquila chrysaetos & 1 & - & - & - & - \\
\hline Aquila heliaca & 10 & - & - & - & - \\
\hline Buteo buteo & 75 & 47 & $\begin{array}{l}\text { P. circumflexum pTURDUS1 } \\
\text { (2), P. circumflexum pBT7 (2), P. } \\
\text { elongatum pGRW06 (1) }\end{array}$ & $\begin{array}{l}\text { H. noctuae } \\
\text { hCIRCUM01 (1), } \\
\text { H. elani hBUBT1 } \\
\text { (2) }\end{array}$ & $\begin{array}{l}\text { L. sp. IASOT06 (1), L. buteonis IBUBT2 (25), L. sp. IBUTBUT07 } \\
\text { (5), L. sp. IBUTBUT08 (2), L. sp. IBUTBUT09 (1), L. sp. IBUT- } \\
\text { BUT10 (1), L. sp. IBUTBUT03 (12), L. sp. IBUTBUT11 (1), L. } \\
\text { sp. IBUTBUT12 (1), L. sp. IMILVUSO1 (4), L. sp. IBUTBUT13 } \\
\text { (1), L. sp. IMILVUS2 (1) }\end{array}$ \\
\hline Buteo lagopus & 1 & 1 & - & - & L. sp. IMILVUS02 (1), L. sp. IBUTBUT07 (1) \\
\hline Buteo sp. & 5 & - & - & - & - \\
\hline Circus aeruginosus & 22 & 15 & $\begin{array}{l}\text { P. circumflexum pTURDUS1 } \\
\text { (5), P. cf. circumflexum } \\
\text { pCIAE07 (1), P. sp. pSYBOR10 } \\
\text { (1) }\end{array}$ & $\begin{array}{l}\text { H. brachiatus } \\
\text { hLK03 (1), H. aff. } \\
\text { elani hCIAE08 } \\
\text { (1) }\end{array}$ & $\begin{array}{l}\text { L. mathisi IACNI04 (1), L. sp. IASOT06 (1), L. buteonis IBUBT2 } \\
\text { (1), L. sp. ICIAE05 (1), L. sp. ICIAE02 (5), L. sp. ICIAE06 (1), L. } \\
\text { sp. ICIAE03 (5), L. sp. ICIAE04 (1) }\end{array}$ \\
\hline Circus cyaneus & 4 & 1 & - & - & L. sp. ICIRCYA01 (1) \\
\hline Clanga pomarina & 2 & 1 & - & - & L. sp. ICLAPOM02 (1), L. sp. ICLAPOM03 (1) \\
\hline Gypaetus barbatus & 2 & - & - & - & - \\
\hline Gyps fulvus & 2 & - & - & - & - \\
\hline Haliaeetus albicilla & 12 & 1 & - & - & L. sp. IMILVUSO2 (1) \\
\hline H. leucocephalus & 1 & & - & - & - \\
\hline Milvus milvus & 8 & & - & - & - \\
\hline Pernis apivorus & 1 & & - & - & - \\
\hline Pandion haliaetus & 1 & & - & - & - \\
\hline
\end{tabular}

Names of parasite species are indicated if lineages were already linked to morphospecies. The numbers in the brackets indicate the number of individuals featuring the respective lineages. Lineages detected for the first time in the present study are highlighted in bold letters

The term 'aff.' ('species affinis') indicates that the lineage is similar to other lineages, which were already linked to morphospecies

individual was infected with both pTURDUS1 and the new lineage pCIAE07, differing in one bp from pTURDUS1. One bird each was infected with the Plasmodium lineages P. elongatum pGRW06 (Buteo buteo), P. cf. elongatum pMILANS05 (Circus aeruginosus), Plasmodium matutinum pLINN1 (Accipiter gentilis), and Plasmodium sp. pSYBOR10 (Circus aeruginosus). One bird each featured Haemoproteus infections with Haemoproteus brachiatus ILK03 (Circus aeruginosus), Haemoproteus noctuae hCIRCUM01 (Circus aeruginosus), and Haemoproteus aff. elani hCIAE08 (Circus aeruginosus), and two individuals of Buteo buteo featured Haemoproteus elani hBUBT1 (Buteo buteo).

\section{Parasites stages detected by CISH}

Among 34 PCR-positive birds (with FFPE tissue samples available), 25 showed haemosporidian parasite stages in histological sections, albeit not of all recorded lineages (Table 3$)$. Particularly Plasmodium parasites (P. circumflexum, $P$. matutinum and $P$. elongatum) were not detected by CISH in any of the birds confirmed positive for Plasmodium spp. by PCR. All 25 CISH-positive birds showed blood stages of the parasites (Fig. 1). In addition to blood stages, haemosporidian tissue stages were found in 14 birds, including 13 Buteo buteo infected with various $L$. toddi group lineages, and a Circus aeruginosus co-infected with Leucocytozoon sp. lCIAE03 and P. circumflexum pTURDUS1 (Table 3). Based on the labelling with the $L$. todd $i$-specific probe, most of the meronts could be attributed to lineages of the $L$. toddi species group. Meronts were observed exclusively in the kidneys, with an abundance ranging from single to a few meronts per renal cross-section. The meronts seemed to develop primarily in renal epithelial cells, although the exact location could not be determined for all of them due to poor preservation of some of the tissues. In some of the infected epithelial cells, a normal-sized host cell nucleus was visible (Fig. 2). Meronts ranged in size from approximately $10 \mu \mathrm{m}$ to a maximum of $50 \mu \mathrm{m}$ and varied in maturity not only between individuals but also in different organs of the same specimens. They contained more or less well-defined developing merozoites. 
Table 3 Haemosporidian parasite stages detected by CISH and histology in tissue sections of accipitriform birds

\begin{tabular}{|c|c|c|c|c|}
\hline ID & Host species & Parasites & Blood stages $^{1,2}$ & $\begin{array}{l}\text { Tissue } \\
\text { stages } \\
\text { (meronts) }^{1}\end{array}$ \\
\hline $\mathrm{AH} 0817$ & Accipiter gentilis & P. matutinum pLINN1 & - & - \\
\hline AH0397 & Accipiter nisus & P. circumflexum pTURDUS1 & - & - \\
\hline $\mathrm{AH} 0810$ & Accipiter nisus & L. aff. toddi IMILANSO4 & + & - \\
\hline AH1336 & Accipiter nisus & L. mathisi IACNI04 & - & - \\
\hline AH1943 & Accipiter nisus & L. aff. toddi IMILANSO4 & + & - \\
\hline AH0156 & Buteo buteo & P. cf. circumflexum pBT7 & - & - \\
\hline AH0182 & Buteo buteo & L. buteonis IBUBT2, L. aff. toddi IBUTBUT07 & + & Kidney \\
\hline $\mathrm{AH} 0234$ & Buteo buteo & L. buteonis IBUBT2 & + & Kidney \\
\hline $\mathrm{AH} 0235$ & Buteo buteo & L. buteonis IBUBT2, L. aff. toddi IBUTBUT08 & + & Kidney \\
\hline AH0236 & Buteo buteo & L. aff. toddi IBUTBUT03 & + & - \\
\hline $\mathrm{AH} 0242$ & Buteo buteo & L. aff. toddi IBUTBUT07 & + & Kidney \\
\hline $\mathrm{AH} 0244$ & Buteo buteo & L. buteonis IBUBT2, L. aff. toddi IBUTBUT03 & + & Kidney \\
\hline $\mathrm{AH} 0252$ & Buteo buteo & L. aff. toddi IBUTBUT03, L. aff. toddi IBUTBUT13 & + & - \\
\hline $\mathrm{AH} 0281$ & Buteo buteo & L. sp. IMILVUS02, L. aff. toddi IBUTBUT03, P. circumflexum pBT7 & + & Kidney \\
\hline $\mathrm{AH} 0282$ & Buteo buteo & L. buteonis IBUBT2 & - & - \\
\hline $\mathrm{AH} 0283$ & Buteo buteo & L. buteonis IBUBT2 & + & - \\
\hline $\mathrm{AH} 0288$ & Buteo buteo & L. buteonis IBUBT2, L. aff. toddi IBUTBUT03 & + & - \\
\hline AH0291 & Buteo buteo & L. buteonis IBUBT2, L. aff. toddi IBUTBUT03 & + & Kidney \\
\hline AH0293 & Buteo buteo & L. buteonis IBUBT2 & + & Kidney \\
\hline AH0545 & Buteo buteo & L. buteonis IBUBT2, L. aff. toddi IBUTBUT03 & + & Kidney \\
\hline AH0822 & Buteo buteo & L. aff. toddi IBUTBUT03 & + & - \\
\hline $\mathrm{AH} 1817$ & Buteo buteo & L. buteonis IBUBT2 & + & - \\
\hline $\mathrm{AH} 1844$ & Buteo buteo & L. aff. toddi IBUTBUT08 & + & Kidney \\
\hline AH1863 & Buteo buteo & L. buteonis IBUBT2, L. aff. toddi IBUTBUT09 & + & Kidney \\
\hline AH1920 & Buteo buteo & L. buteonis IBUBT2 & + & Kidney \\
\hline AH1952 & Buteo buteo & L. aff. toddi IBUTBUT12 & + & Kidney \\
\hline AH0249 & Circus aeruginosus & P. cf. elongatum pMILANS05, L. aff. toddi ICIAE04 & - & - \\
\hline $\mathrm{AH} 0250$ & Circus aeruginosus & P. circumflexum pTURDUS1, L. aff. toddi ICIAE03 & + & Kidney \\
\hline $\mathrm{AH} 0254$ & Circus aeruginosus & H. sp. hCIAE08 & + & - \\
\hline $\mathrm{AH} 0255$ & Circus aeruginosus & L. cf. californicus ICIAE02, L. mathisi IACNI04 & $+($ Leuco18S) & - \\
\hline $\mathrm{AH} 0260$ & Circus aeruginosus & $\begin{array}{l}\text { L. cf. californicus ICIAE02, L. cf. californicus ICIAE06, P. circumflexum } \\
\text { pTURDUS1 }\end{array}$ & - & - \\
\hline AH1869 & Circus aeruginosus & L. sp. IASOT06, L. buteonis IBUBT2 & - & - \\
\hline AH1929 & Circus aeruginosus & L. aff. toddi ICIAEO3 & + & - \\
\hline
\end{tabular}

${ }^{1}$ Unless otherwise stated, parasite stages were labelled with the Leucocytozoon toddi-specific probe (Ltod18S)

${ }^{2}-$ No blood stages detected,+ blood stages detected

Cytomeres could not be definitely distinguished. Megalomeronts were not observed in the inspected sections. As far as a histologic evaluation was possible, no major tissue alterations were associated with the detected tissue stages. In the Circus aeruginosus co-infected with pTURDUS1 and ICIAE03, a single meront of approximately $50 \mu \mathrm{m}$ in length, was found in a HE-stained section of the heart muscle. However, due to the absence of this meront in the corresponding in situ hybridized section, its haemosporidian origin could not be confirmed by CISH. The morphology resembles tissue cysts of parasites belonging to the family Sarcocystidae (Conoidasida, Apicomplexa) (Additional file 1: Fig. S1).

\section{Avian haemosporidian parasites in accipitriform raptors worldwide}

Leucocytozoon parasites in accipitriform raptors

All 10 Leucocytozoon parasites described from accipitriform hosts belong to the $L$. toddi species group, but most names were previously synonymized with $L$. toddi due to 
morphological similarity of their gametocytes and hostcells [3]. However, the genetic diversity within this clade is high, potentially indicating a higher number of parasite species than previously assumed. The only other clade featuring multiple Leucocytozoon lineages from accipitriform raptors contains the sequence linked to $L$. californicus and related parasite lineages. Another five lineages clustered into different clades, four of which were found mostly in birds of other orders and probably appeared in accipitriform birds as abortive infections. Table 4 features a summary of Leucocytozoon lineages found in accipitriform raptors. Two separate BI trees are provided for the L. toddi group (Fig. 3) and the other Leucocytozoon lineages (Additional file 2: Fig. S2).

\section{Leucocytozoon toddi species group}

Parasite lineages of the $L$. toddi species group were exclusively found in accipitriform raptors and belong to a clade, which differs from the other Leucocytozoon taxa by about $20 \%$ in the $C y t B$. The lineages were found in birds in Europe, Northern America and Western Asia.

Eight major clades (L201 to L208; Fig. 3), separated by more than $5.6 \% p$-distance in the $C y t B$ barcode section, were identified. These clades feature 18 sub-clades separated by at least five bp (ca 1.2\%) from each other. The haplotypes/lineages within the sub-clades differ by three bp or less from each other or the most common, central haplotypes. Haplotype networks showing the geographic and host distribution of the lineages within each clade are shown in Fig. 4.

Clade L201 contains five sub-clades featuring similar lineages (L201a to L201f). Sub-clade L201a contains lBUBT2 (29), IBUTBUT07 (6), IBUTBUT08 (2), IBUTBUT09 (1), IBUTBUT10 (1), and IBUTJAM15 (1). Lineage IBUTJAM15 was found in Buteo jamaicensis (1) in the USA [10], the others mostly in Buteo buteo in Western Europe. Lineage 1BUBT2 was found in Buteo buteo from Austria (24), B.-H. (1) and Kazakhstan (1), and in Accipiter gentilis (1) and Circus aeruginosus (1) from Austria [9,
14]. Lineage lBUTBUT07 was found in Buteo buteo from Austria (4) and B.-H. (1), and in Buteo lagopus (1) from Austria. The lineages IBUTBUT08 (2), IBUTBUT09 (1), and IBUTBUT10 (1) were exclusively detected in Buteo buteo in Austria. Sub-clade L201b contains IBUTJAM04 (22), IBUTJAM07 (18), lBUTREG01 (2), IBUTJAM02 (1), IBUTJAM03 (1), IBUTJAM05 (1), IBUTJAM06 (1), IBUTJAM08 (1), IBUTJAM09 (1), IBUTJAM14 (1), IBUTJAM16 (1), IBUTJAM17 (1), and IBUTJAM18 (1) $[9,10]$. All lineages were exclusively found in Buteo jamaicensis in the USA, except for IBUTREG01 and IBUTJAM07, which were also found in single individuals of Buteo regalis and in Buteo lineatus, respectively. Subclade L201c features IMILVUS01 (9) and IBUTBUT13 (1). Lineage IMILVUS01 was found in Buteo buteo (4) in Austria and Milvus milvus (4) and Milvus migrans (1) in Spain [8], and IBUTBUT13 was detected in a single specimen of Buteo buteo in Austria. Sub-clades L201d (lBUTJAM11) and L201e (IBUTJAM10) feature single lineages reported from Buteo jamaicensis in the USA $[9,10]$. Last, sub-clade L201f contains ICLAPOM02 and ICLAPOM03, which were detected in one specimen of the lesser spotted eagle Clanga pomarina in Austria. Based on a combined analysis of morphological and $C y t B$ sequence data, [29] linked IBUBT2 (L201a), lBUTJAM10 (L201e), and lBUTREG01 (L201b) to Leucocytozoon buteonis. The latter three lineages belong to distinct sub-clades (L201, Fig. 4) and differ by 1.5 to $3.4 \%$ from each other in the $C y t B$. The patterns regarding host and geographic distribution suggest that the lineages in clade L201 might belong to six different parasite species.

Clade L202 features five lineages in four sub-clades. L202a contains lACCOP01, exclusively detected in Accipiter cooperi (11) in the USA [9]. L202b contains 1ACCGEN01 (11) and IACCGEN03 (1), exclusively found in Accipiter gentilis from Czechia [12] and Austria. L202c features lCIRCYA01 from Circus cyanaeus (1) in Austria. Last, sub-clade L202d contains 1ACNI04 found in Accipiter nisus (3) from Austria and Kazakhstan [9] and

\footnotetext{
(See figure on next page.)

Fig. 1 Leucocytozoon spp. blood stages (gametocytes) in histological sections of accipitriform birds (a-f Accipiter nisus, $\mathbf{g}-\mathbf{I}$ Circus aeruginosus, $\mathbf{m}-\mathbf{r}$ Buteo buteo). Blood stages were labelled by the L. toddi-specific probe during CISH (a, $\mathbf{b}, \mathbf{d}, \mathbf{e}, \mathbf{g}, \mathbf{h}, \mathbf{j}, \mathbf{k}, \mathbf{m}-\mathbf{r})$ and identified in HE-stained sections $(\mathbf{c}, \mathbf{f}, \mathbf{i}, \mathbf{I})$. a- $\mathbf{f}$ Blood stages detected in capillaries and vessels in the heart (a-c), kidneys (d) and lungs (e, $\mathbf{f})$ of an Accipiter nisus infected with L. aff. toddi IMILANSO4. Note the presence of larger, elongate signals ( $\mathbf{a}, \mathbf{d}$, arrowheads) besides numerous smaller roundish signals in the heart ( $\mathbf{a}$, b) and kidney (d). In the lung, the shape of the signals appeared wormlike (e). In HE-stained sections, elongate gametocytes were identified (c, $\mathbf{f}$, black arrows), sometimes with a cap-like host cell nucleus visible (c, white arrowhead). $\mathbf{g}-\mathbf{I}$ Blood stages detected in the heart ( $\mathbf{g}-\mathbf{i})$ and lung (j-I) of a Circus aeruginosus infected with L. aff. toddi ICIAE03. Also in this individual, elongate (g, arrowheads) or wormlike (j, $\mathbf{k}$ ) signals were observed alongside smaller roundish signals $(\mathbf{g}, \mathbf{h})$. In HE-stained sections, gametocytes were identified in fusiform host cells in heart vessels (i, black arrow) and in the lung (I, black arrow). Infected host cells showed an almond-shaped or cap-like nucleus (i, I, white arrowheads). $\mathbf{m}$-n Blood stages detected in a Buteo buteo infected with L. aff. toddi IBUTBUT07. Blood stages detected in the heart were roundish to oval (m), while blood stages in the lung appeared wormlike (n). o Roundish blood stages detected in the heart of a Buteo buteo infected with L. aff. toddi IBUTBUT08. p Numerous oval to elongate blood stages detected in lung capillaries of a Buteo buteo infected with L. buteonis IBUBT2. q-r Blood stages detected in the heart of a Buteo buteo co-infected with L. buteonis IBUBT2 and L. aff. toddi IBUTBUT03. Blood stage signals were roundish and small or appeared large and elongate (arrowheads). Scale bars $=50 \mu \mathrm{m}$; insert scale bars $=20 \mu \mathrm{m}$
} 

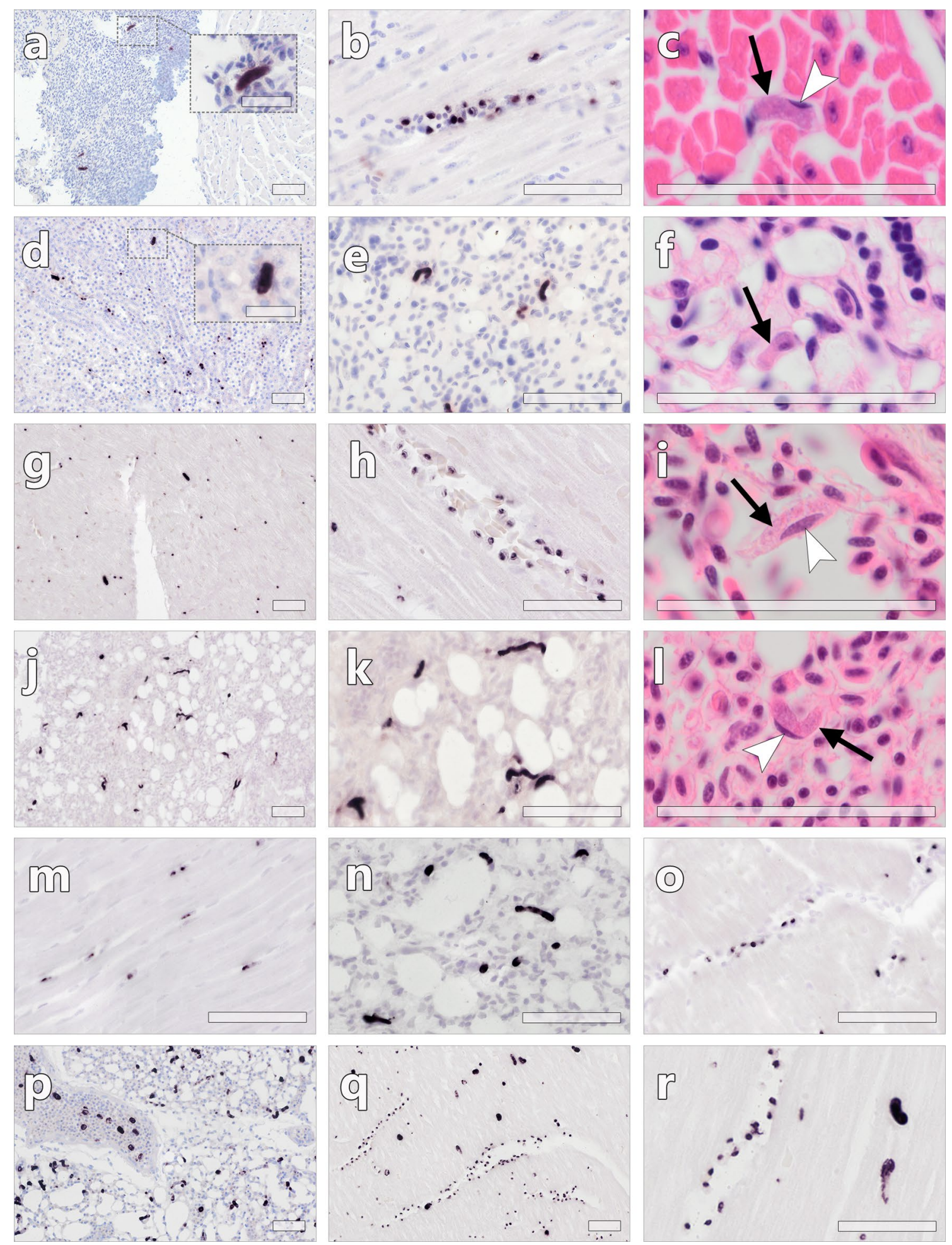

Fig. 1 (See legend on previous page.) 

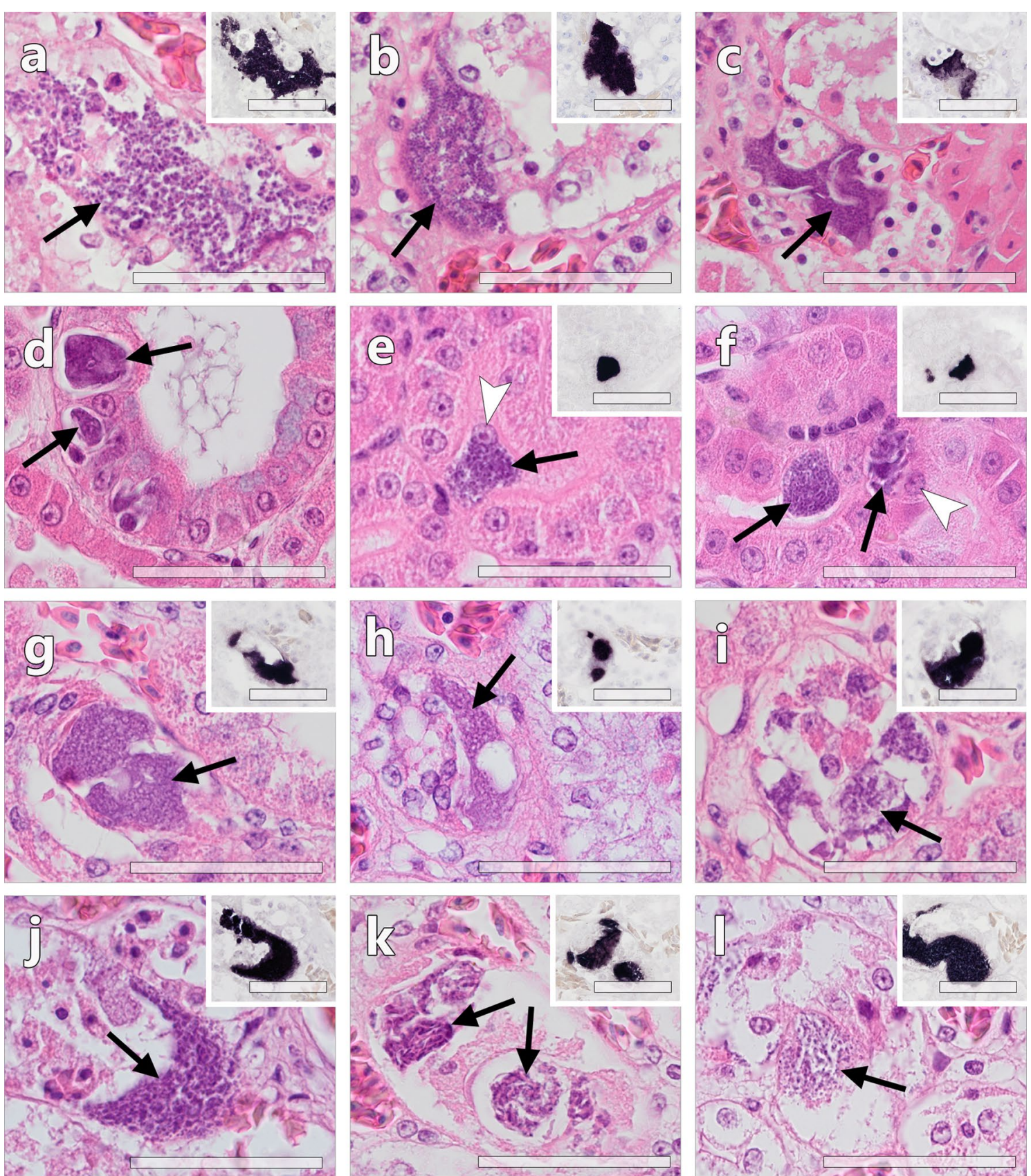

Fig. 2 Leucocytozoon spp. tissue stages in kidney sections of accipitriform birds, detected by HE-staining and CISH (inserts). Meronts were frequently observed in epithelial cells of renal tubules and labelled by the L. toddi-specific probe (inserts, CISH). a-d Meronts (black arrows) detected in the kidneys of several Buteo buteo co-infected with L. buteonis IBUBT2 and L. aff. toddi IBUTBUT03. The meronts were of irregular shape and contained numerous basophilic merozoites. Several smaller meronts were located in renal epithelial cells (d). e-f Meronts detected in renal tubules of a Buteo buteo infected with L. buteonis IBUBT2. Mature meronts packed with merozoites often occupied the entire intracellular space of infected epithelial cells, causing protrusion into the tubular lumen and lateral displacement of the host cell nucleus (e, white arrow). $\mathbf{g}$-i Meronts detected in renal tubules of a Buteo buteo infected with L. aff. toddi IBUTBUT12. Meronts shown in $\mathbf{g}$ and $\mathbf{h}$ contained nuclear material but developing merozoites were not discernible, indicating early stage of parasite development. Other meronts were more mature and contained developing merozoites (i). j A mature meront detected in a kidney tubule of a Buteo buteo co-infected with L. buteonis IBUBT2 and L. aff. toddi IBUTBUT07. $\mathbf{k}-\mathrm{I}$ Developing meronts detected in a Circus aeruginosus co-infected with L. aff. toddi ICIAE03 and P. circumflexum pTURDUS1. Black arrow= meront, white arrowhead $=$ host cell nucleus. All scale bars $=50 \mu \mathrm{m}$ 
Table 4 CytB lineages of Leucocytozoon spp. in accipitriform raptors

\begin{tabular}{|c|c|c|c|c|c|c|}
\hline Lineage & Accession & Parasite species & Host species & Host environment & Countries & References \\
\hline \multicolumn{7}{|c|}{ Leucocytozoon toddi group } \\
\hline IBUBT2 & EF607293 & L. buteonis & $\begin{array}{l}\text { Buteo buteo (27), Accipiter } \\
\text { gentilis (1), Circus aerugi- } \\
\text { nosus (1) }\end{array}$ & Wild/captive & Austria, B.-H., Kazakhstan & [9]; present study \\
\hline IBUTBUT07 & OL598481 & L.sp. & $\begin{array}{l}\text { Buteo buteo (5), Buteo } \\
\text { lagopus (1) }\end{array}$ & Wild & Austria & Present study \\
\hline IBUTBUT08 & OL598478 & L. sp. & Buteo buteo (2) & Wild & Austria & Present study \\
\hline IBUTBUT09 & OL598480 & L.sp. & Buteo buteo (1) & Captive & Austria & Present study \\
\hline IBUTBUT10 & OL598487 & L. buteonis & Buteo buteo (1) & Wild & Austria & Present study \\
\hline IBUTJAM15 & HM142917 & L.sp. & Buteo jamaicensis (1) & Wild & USA & {$[10]$} \\
\hline IBUTJAM04 & DQ177269 & L.sp. & Buteo jamaicensis (22) & Wild & USA & {$[9,10]$} \\
\hline IBUTJAM07 & DQ177255 & L. sp. & $\begin{array}{l}\text { Buteo jamaicensis (16), } \\
\text { Buteo lineatus (2) }\end{array}$ & Wild & USA & {$[9,10]$} \\
\hline |BUTREG01 & DQ177264 & L. buteonis & $\begin{array}{l}\text { Buteo jamaicensis (1), } \\
\text { Buteo regalis (1) }\end{array}$ & Wild & USA & {$[9,10]$} \\
\hline IBUTJAM02 & DQ177270 & L.sp. & Buteo jamaicensis (1) & Wild & USA & [9] \\
\hline IBUTJAM03 & DQ177271 & L.sp. & Buteo jamaicensis (1) & Wild & USA & [9] \\
\hline IBUTJAM05 & DQ177272 & L.sp. & Buteo jamaicensis (1) & Wild & USA & [9] \\
\hline IBUTJAM06 & DQ177265 & L. sp. & Buteo jamaicensis (1) & Wild & USA & [9] \\
\hline IBUTJAM08 & DQ177268 & L. sp. & Buteo jamaicensis (1) & Wild & USA & [9] \\
\hline IBUTJAM09 & DQ177263 & L. sp. & Buteo jamaicensis (1) & Wild & USA & [9] \\
\hline IBUTJAM14 & HM142916 & L. sp. & Buteo jamaicensis (1) & Wild & USA & [10] \\
\hline IBUTJAM16 & HM142918 & L.sp. & Buteo jamaicensis (1) & Wild & USA & {$[10]$} \\
\hline IBUTJAM17 & HM142919 & L.sp. & Buteo jamaicensis (1) & Wild & USA & {$[10]$} \\
\hline IBUTJAM18 & HM142922 & L.sp. & Buteo jamaicensis (1) & Wild & USA & [10] \\
\hline IMILVUSO1 & JN164716 & L.sp. & $\begin{array}{l}\text { Buteo buteo (4), Milvus } \\
\text { milvus (4), Milvus migrans } \\
\text { (1) }\end{array}$ & Wild/captive & Austria, Spain & [8]; present study \\
\hline IBUTBUT13 & OL598492 & L.sp. & Buteo buteo (1) & Wild & Austria & Present study \\
\hline IBUTJAM11 & DQ177254 & L.sp. & Buteo jamaicensis (1) & Wild & USA & [9] \\
\hline IBUTJAM10 & DQ177273 & L.sp. & Buteo jamaicensis (1) & Wild & USA & [9] \\
\hline ICLAPOM02 & OL598493 & L. sp. & Clanga pomarina (1) & Wild & Austria & Present study \\
\hline ICLAPOM03 & OL598494 & L. sp. & Clanga pomarina (1) & Wild & Austria & Present study \\
\hline IACCOP01 & DQ177241 & L. mathisi & Accipiter cooperi (11) & Wild & USA & [9] \\
\hline IACCGEN01 & KP256190 & L.sp. & Accipiter gentilis (11) & Wild & Czechia, Austria & [12]; Present study \\
\hline IACCGEN03 & KP256192 & L.sp. & Accipiter gentilis (1) & Wild & Czechia & {$[12]$} \\
\hline ICIRCYA01 & OL598499 & L.sp. & Circus cyanaeus (1) & Wild & Austria & Present study \\
\hline IACNI04 & DQ177252 & L. mathisi & $\begin{array}{l}\text { Accipiter nisus (3), Circus } \\
\text { aeruginosus (1) }\end{array}$ & Wild & Austria, Kazakhstan & [9]; Present study \\
\hline IACCBRE02 & DQ177235 & L.sp. & Accipiter brevipes (1) & Wild & Kazakhstan & [9] \\
\hline IACCBRE03 & DQ177236 & L. sp. & Accipiter brevipes (1) & Wild & Kazakhstan & [9] \\
\hline IACCFRA02 & MF442621 & L. sp. & $\begin{array}{l}\text { Accipiter francesiae (1), } \\
\text { Accipiter madagascarien- } \\
\text { sis (1) }\end{array}$ & Wild & Madagascar & {$[30]$} \\
\hline IBUTBUT03 & MK652270 & L. sp. & $\begin{array}{l}\text { Buteo buteo (13), Accipiter } \\
\text { gentilis (2) }\end{array}$ & Wild/captive & Austria & Present study \\
\hline IBUTBUT11 & OL598440 & L. sp. & Buteo buteo (1) & Captive & Austria & Present study \\
\hline ICIAE05 & OL598441 & L. sp. & Circus aeruginosus (1) & Wild & Austria & Present study \\
\hline IACCGEN02 & KP256191 & L. sp. & Accipiter gentilis (1) & Wild & Czechia & {$[12]$} \\
\hline ICIAE03 & MK652272 & L.sp. & Circus aeruginosus (5) & Wild/captive & Austria & Present study \\
\hline ICIAE04 & OL598446 & L.sp. & Circus aeruginosus (1) & Wild & Austria & Present study \\
\hline
\end{tabular}


Table 4 (continued)

\begin{tabular}{|c|c|c|c|c|c|c|}
\hline Lineage & Accession & Parasite species & Host species & Host environment & Countries & References \\
\hline IACNI01 & MF928785 & L. sp. & Accipiter nisus (4) & Wild/captive & $\begin{array}{l}\text { Austria, Germany, } \\
\text { Kazakhstan, Turkey }\end{array}$ & $\begin{array}{l}{[14,147] \text {; Simsek et al. }} \\
\text { unpub.; present study }\end{array}$ \\
\hline IACNI02 & DQ177239 & L. sp. & Accipiter nisus (2) & Wild & Kazakhstan & [9] \\
\hline IACNIO3 & DQ177237 & L. sp. & Accipiter nisus (3) & Wild & $\begin{array}{l}\text { Austria, Kazakhstan, } \\
\text { Turkey }\end{array}$ & $\begin{array}{l}\text { [9]; Simsek et al. unpub.; } \\
\text { present study }\end{array}$ \\
\hline IACNI05 & OL598447 & L. sp. & Accipiter nisus (1) & Wild & Austria & Present study \\
\hline IACNI06 & OL598448 & L. sp. & Accipiter nisus (1) & Captive & Austria & Present study \\
\hline IACNI07 & OL598450 & L. sp. & Accipiter nisus (1) & Wild & B.- $-\mathrm{H}$ & Present study \\
\hline IACNI02 & DQ177239 & L. sp. & Accipiter nisus (1) & Wild & Kazakhstan & [9] \\
\hline IMILANSO4 & JN164713 & L. sp. & $\begin{array}{l}\text { Milvus milvus (3), Milvus } \\
\text { migrans (1), Accipiter } \\
\text { nisus (2) }\end{array}$ & Wild/captive & Spain, Austria & [8]; present study \\
\hline IBUTBUT12 & OL598531 & L. sp. & Buteo buteo (1) & Captive & Austria & Present study \\
\hline \multicolumn{7}{|c|}{ Leucocytozoon californicus group } \\
\hline ICIAE02 & EF607287 & L. aff. californicus & $\begin{array}{l}\text { Accipiter nisus (3), Aquila } \\
\text { heliaca (1), Buteo buteo } \\
\text { (2), Buteo rufinus (1), } \\
\text { Circus aeruginosus (6), } \\
\text { Circus cyaneus (1), Milvus } \\
\text { migrans (16) }\end{array}$ & & $\begin{array}{l}\text { Austria, China, Germany, } \\
\text { Spain, Thailand, Turkey }\end{array}$ & $\begin{array}{l}{[8,11,14,15,69] \text {; Present }} \\
\text { study }\end{array}$ \\
\hline IBUTBUT01 & KP000841 & L. aff. californicus & Buteo buteo (1) & Wild & Turkey & {$[15]$} \\
\hline ICIAE06 & OL598524 & L. aff. californicus & Circus aeruginosus (1) & Wild & Austria & Present study \\
\hline ACCTRI01 & KX950744 & L. aff. californicus & Accipiter trivergatus (1) & Unknown & Thailand & Prasopsom et al. unpub \\
\hline \multicolumn{7}{|c|}{ Other Leucocytozoon lineages } \\
\hline IBT2 & AY393802 & L. sp. & Accipiter gentilis (2) & Wild & Czechia & {$[12]$} \\
\hline IBUTBUT05 & MT281506 & L. sp. & Buteo buteo (1) & Captive & China & {$[11]$} \\
\hline IBUBO01 & KF146934 & L. danilewskyi & Buteo buteo (1) & & Iran & {$[50]$} \\
\hline IASOT06 & MT281492 & L. sp. & Accipiter nisus (3) & Captive & Austria, China & [11]; present study \\
\hline IMILVUSO2 & JN164717 & L. sp. & $\begin{array}{l}\text { Milvus milvus (1), Buteo } \\
\text { buteo (1), Buteo lagopus } \\
\text { (1), Haliaeetus albicilla (1) }\end{array}$ & Wild & Austria, Spain & [8]; present study \\
\hline
\end{tabular}

The numbers in the brackets indicate the number of individuals that featured the respective lineages. One GenBank accession number is indicated for each MalAvi lineage. The term 'aff.' ('species affinis') indicates that the lineage is similar to other lineages, which were already linked to morphospecies

in Circus aeruginosus (1) from Austria. Valkiūnas et al. [29] linked 1ACCOP01 and 1ACNI04 to Leucocytozoon mathisi based on the morphological similarity of their gametocytes and host cells. The two latter lineages fall into sub-clades L201a and L201b and differ by $4.6 \%$ in the $C y t B$. The genetic distances between lineages, the observed host specificity, and their geographic distribution suggests that the five lineages potentially belong to four distinct parasite species of L. mathisi.

Clade L203 features three lineages in two sub-clades. Sub-clade L203a contains lACCBRE02 and 1ACCBRE03, each found in single individuals of Accipiter brevipes in Kazakhstan [9]. Sub-clade L203b only features lACCFRA02 found in Accipiter francesiae (1) and Accipiter madagascariensis (1) from Madagascar [30].

Clade L204 features four lineages in two sub-clades. Sub-clade L204a contains lBUTBUT03 from Buteo buteo (13) in Austria and Accipiter gentilis (2) in B.-H., IBUTBUT11 from Buteo buteo (1) in Austria, and
ICIAE05 from Circus aeruginosus (1) in Austria. Subclade L204b contains only lACCGEN02 from one individual of Accipiter gentilis sampled in Czechia [12].

Clade L205 contains lCIAE03 (5) and ICIAE04 (1), which were exclusively detected in Circus aeruginosus in Austria.

Clade L206 contains six lineages exclusively found in Accipiter nisus. Lineage 1ACNI01 was found in Austria (1), Germany (1) [14], Kazakhstan (1) [9], and Turkey (1) (Simsek et al. unpublished), and lACNI03 was found in Austria (1), Kazakhstan (1) [9], and Turkey (1) (Simsek et al. unpublished). Lineages lACNI05 (1) and lACNI06 (1) were found in Austria, lACNI07 (1) in B.-H., and lACNIO2 (2) in Kazakhstan [9]. The lineages within clade L206 are similar and were found only in Accipiter nisus, suggesting that they belong to a Leucocytozoon parasite specific to this host species. The data also suggest that at least two species of this 


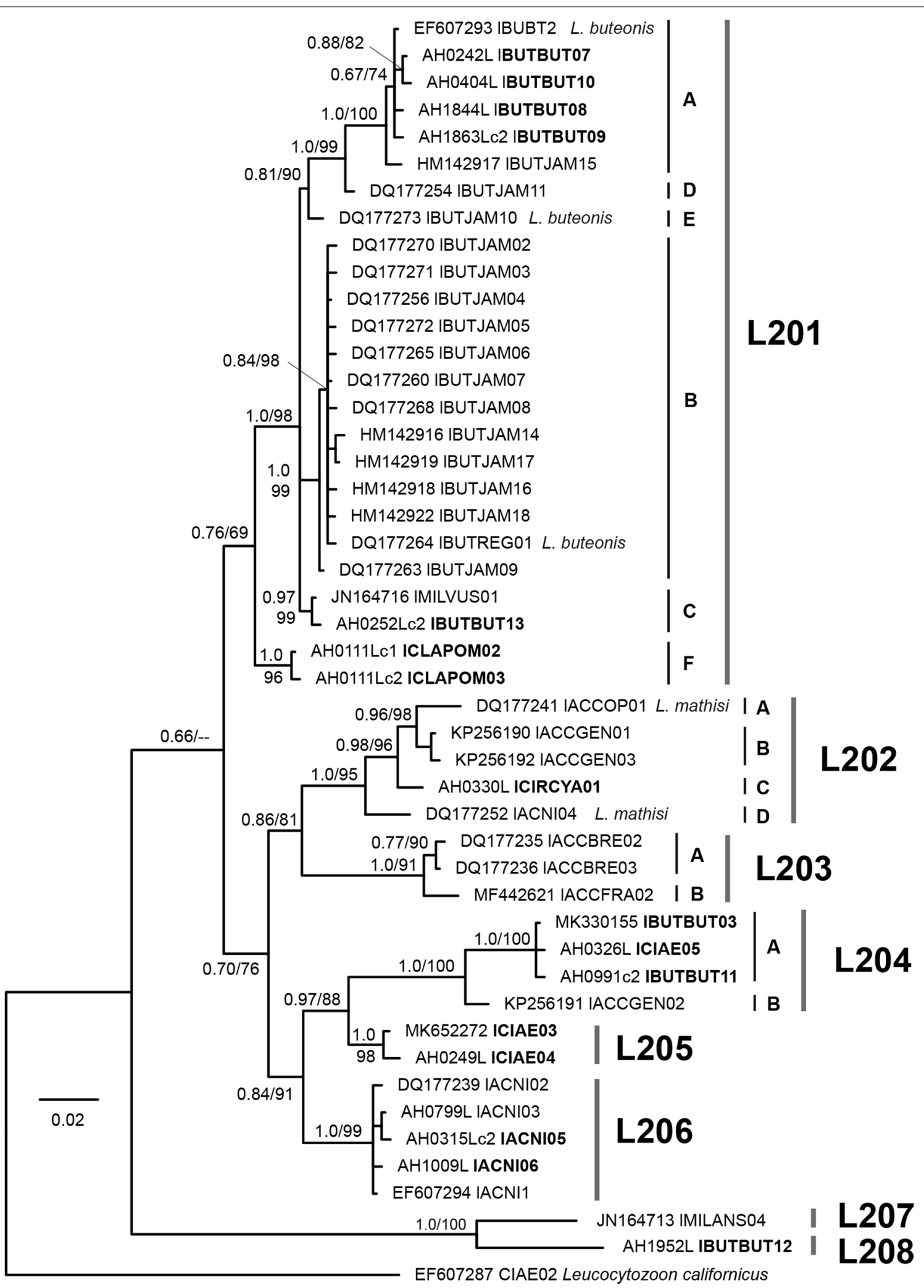

Fig. 3 Phylogeny of haemosporidian CytB lineages (474 bp) belonging to the Leucocytozoon toddi species group. Bayesian posterior probabilities and Maximum likelihood bootstrap values are indicated at most nodes. The scale bars indicate the expected number of substitutions per site according to the model of sequence evolution applied. Bold letters indicate lineage names found for the first time in the present study. Species names indicate that the lineages were already linked to the respective morphospecies 
parasite group might infect Accipiter nisus, L. mathisi, and another $L$. toddi group parasite.

Clade L207 and L208 together form a clade taking the most basal position in the phylogeny of the $L$. toddi species group (Fig. 4), differing by more than $15 \%$ in the $C y t B$ from the other clades. Clade L207 features lineage IMILANS04, which was found in Milvus milvus (3) and Milvus migrans (1) from Spain [8], and in Accipiter nisus (2) from Austria. Clade L208 features lineage lBUTBUT12, found in one specimen of Buteo buteo in Austria.

\section{Leucocytozoon californicus species group}

Leucocytozoon californicus was described from Falco sparverius in California (USA) and linked to lineage IFASPA02 by [31]. Morphologically similar parasites were found before in migrating falconiform birds in Southern Kazakhstan, indicating that transmission of $L$. californicus might also take place in Eurasia [20,31]. The lineage was later found in Falco columbarius from Italy, confirming its presence in Europe [32]. Lineage IFASPA02 is part of a clade (Fig. 5), which features 15 lineages found in Accipitriformes, Falconiformes, Strigiformes, and members of other bird orders. The most frequent lineage ICIAE02 was found in 62 birds of the orders Accipitriformes (30), Charadriiformes (17), Strigiformes (3), Falconiformes (2), Columbiformes (2), Coraciiformes (2), Gruiformes (2), Piciformes (2), Cuculiformes (1), and Ciconiiformes (1) in Europe, Asia and Africa (Additional file 3: Table S1). In accipitriform raptors, ICIAE02 was detected in Accipiter nisus from China (3) [11], Aquila heliaca from Thailand (1) [33], Buteo buteo from Turkey (1) [15] and China (1) [11], Buteo rufinus from Turkey (1) [15], Circus aeruginosus from Austria (5) and Germany (1) [14], Circus cyaneus from China (1) [11], and Milvus migrans from Spain (16) [8]. Lineage lBNOW04 was exclusively reported from Strigiformes (9) in the USA $[34,35]$ and IFASPA02 from Falconiformes in the USA (13) [31] and Italy (1) [32]. Lineage lAEMO02 was found in Columbidae in Japan (2) [36], Taiwan (1) (Huang et al., unpublished; KT779209), Spain (1) [37], Portugal (2) [38, 39], and the UK (1) [40]. The clade contains several less frequent lineages, which are separated from the latter ones by one to three bp: IBUTBUT01 from Buteo buteo (1) in Turkey [15], ICIAE06 from Circus aeruginosus (1) in Austria, lACCTRI01 from Accipiter trivergatus
(2) in Thailand [41], IALEMAD01 from the Madagascan blue pigeon Alectroenas madagascariensis (1) in Madagascar [30], lCOLPAL03 from the common wood pigeon Columba palumbus (3) in the UK [40], MH644759 from the western cattle egret Bubulcus ibis (1) in Western Africa [42], KT779208 from the red collared dove Streptopelia tranquebarica (1) in Taiwan (Huang Y. L. et al., unpublished), MK062201 from the northern saw-whet owl Aegolius acadicus (1) in the USA [34], MK358451 from the tawny frogmouth Podargus strigoides (2) in Australia [43], and LC440383 from the whistling green pigeon Treron formosae (1) in Japan [44]. The L. californicus clade is exceptional because it contains several closely related lineages from birds of various host orders and geographic regions. While the other lineages were each found in birds of one host order, ICIAE02 was found in birds belonging to 10 different host orders from Eurasia and Africa. Further studies on ICIAE02 and other lineages are required to confirm or refute their identity as $L$. californicus.

\section{Other Leucocytozoon lineages in accipitriform raptors}

Another five Leucocytozoon lineages were found in a few accipitriform birds. Lineage lBT2 was detected in two wild juvenile Accipiter gentilis from Czechia [12]. The lineage was found in more than 100 passeriform birds (mainly Sylviidae, Muscicapidae, and Fringillidae) in Europe, China, and Nigeria [38, 45, 46]. It was also found in both juvenile and adult boreal owls Aegolius funereus (7) in Czechia [47].

Lineage 1BUTBUT05 was detected in Buteo buteo (1) kept at the Beijing Raptor Rescue Centre in Beijing, China [11]. Elsewhere, the lineage was found in bloodengorged females of the black fly species Simulium chumpornense in Thailand. Blood meal analysis revealed that the black flies were feeding on domestic chicken Gallus gallus [48]. Lineage lBUTBUT05 is similar to more than 20 haemosporidian yet unnamed lineages, which were found in Simulium asakoae and other black flies in Thailand [49].

Lineage lBUBO01 was found in Buteo buteo (1) and the Eurasian eagle-owl Bubo bubo (1) kept together at a rehabilitation centre in Mashhad, Iran [50], and in Bubo bubo in Austria (2) [23] and Spain (1) [51]. Ortego \& Cordero [51] identified the lineage as Leucocytozoon ziemanni,

(See figure on next page.)

Fig. 4 Median-Joining DNA haplotype network of partial (474 bp) CytB sequences belonging to the Leucocytozoon toddi species group. Two representations were prepared for each network, the first indicating the host species and the second the geographic origin according to the United Nations geoscheme. Asterisks mark haplotypes detected in the present study and new lineage names are indicated in bold letters. Each circle represents a unique haplotype/lineage. The frequency of each lineage is indicated for all haplotypes with more than one record and corresponds to the size of circles. Bars on branches and numbers in squares indicate the number of substitutions between two haplotypes. Small white circles represent median vectors, which are hypothetical (often ancestral or unsampled) sequences required to connect existing haplotypes with maximum parsimony 


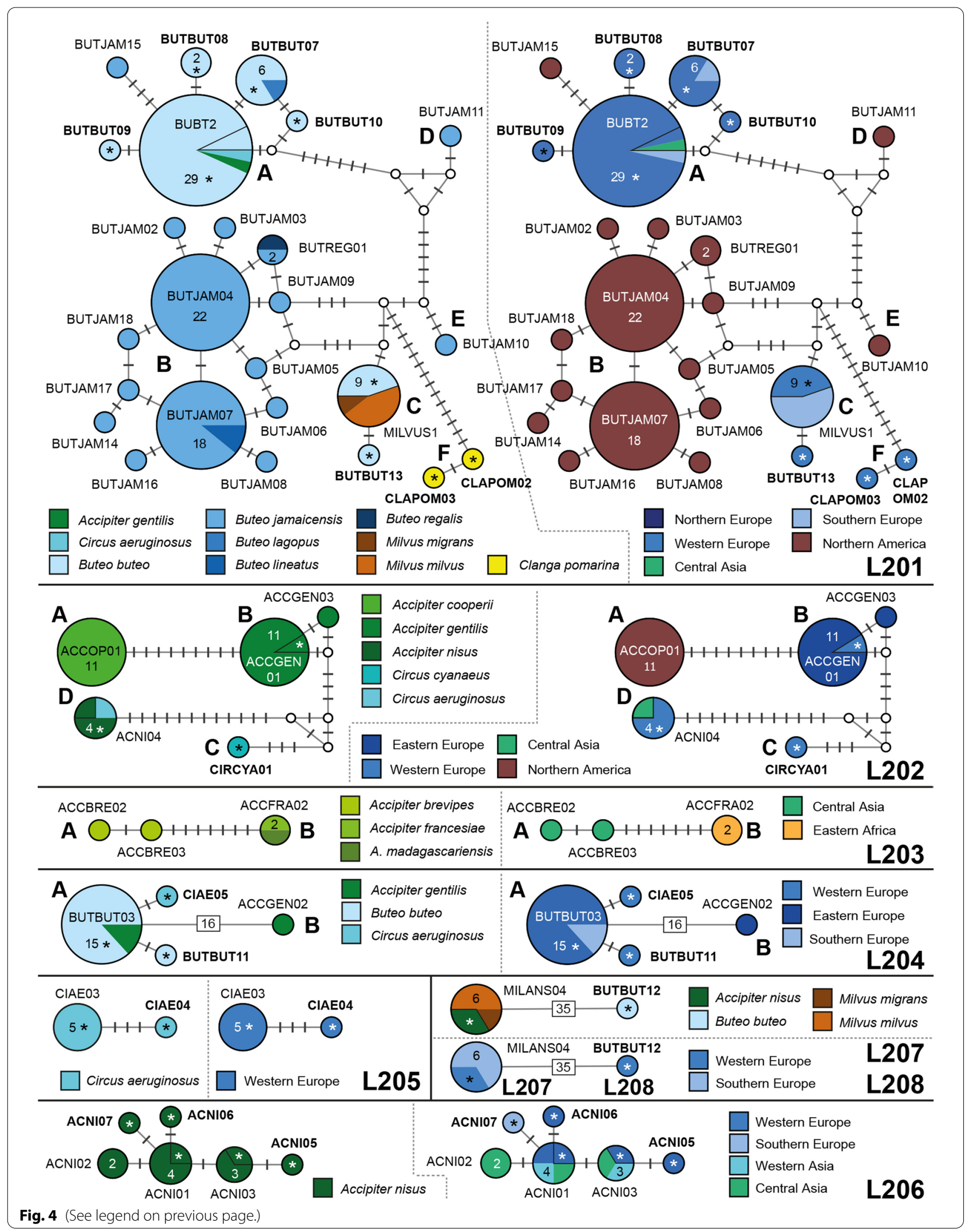




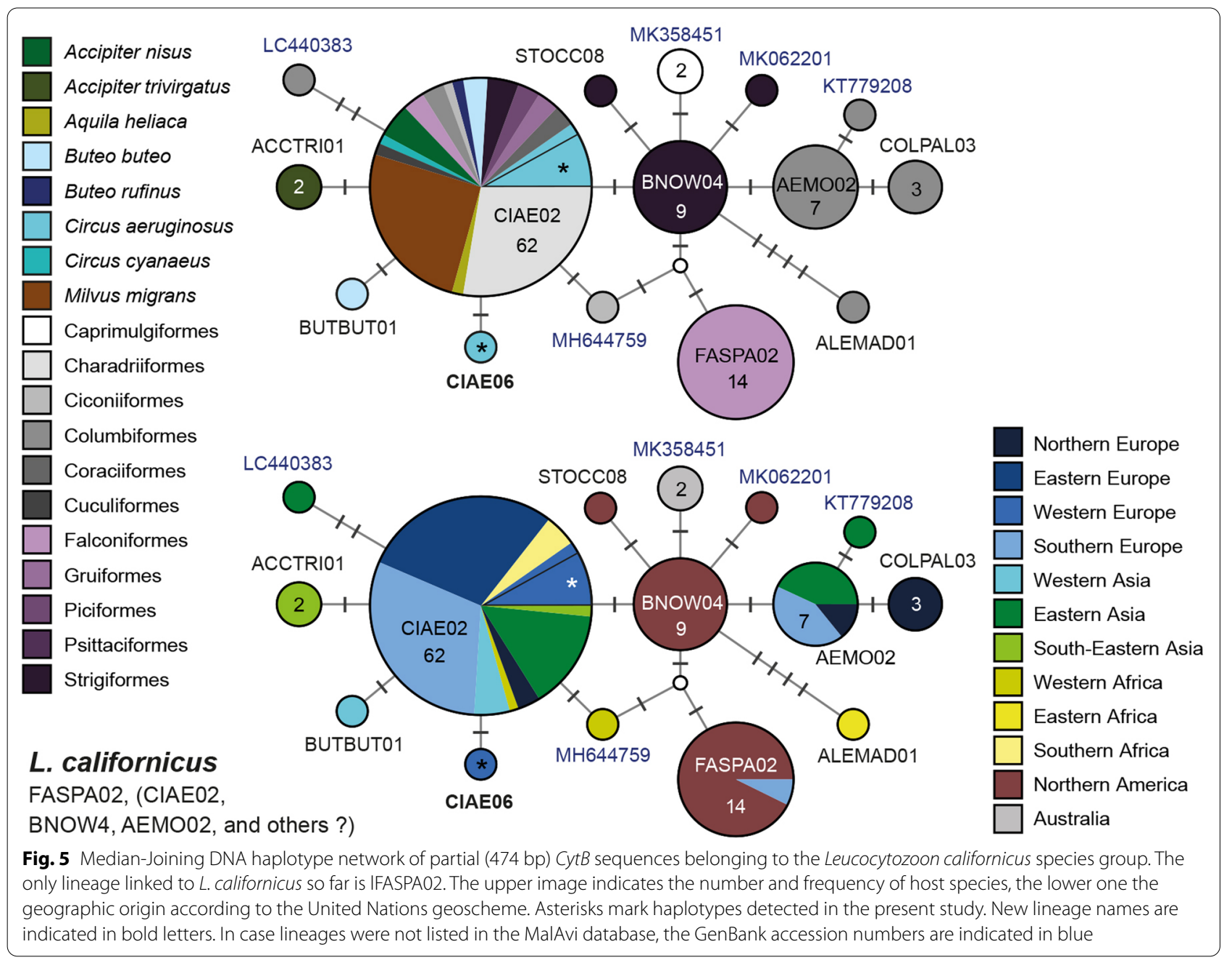

which is a synonym of Leucocytozoon danilewskyi, a common parasite in owls [3].

Lineage lASOT06 was found in Accipiter nisus (1) and Circus aeruginosus (1) from Austria, and Accipiter nisus (1) from China [11]. It was detected in the owls Asio otus (6), Athene noctua (2), and Aegolius funereus (1) in China [11], Asio otus (1) in Germany [14], Falco tinnunculus (1) in China [11], and the common blackbird Turdus merula (4) in Austria [1, 4]. The three accipitriform raptors infected with 1ASOT06 were kept at rehabilitation facilities together with owls, which are probably the natural hosts of this lineage. The CISH performed on the Circus aeruginosus sample was negative, which was also the case for Turdus merula investigated by [1], thus indicating that both species are probably not competent hosts.

Lineage IMILVUS02 was found in Buteo buteo (1), Buteo lagopus (1) and Haliaeetus albicilla (1) from Austria (present study), and Milvus milvus (1) from Spain [8]. The lineage resembles lFURRUF01 (8 bp difference) from the rufous hornero Furnarius rufus and IPHARUB01
(9 bp difference) from the sepia-capped flycatcher Leptopogon amaurocephalus (1) and the reddish hermit Phaethornis ruber (1), which were all sampled in Brazil [52].

\section{Plasmodium parasites in accipitriform raptors}

Only one of the known Plasmodium species, Plasmodium accipiteris, has been described specifically from accipitriform raptors, but three species were reported to also infect birds of this host group: $P$. circumflexum, $P$. fallax, and $P$. forresteri $[3,53]$. Of these, $P$. circumflexum is the only Plasmodium species, which was found in more than two species of accipitriform hosts and which was already characterized by DNA barcoding. Three clades were identified, which feature several lineages detected in accipitriform hosts. None of these lineages could be linked to any known morphospecies. Plasmodium fallax and $P$. forresteri are only known from morphological and experimental studies, but the $C y t B$ lineages of these species have not been identified yet. In total, 25 Plasmodium lineages were reported from accipitriform birds 
(Table 5). A BI tree featuring all Plasmodium lineages from accipitriform raptors is shown in Additional file 4: Fig. S3.

\section{Plasmodium clade 1: Plasmodium circumflexum}

Palinauskas et al. [54] linked the lineage pTURDUS1 to $P$. circumflexum and suggested that pBT7, which differs in one bp from pTURDUS1 in the $C y t B$, might belong to the same morphospecies. These two common lineages are part of one sub-clade together with seven rare and closely related lineages (Fig. 6). The entire clade features several additional, less closely related lineages (see Discussion), which might resemble $P$. circumflexum morphologically as well.

Most records of pTURDUS1 (764 records in total) originate from Northern Europe (662), Western Europe (42) and Eastern Europe (35), whereas the lineage was rarely recorded in Eastern Asia (10), Western Asia (6), Southern Europe (4), and Western Africa (2), and has never been found in the Americas so far. The most common hosts of pTURDUS1 are birds of the families Paridae (620), Muscicapidae (45), Turdidae (14), Fringillidae (14), Certhiidae (11), and Sylviidae (10). The two Paridae species Cyanistes caeruleus (381) and Parus major (222) together

Table 5 Plasmodium CytB lineages found in accipitriform raptors

\begin{tabular}{|c|c|c|c|c|c|c|}
\hline Lineage & Accession & Parasite species & $\begin{array}{l}\text { Host species (only } \\
\text { accipitriform birds) }\end{array}$ & Host env & Countries & References \\
\hline pTURDUS1 & AF495576 & P. circumflexum & $\begin{array}{l}\text { Accipiter nisus (8), Accipiter } \\
\text { gularis (3), Accipiter gentilis } \\
\text { (2), Buteo buteo (8), Circus } \\
\text { aeruginosus (5) }\end{array}$ & Wild/captive & $\begin{array}{l}\text { Austria, B.-H., China, } \\
\text { Czechia, Germany, Japan, } \\
\text { Sweden, Turkey }\end{array}$ & $\begin{array}{l}{[11,12,14,15,38,44] ;} \\
\text { present study }\end{array}$ \\
\hline pBT7 & AY393793 & P. circumflexum & $\begin{array}{l}\text { Buteo buteo (3), Buteo } \\
\text { lagopus (1), Buteo rufinus } \\
\text { (1), Accipiter nisus (2), } \\
\text { Accipiter gentilis (1), Accipi- } \\
\text { ter gularis (1), Accipiter } \\
\text { striatus (1) }\end{array}$ & Wild/captive & $\begin{array}{l}\text { Austria, China, Germany, } \\
\text { Iran, USA }\end{array}$ & {$[11,14,58] ;$ present study } \\
\hline pCIAE07 & OL598513 & P. aff. circumflexum & Circus aeruginosus (1) & Captive & Austria & present study \\
\hline pBUTBUT02 & KP883279 & P. aff. circumflexum & $\begin{array}{l}\text { Accipiter nisus (1), Buteo } \\
\text { buteo (1) }\end{array}$ & Wild & Turkey & {$[15]$} \\
\hline pLINN1 & DQ847270 & P. matutinum & Accipiter gentilis (1) & Captive & Austria & present study \\
\hline PMYCAME02 & $J \times 546135$ & P.paranucleophilum & $\begin{array}{l}\text { Buteo brachyurus (1), } \\
\text { Rupornis magnirostris (1) }\end{array}$ & Captive & Brazil & {$[88]$} \\
\hline pEMSPO06 & EF380135 & P. aff. homonucleophilum & Accipiter nisus (1) & Captive & China & {$[11]$} \\
\hline pMILANS05 & JN164714 & P. aff. elongatum & Circus aeruginosus (1) & Wild & Austria & present study \\
\hline pPLACASO2 & EU810612 & P. aff. elongatum & Accipiter tachiro (1) & Wild & Gabon & {$[64]$} \\
\hline pACCBAD01 & JN639001 & P. sp. & Accipiter badius (2) & Captive & Thailand & {$[68]$} \\
\hline pACCNIS05 & MT281522 & P. sp. & Accipiter nisus (1) & Captive & China & {$[11]$} \\
\hline pBUTBUT06 & MT281514 & P. aff. gallinaceum & Buteo buteo (1) & Captive & China & {$[11]$} \\
\hline pMILANS06 & JN164715 & P. sp. & Milvus migrans (1) & Wild & Spain & {$[8]$} \\
\hline pNYCNYC01 & KU057967 & P. sp. & Sarcoramphus papa (2) & Captive & Brazil & {$[87]$} \\
\hline pPESA01 & EU684543 & P. sp. & Buteogallus urubitinga (1) & Captive & Brazil & {$[70]$} \\
\hline pRHYSIM01 & KU562769 & P. sp. & Nisaetus alboniger (1) & Uncertain & Thailand & {$[92]$} \\
\hline pRTSR1 & AF495568 & P. sp. & Aquila wahlbergi (1) & Wild & Malawi & {$[95]$} \\
\hline pSYBOR10 & DQ368390 & P. sp. & Circus aeruginosus (1) & Wild & Austria & present study \\
\hline pZEMAC01 & AY099032 & P. sp. & Aquila chrysaetos (2) & Captive & USA & {$[100]$} \\
\hline pORW1 & AF254963 & P. sp. & Gyps bengalensis (14) & Wild & India & {$[13]$} \\
\hline pACCTAC01 & EU810700 & P. sp. & Accipiter tachiro (1) & Wild & Gabon & {$[64]$} \\
\hline pGYPTEN01 & DQ212194 & P. sp. & Gyps tenuirostris (1) & Wild & Cambodia & Duval et al. unpub \\
\hline pGYPBEN01 & DQ212195 & P. sp. & Gyps bengalis (1) & Wild & Cambodia & Duval et al. unpub \\
\hline pCIAE01 & EF607288 & P. sp. & Circus aeruginosus (1) & Wild & Germany & {$[14]$} \\
\hline pHALVOC01 & EF011195 & P. sp. & Haliaeetus vocifer (1) & Wild & Uganda & {$[67]$} \\
\hline
\end{tabular}

The list features records of all Plasmodium CytB lineages found in accipitriform birds, other host species are not listed. The numbers in the brackets indicate the number of individuals that featured the respective lineages. One GenBank accession number is indicated for each MalAvi lineage. The term 'aff.' means 'species affinis', indicating that the lineage is similar to others, which were already linked to morphospecies 
Accipiter gentilis Accipiter gularis Accipiter nisus Buteo buteo Buteo lagopus Buteo rufinus Circus aeruginosus Passeriformes Anseriformes Apodiformes Charadriiformes Gaviiformes Falconiformes Strigiformes Diptera

\section{Northern Europe} Eastern Europe Western Europe Southern Europe Western Asia Eastern Asia South-Eastern Asia Southern Asia Central Asia Northern America Central America South America Western Africa
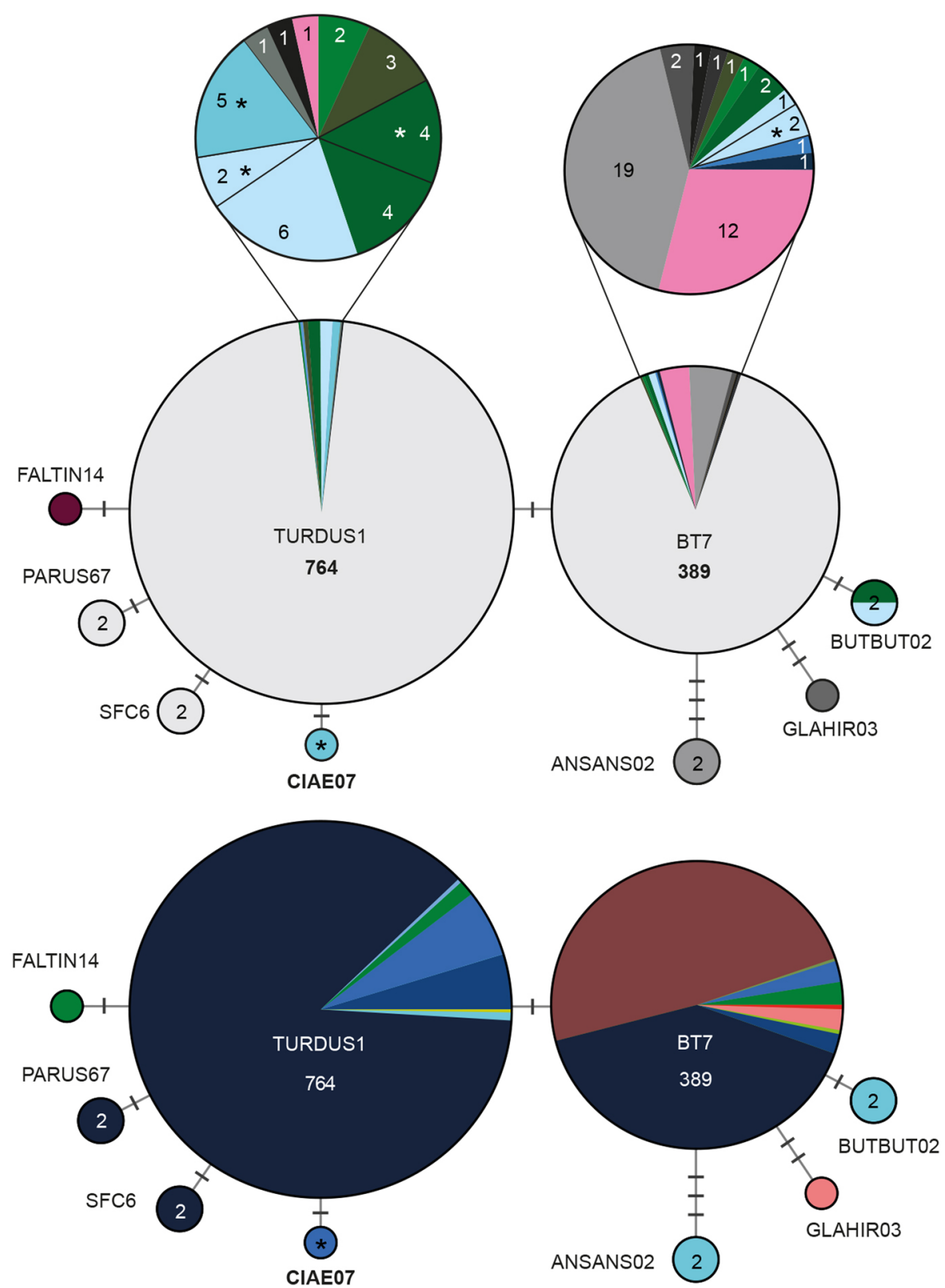

$\begin{array}{lllll}\text { Passeriform birds } & \text { TURDUS1 } & & \text { BT7 } & \\ & \text { Certhiidae: } 11 & \text { Paridae: } & \text { Corvidae: } 17 & \text { Paridae: } \\ & \text { Corvidae: } 2 & \text { Cyanistes caeruleus: } 381 & \text { Emberizidae: } 1 & \text { Cyanistes caeruleus: } 101 \\ & \text { Fringillidae: } 15 & \text { Parus major: } 222 & \text { Fringillidae: } 16 & \text { Parus major: } 40 \\ & \text { Hirundinidae: } 2 & \text { Parus palustris: } 6 & \text { Hirundinidae: } 47 & \text { Parus palustris: } 3 \\ \text { Motacillidae: } 2 & \text { Peripus ater: } 8 & \text { Motacillidae: } 1 & \text { Periparus ater: } 4 \\ & \text { Muscicapidae: } 46 & \text { Poecile montanus: } 5 & \text { Muscicapidae: } 12 & \text { Poecile atricapillus: } 6 \\ & \text { Passeridae: } 8 & & \text { Emberizidae: } 1 & \text { Poecile hudsonica: } 4 \\ & \text { Sittidae: } 3 & & \text { Parulidae: } 26 & \text { Poecile montanus: } 1 \\ & \text { Sylviidae: } 10 & & \text { Passeridae: } 1 & \\ \text { Troglodytidae: } 1 & & \text { Sylviidae: } 1 & \\ & & \text { Turdidae: } 60 & \end{array}$

Fig. 6 Median-Joining DNA haplotype network of partial (474 bp) CytB sequences belonging to the Plasmodium circumflexum species group. The upper image indicates the number and frequency of host species, the lower one the geographic origin according to the United Nations geoscheme. Asterisks mark haplotypes detected in the present study. New lineage names are indicated in bold letters 
constitute more than $80 \%$ of all pTURDUS1 records. Although only 26 records originate from accipitriform raptors, pTURDUS1 is still one of the most common haemosporidian lineages in this host group and was found in Accipiter nisus (8), Buteo buteo (8), Circus aeruginosus (5), Accipiter gularis (3), and Accipiter gentilis (2) $[11,12,14,15,38,44]$. There is only one record of pTURDUS1 from Strigiformes (Aegolius funereus; [47]), but no records from Falconiformes, Anseriformes, Coraciiformes, Columbiformes, and Galliformes, all of which were also considered as host groups of $P$. circumflexum based on the morphology of the observed blood stages [3]. These reports might belong to other closely related lineages of the same morphospecies. Five lineages differ from pTURDUS1 in one bp: pFALTIN14 from Falco tinnunculus (1) in China [11], pCIAE07 from Circus aeruginosus (1) in Austria, pPARUS67 from Parus major (1) and Poecile palustris (1) in Sweden [38, 55], pSFC6 from Muscicapa striata (1) and Phoenicurus phoenicurus (1) in Sweden $[56,57]$, and pBT7.

Most records of pBT7 (389 records in total) originate from Northern America (190) and Northern Europe (158), whereas few records stem from Eastern Asia (10), South America (9), Western Europe (9), Eastern Europe (8), Central America (2), Western Asia (1), South-Eastern Asia (1), and Southern Asia (1). Most records of pBT7 originate from passeriform birds (347 of 389 records) of the families Paridae (159), Turdidae (58), Hirundinidae (47), Corvidae (17), Muscicapidae (15), Fringillidae (16), Sylviidae (10), and Certhiidae (4). The most common host species are Cyanistes caeruleus (101) and Parus major (40), which is also the case with pTURDUS01. Lineage pBT7 was found also in Accipitriformes from Europe and Asia, in Buteo buteo (3), Buteo lagopus (1), Buteo rufinus (1), Accipiter nisus (2), Accipiter gentilis (1), Accipiter gularis (1), and Accipiter striatus (1) [11,14,58, present study], and in Anseriformes (19) [59] and Strigiformes (12) [34] from northern America. More than half of the pBT7 records (201/389) originate from American birds, and the host composition in the Americas differs quite strongly from that in Europe and Asia, e.g., all pBT7 records from Hirundinidae (47), Corvidae (17), Anatidae (17), Charadriiformes (2), and most records from Turdidae (45/47) and Strigidae (11/12) originate from the Americas, particularly northern America. In Central and South America, pBT7 was only found in thrushes of the genus Catharus spp. in their wintering habitats in Costa Rica, Belize, Colombia, and Peru [60, 61]. Apart from pTURDUS1, three other lineages are connected directly to pBT7, separated by one to three bp: pBUTBUT02 from Accipiter nisus (1) and Buteo buteo (1) in Turkey [15], pGLAHIR03 from the rufous-breasted hermit
Glaucis hirsutus (1) in Brazil [62], and pANSANS02 from the greylag goose Anser anser (2) in Turkey [63].

\section{Plasmodium clade 2: Plasmodium spp.}

This Plasmodium clade features 11 lineages, two of which (pORW1 and pACCTAC01) were found in accipitriform raptors (Fig. 7). Lineage pORW1 was found in passeriform birds in Australia (14), India (7), Kyrgyzstan (4), Turkey (3), Russia (3), Armenia (1), the UK (1), Japan (1), and Myanmar (1), in coraciiform birds in Australia (2), in strigiform birds in China (2), Thailand (1), and Japan (1), and in the white-backed vulture Gyps bengalensis (14) in India (Additional file 3: Table S1). Poharkar et al. [13] detected PORW1 in 12 dead and two living individuals of Gyps bengalensis in the Gadchiroli district in Maharashtra (central India). Lineage pACCTAC01 was found in Passeriformes (mainly Muscicapidae) from Sweden (8), Gabon (5), Tanzania (4), and Malawi (3), and France (1), in the corncrake Crex crex (1) from France, in the rosy bee-eater Merops malimbicus (1) from Gabon, in the crowned hornbill Tockus alboterminatus (1) from Malawi, in the mosquito Coquillettidia aurites (2) from Cameroon (Additional file 3: Table S1), and in one individual of the African goshawk Accipiter tachiro from Gabon [64]. In Europe, pACCTAC01 was found in the passeriform species Ficedula albicollis, Ficedula hypole$u c a$, and Hirundo rustica, and in the gruiform corncrake Crex crex, which all migrate to wintering sites in the latter region.

\section{Plasmodium clade 3: Plasmodium spp.}

This clade features five lineages in four sub-clades, which mostly originate from single species of accipitriform raptors (Fig. 8). The lineages pGYPTEN01 (sub-clade A; GenBank accession no. DQ212194) from Gyps tenuirostris (1) and pGYPBEN01 (sub-clade B; DQ212195) from Gyps bengalis (1) were found in Cambodia by Duval et al. (unpublished). The lineages pCIAE01 and pPADOM04 (sub-clade C) were found in Circus aeruginosus (1) from Germany [14] and Passer domesticus from France [65]. Last, the lineage pHALVOC01 (=CXPOI01; subclade D) was found in Culex poicilipes (1) from Cameroon [66] and Haliaeetus vocifer (1) from Uganda [67]. The alignment for this clade was trimmed to 462 bp because pGYPTEN01, pGYPBEN01, and pHALVOC01 did not cover the entire DNA barcode sequence.

\section{Other Plasmodium lineages in accipitriform raptors}

Another 17 Plasmodium lineages were found in one or two accipitriform birds. In nine cases, the raptors were kept in zoos or rehabilitation centres together with birds of other orders featuring these parasite lineages. Hence, 


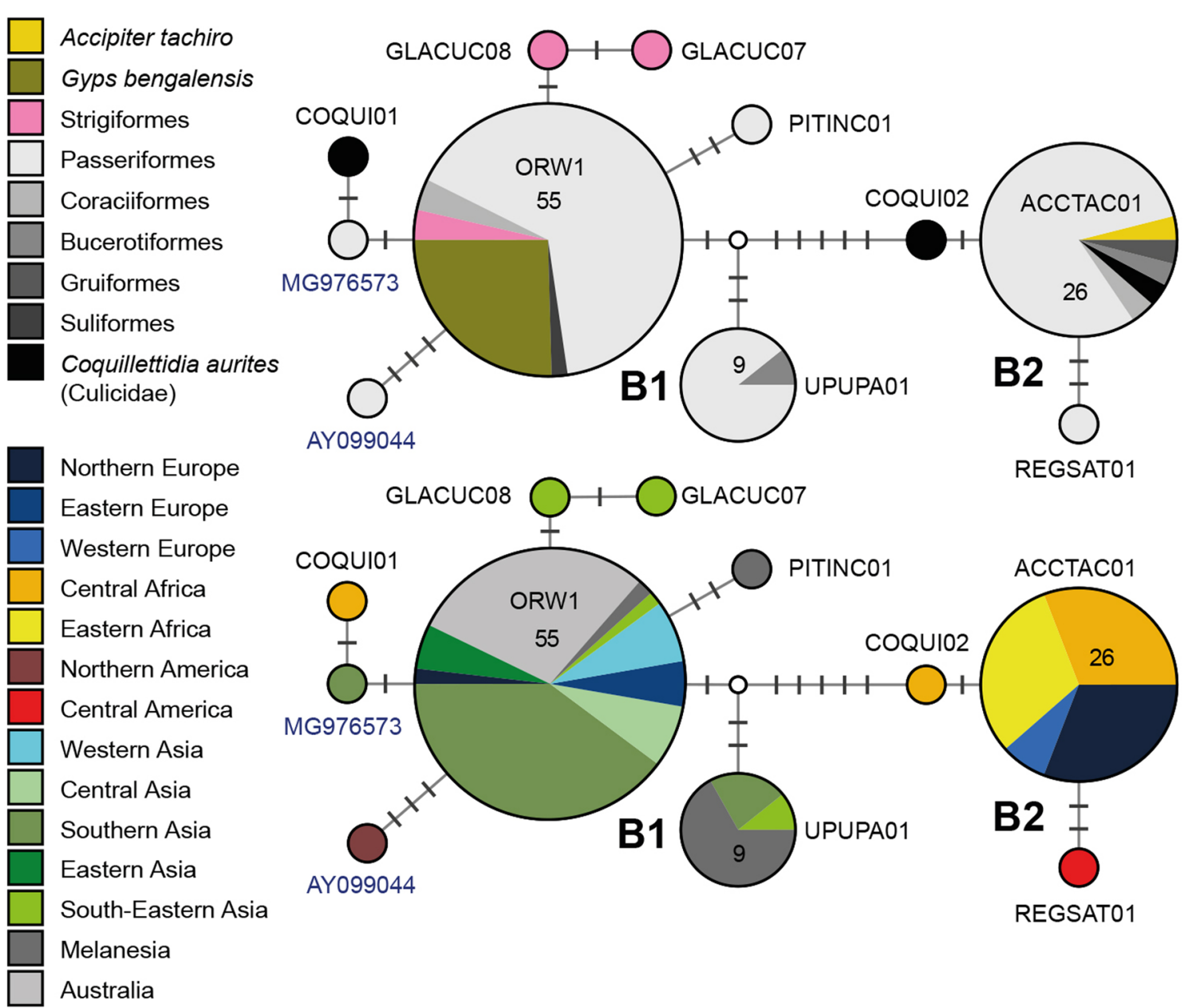

Fig. 7 Median-Joining DNA haplotype network of partial (474 bp) CytB sequences belonging to a Plasmodium clade, whose lineages have not been studied morphologically yet. The clade features the lineages PORW1 and PACCTAC01, which were found in the white-rumped vulture Gyps bengalis and the African goshawk Accipiter tachiro, respectively. The upper image indicates the number and frequency of host species, the lower one the geographic origin according to the United Nations geoscheme. In case lineages were not listed in the MalAvi database, the GenBank accession numbers are indicated in blue

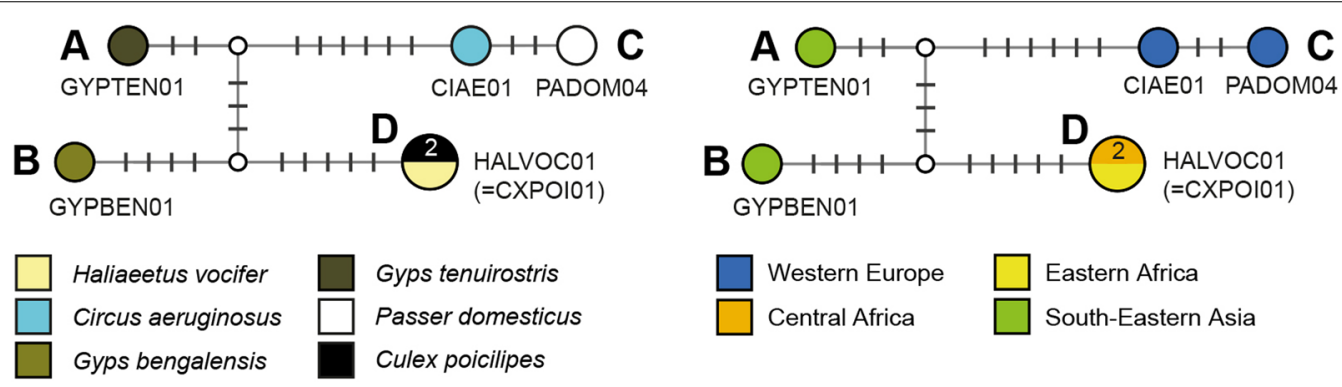

Fig. 8 Median-Joining DNA haplotype network of partial (462 bp) CytB sequences belonging to a Plasmodium clade featuring four lineages from accipitriform raptors. None of the lineages has been characterized morphologically yet. The left image indicates the number and frequency of host species, the right one the geographic origin according to the United Nations geoscheme 
accipitriform raptors are probably not natural hosts of some of these lineages.

Lineage pACCBAD01 was detected in Accipiter badius (2) [68] and the owls Athene brama (2), Bubo sumatranus (2) and Tyto alba (4) in Thailand [69]. It differs by six bp from pPESA01, which was found in Anseriformes in the USA (8), Brazil (3), and Canada (2), in the white-tipped dove Leptotila verreauxi (2) in Uruguay, in the passeriform Phaeomyias murina (1) and Piprites chloris (1) in Brazil, in the pectoral sandpiper Calidris melanotos (1) in Alaska, and one great black hawk Buteogallus urubitinga in Brazil [70]. Cygnus atratus and Cygnus melancoryphus infected with pPESA01 were kept together with great black hawks in the São Paulo Zoo, Brazil, and might be the source of infection [70].

Lineage pACCNIS05 was only found in Accipiter nisus (1) at the Beijing Raptor Rescue Centre in China [11]. It differs by one bp from Plasmodium gallinaceum pGALLUS01, a common parasite of the domestic chicken in Southeast Asia and one of the most thoroughly studied parasites in early haemosporidian research [3]. Although natural transmission of $P$. gallinaceum previously has not been reported from the Americas [3], lineage pGALLUS01 was also found in Tyrannidae (3) from Brazil [71] and in the common grackle Quiscalus quiscula (1) in the USA [72]. Recently, lineage pDENFUL02 was found in Harpagus diodon (1) in Brazil [73], but the sequence (MT919269) covers only 413 bp of the CytB barcode section in which it is identical with pACCNIS05 and pGALLUS01.

Lineage pEMSPO06 was found in Accipiter nisus (1) and Otus scops (1) at the Beijing Raptor Rescue Centre in China [11], the mallard Anas platyrhynchos (1) in Japan [74], the black-faced bunting Emberiza spodocephala (1) in South Korea [75], and the common stonechat Saxicola torquatus (1) in China [76]. The lineage differs by one bp from $\mathrm{pSW} 2$, which was linked to Plasmodium homonucleophilum by [77].

Lineage pMILANS05 was found in Circus aeruginosus (1) in Austria and in Milvus migrans (2) in Spain [8]. It was also found in the ruddy quail-dove Geotrygon montana (1) in Jamaica [78], the cattle egret Bubulcus ibis (1) in Africa [42], the ruff Philomachus pugnax in Malawi (1) and The Netherlands (1) [79], and Culex neavei (1) in Cameroon [66].

Lineage pPLACAS02 was found in Accipiter tachiro (1) and the chestnut wattle-eye Platysteira castanea (1) in Gabon [64], the olive sunbird Cyanomitra olivacea (3) in Cameroon [80, 81], and the Príncipe seedeater Crithagra rufobrunnea (1) and the Newton's sunbird Anabathmis newtonii (1) in Sao Tome and Principe [82]. Both pMILANS05 and pPLACAS02 differ by one bp from $P$. elongatum pGRW06, like several other lineages, which have not been studied morphologically yet but probably belong to P. elongatum. Lineage pGRW06 was found in Buteo buteo (1) from Austria and Rostrhamus sociabilis (1) from Brazil [73], whereby the sequence of the latter record (MT919272) covers only a 413 bp section of the $C y t B$ barcode section in which it is identical with pTRMUS02, a lineage found in one columbiform and four passeriform bird species in Brazil [62, 83, 84].

Lineage pMILANS06 was detected in Milvus migrans (1) in Spain [8], the Asian barred owlet Glaucidium cuculoides (1) in Thailand [69], the European turtle dove Streptopelia turtur (1) in Greece [85], the blue-spotted wood dove Turtur afer (1) in Gabon [82], and the European bee-eater Merops apiaster in Germany (2) and Portugal (1) [86]. The lineage is most similar to pNYCNYC01 (9 bp difference), which was found in the king vulture Sarcoramphus papa (2) and other birds in the Sao Paolo Zoo in Brazil [87]. Lineage pNYCNYC01 was also found in more than 60 birds (mainly Anseriformes) in the Americas [59, 87]. Accipitriform birds are probably not the natural hosts of these two lineages.

Lineage pMYCAME02 was recently linked to the morphospecies Plasmodium paranucleophilum by [88] Tostes et al. [88] detected the lineage in seven avian raptor species caught in Rio de Janeiro state, southeastern Brazil, and held in captivity at the Instituto Brasileiro do Meio Ambiente e dos Recursos Naturais Renováveis (IBAMA): the accipitriform Buteo brachyurus (1) and Rupornis magnirostris (1), the strigiform Asio clamator (3) and Pulsatrix koeniswaldiana (1), and the falconiform Falco peregrinus (1) and Caracara plancus (2). Other studies recorded pMYCAME02 in the wood stork Mycteria americana (14) in the USA [89], in the blue-winged teal Anas discors (7) in the USA [59], and a few birds of other orders in South America. Lineage pMYCAME02 is part of a clade featuring numerous similar lineages, which were mainly found in the cattle egret Bubulcus ibis in western Africa and Southern Africa [42] and other Ciconiiformes in northern America [89]. Based on the diversity of lineages and infected bird species, the natural hosts of pMYCAME02 and related lineages are probably ciconiiform birds. The cattle egret colonized the Americas only recently in the late nineteenth century [90] and might have naturally introduced these parasites. Despite the morphological similarities, it is possible that pMYCAME02 does not belong to $P$. paranucleophilum. The parasite was originally described from one individual of Tachyphonus sp. (Thraupidae, Passeriformes) imported to the USA from Brazil [91], but lineage pMYCAME02 has never been detected in birds of this family. The avian raptors found infected at the IBAMA in Brazil also might not be natural hosts of this lineage. 
Lineage pRHYSIM01 was found in the Blyth's hawkeagle Nisaetus alboniger (1) in Thailand [92]. Moreover, it was also found in the greyish mourner Rhytipterna simplex (1) in Brazil [93], the yellow warbler Setophaga petechia in the USA [94], and the green honeycreeper Chlorophanes spiza (1) in Peru [93]. Similar lineages clustering with pRHYSIM01 were found exclusively in passeriform birds in the Americas.

Lineage pRTSR1 was detected in the Wahlberg's eagle Hieraaetus wahlbergi (1) in Malawi [95], Milvus migrans (1) in Spain [8], and Falco naumanni (20) in Spain [96]. More than 50 other records of pRTSR1 originate from passeriform birds, mainly Sylviidae and Muscicapidae in Europe and Africa.

Lineage pRUMAG01 was found in Rupornis magnirostris (1) in Brazil [73], but the sequence (MT919274) covers only $383 \mathrm{bp}$ of the $C y t B$ barcode section. With 97\% identity, the sequence is most similar to pPESA01, which was found in anseriform birds in the Americas $[59,70]$.

Lineage pSYBOR10 was found in Circus aeruginosus (1) in Austria, the corncrake Crex crex in Poland (1) and Czechia (1) [97], and passeriform birds in Sweden (12), Hungary (2), Turkey (1), Nigeria (2), Botswana (1), and Japan (1) [e.g., 98, 99]. It differs by six bp from pRTSR1.

Lineage pZEMAC01 was detected in Aquila chrysaetos (2) kept in the Southwest Zoo in Arizona, USA [100]. It was also found in the mourning dove Zenaida macroura (3) $[72,101]$ and the great roadrunner Geococcyx californianus (2) [100] in the USA, the Neotropic cormorant Phalacrocorax brasilianus (4) in Chile [102], and passeriform birds in Argentina (1) [62], Mexico (1) [103], the USA (1) [104], and Australia (1) [105]. The lineage differs by nine bp from P. matutinum pLINN1, which was also found in one individual of Accipiter gentilis in Austria.

Lineage pBUTBUT06 was detected in Buteo buteo (1) in China [11]. It resembles pTSUB01 (4 bp difference), pGALLUS02 (5 bp difference), and several other lineages, which are currently associated with Plasmodium juxtanucleare. The lineages in this clade were mainly detected in the domestic chicken Gallus gallus in Eastern Asia and Southeast Asia (Additional file 3: Table S1), but a spillover was documented to seven species of wild passeriform birds in Brazil [106].

Lineage pTEPON02 was found in the crested serpent eagle Spilornis cheela (1), the Asian barred owlet Glaucidium cuculoides (1), and the buffy fish owl Ketupa ketupu (1) in Thailand [68, 69], and in the common woodshrike Tephrodornis pondicerianus in Myanmar [75]. It is part of a clade featuring lineages detected mainly in owls in Southeast Asia.

\section{Haemoproteus parasites in accipitriform raptors}

Five Haemoproteus species have been described from accipitriform hosts: Haemoproteus buteonis, Haemoproteus catharti, Haemoproteus elani, Haemoproteus janovyi, and Haemoproteus nisi. Only $H$. catharti and $H$. elani were characterized molecular genetically, but the $C y t B$ lineages linked to these species do not group phylogenetically into the genus Haemoproteus. The lineage $H$. catharti hCATAUR01 most likely belongs to the genus Plasmodium, while $H$. elani hBUBT1 cannot be assigned to any of the known haemosporidian genera because of its distinct sequence features. Two Haemoproteus clades contain lineages from accipitriform raptors, which have not been linked to morphospecies yet. The lineages in one of these clades were found exclusively in accipitriform birds, while those in the other one were mainly found in falconiform birds. Haemoproteus buteonis and $H$. janovyi could not be linked to any published $C y t B$ sequences. A summary of Haemoproteus lineages found in accipitriform raptors is provided in Table 6. A BI tree featuring all Haemoproteus lineages from accipitriform raptors is shown in Additional file 5: Fig. S4.

\section{Haemoproteus clade 1: Haemoproteus spp.}

This clade features about 30 haplotypes, which were mainly found in falconiform, strigiform, and accipitriform birds (Fig. 9). Of these, only Haemoproteus brachiatus hLK03 and Haemoproteus tinnunculi hFALSUB01 were linked to morphospecies. The latter two species were reported to be morphologically similar to $H$. nisi, which has not been characterized molecular genetically yet. Haemoproteus brachiatus hLK03 was found in Falco tinnunculus from China (11), Germany (1), and Turkey (1), in Falco columbarius (1) from Italy, in Falco naumanni (1) from Spain, in Ninox scutulata (1) and Otus scops (1) from China, and in Circus aeruginosus (1) from Austria. Haemoproteus tinnunculi hFALSUB01 is known from one specimen of the type host Falco subbuteo sampled in Lithuania [107]. The network contains seven lineages, which were exclusively reported from single accipitriform raptors in China by [11]: hBUTHEM01 from Buteo hemilasius, hACCGUL01 and hACCGUL02 from Accipiter gularis, hACCNIS01, hACCNIS02, hACCNIS03 from Accipiter nisus, and hBUTIND01 from Butastur indicus. Lineage hBUTBUT04 was found in Buteo buteo from China [11] and Falco eleonorae from Spain [108]. Last, lineage hBUBIBI01 was found in Buteo buteo (2), Accipiter nisus (1), and Buteo indicus (1), and Strigiformes (7) in China and Falconiformes in China (6), France (1), and Spain (1) [11, 109, 110]. Puech et al. [109] analyzed a blood sample of Falco subbuteo from France featuring a mixed infection with $H$. brachiatus and a new species, Haemoproteus obainae, but they only retrieved a 
Table 6 Haemoproteus CytB lineages of accipitriform raptors

\begin{tabular}{|c|c|c|c|c|c|c|}
\hline Lineage & Accession & Parasite species & Host species (only accipitriform birds) & Host env & Countries & References \\
\hline hBUBT1 & EF607291 & H. elani & Buteo buteo (2), Buteo jamaicensis (3) & Wild & Austria, Germany, USA & {$[14,112] ;$ present study } \\
\hline hCIAE08 & OL598532 & H. aff. elani & Circus aeruginosus (1) & Wild & Austria & present study \\
\hline hCATAUR01 & MF953291 & H. catharti & Cathartes aura (17) & Wild & USA & [114] \\
\hline hLK03 & EF564176 & H. brachiatus & Circus aeruginosus (1) & Wild & Austria & present study \\
\hline hBUTHEM01 & MT281482 & H. sp. & Buteo hemilasius (1) & Captive & China & [11] \\
\hline hACCGUL01 & MT281470 & H. sp. & Accipiter gularis (1) & Captive & China & [11] \\
\hline hACCGUL02 & MT281490 & H. sp. & Accipiter gularis (1) & Captive & China & [11] \\
\hline hACCNIS01 & MT281461 & H. sp. & Accipiter nisus (1) & Captive & China & [11] \\
\hline hACCNISO2 & MT281462 & H. sp. & Accipiter nisus (1) & Captive & China & [11] \\
\hline hACCNISO3 & MT281483 & H. sp. & Accipiter nisus (1) & Captive & China & [11] \\
\hline hBUTIND01 & MT281473 & H. sp. & Butastur indicus (1) & Captive & China & [11] \\
\hline hBUTBUT04 & MT281481 & H. sp. & Buteo buteo (1) & Captive & China & [11] \\
\hline hBUB|B|01 & KC994901 & H. obainae* & $\begin{array}{l}\text { Buteo buteo (2), Accipiter nisus (1), Butastur } \\
\text { indicus (1) }\end{array}$ & Captive & China & [11] \\
\hline hMILANS01 & JN164710 & H. sp. & Milvus migrans (3) & Wild & Spain & {$[8]$} \\
\hline hMILANS02 & JN164711 & H. sp. & $\begin{array}{l}\text { Milvus migrans (1), Buteo buteo (1), Buteo } \\
\text { rufinus (1), Clanga pomarina (1) }\end{array}$ & Wild & Spain, Turkey & $\begin{array}{l}\text { [8]; Yilmaz et al. unpub.; } \\
\text { Simsek et al. unpub }\end{array}$ \\
\hline hMILANS03 & JN164712 & H. sp. & Milvus migrans (6) & Wild & Spain & [8] \\
\hline hAFR048 & KM056451 & H. sp. & Milvus migrans (1) & Wild & Malawi & [95] \\
\hline unknown & MG428418 & H. sp. & Buteo rufinus (1) & Unknown & Iran & Norouzian et al. unpub \\
\hline hSTAL4 & JQ768232 & H. sp. & Buteo buteo (1) & Unknown & Turkey & Simsek et al. unpub \\
\hline hCIRCUM01 & KC994896 & H. noctuae & Buteo buteo (1) & Captive & Austria & present study \\
\hline hOTUSCO01 & MT281465 & H. sp. & Accipiter gularis (1), Circus cyaneus (1) & Captive & China & [11] \\
\hline
\end{tabular}

The list features records of all Haemoproteus CytB lineages found in accipitriform birds, other host species are not listed. The numbers in the brackets indicate the number of individuals that featured the respective lineages. One GenBank accession number is indicated for each MalAvi lineage. The term 'aff.' means 'species affinis', indicating that the lineage is similar to other lineages, which were already linked to morphospecies. ${ }^{*}$ Haemoproteus obainae might be a species inquirenda

sequence of lineage hBUBIBI01 by PCR and sequencing and could not assign it to either one of the two species.

\section{Haemoproteus clade 2: Haemoproteus sp.}

This clade (Fig. 10) features five similar lineages, which were exclusively reported from accipitriform raptors. The lineages hMILANS01 (3) and hMILANS03 (6) were found in Milvus migrans from Spain [8], hAFR048 in Milvus migrans (1) from Malawi [95], and pMILANS02 in Milvus migrans (3) from Spain [8] and Buteo rufinus (1, GenBank accession no. MN369025, Yilmaz et al. unpublished), Buteo buteo (1, MF928783, Simsek et al. unpublished), and Clanga pomarina (1, MH921565, Yilmaz et al. unpublished) from Turkey. A yet unnamed lineage (MG428418, Norouzian et al. unpublished) was found in one individual of Buteo buteo from Iran.

\section{Haemoproteus clade 3: Haemoproteus elani}

Haemoproteus elani was originally described from the black-winged kite Elanus caeruleus (Accipitriformes) in Daman, western India by de Mello (1935). The first molecular genetic record originates from [112], who identified lineage hBUBT1 from Buteo jamaicensis as
H. elani. Ishak et al. [112] detected three similar and yet unnamed lineages diverged by $4 \%$ from hBUBT 1 in Accipiter cooperii (FJ966920, FJ966921, FJ966923), but the quality of blood films did not allow morphological identification. The PCR assay used in the latter study covered only 243 nucleotide sites of the standard DNA barcode region, therefore, the sequences were not included in the DNA haplotype networks (Fig. 11). Elsewhere, hBUBT1 was only found in Buteo buteo in Austria (2) and Germany (1) [14], and the new lineage hCIAE08 was found in Circus aeruginosus in Austria (present study).

\section{Haemoproteus clade 4: Haemoproteus catharti}

Haemoproteus catharti was described from the New World vulture Cathartes aura in South Carolina (USA) by [113]. Morphologically, mature gametocytes of $H$. catharti have some similarities with $H$. tinnunculi and $H$. elani $[113,114]$. Yabsley et al. [114] screened blood samples of Cathartes aura in the USA and found $24 \%$ of 162 individuals positive for $H$. catharti. They sequenced the PCR products of 18 samples and found 17 individuals infected with hCATAUR01 and one sample with hCATAUR02 (one bp difference from hCAT 


$\square$ Accipiter gularis
$\square$ Accipiter nisus
$\square$ Butastur indicus
$\square$ Buteo buteo
$\square$ Buteo hemilasius
$\square$ Circus aeruginosus
$\square$ Passeriformes
$\square$ Ciconiiformes
$\square$ Coraciiformes
$\square$ Falconiformes
$\square$ Strigiformes

\section{H. tinnunculi FALSUB01 \\ $H$. brachiatus LK03}

\section{H. obainae} BUBIBI01?
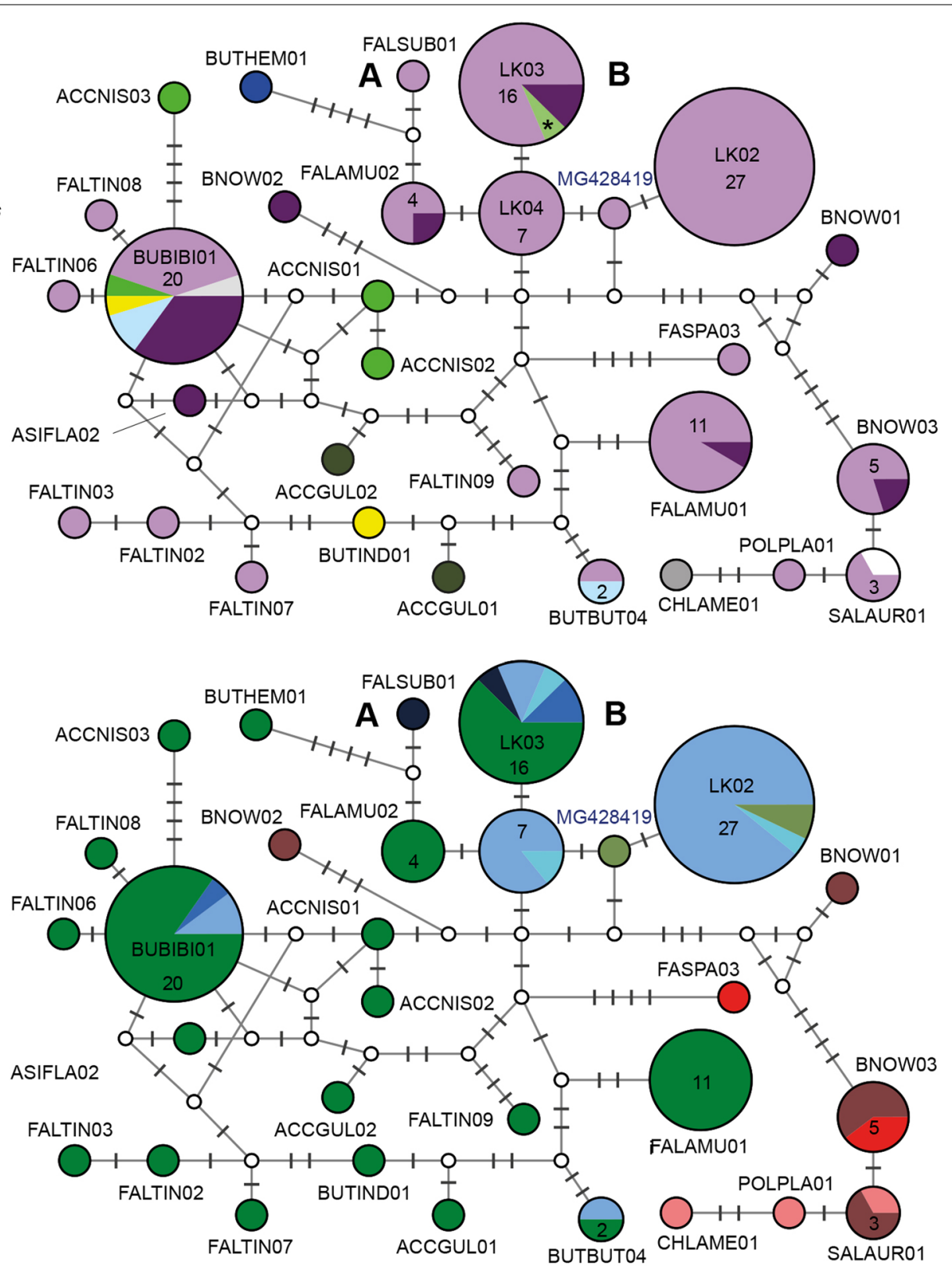

Fig. 9 Median-Joining DNA haplotype network of partial (474 bp) CytB sequences belonging to the Haemoproteus clade featuring Haemoproteus tinnunculi hFALSUB01 (A), Haemoproteus brachiatus hLK3 (B), and several other lineages detected in Falconiformes, Strigiformes, and Accipitriformes. The upper image indicates the number and frequency of host species, the lower one the geographic origin according to the United Nations geoscheme. Asterisks mark haplotypes detected in the present study

AUR01). Lineage hCATAUR02 covers only $367 \mathrm{bp}$ of the standard $C y t B$ barcode region and therefore is not included in the network (Fig. 12). The two lineages are most similar to pMYCAME08 from American and African Ciconiiformes with $97 \%$ sequence similarity. The latter lineage was found in the wood stork Mycteria americana in the USA (5) [89] and Brazil (1) [62], and in the western cattle egret Bubulcus ibis (number not indicated in publication) in western Africa [42]. Two yet unnamed lineages, GenBank accession numbers MH644685 from Buteo ibis in western Africa [42] and MG973753 from the roseate spoonbill Platalea ajaja in Brazil [115], differ from hMYCAME08 by one and two bp, respectively. 


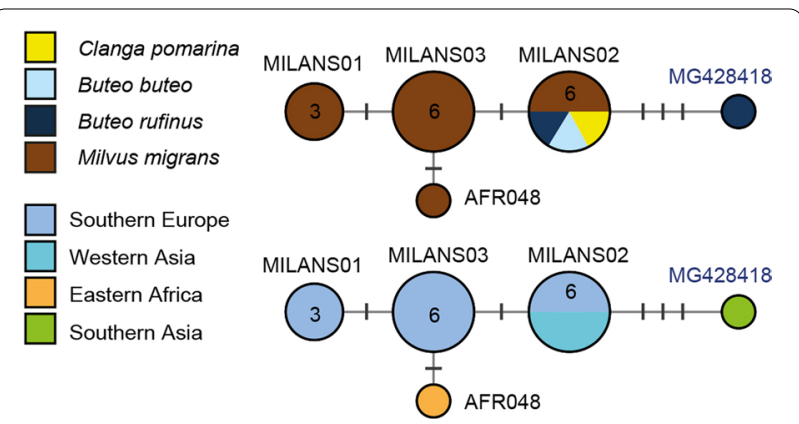

Fig. 10 Median-Joining DNA haplotype network of partial (474 bp) $C y t B$ sequences belonging to a Haemoproteus clade featuring five lineages detected in accipitriform raptors. The upper image indicates the number and frequency of host species, the lower one the geographic origin according to the United Nations geoscheme

\section{Other Haemoproteus lineages in accipitriform raptors}

Lineage hSTAL4 was reported from Buteo buteo (1) and the tawny owl Strix aluco (4) in Turkey by [116] and Simsek et al. (unpublished; MF928779-82). The present study found hCIRCUM01 in one Buteo buteo treated at the service unit for birds and reptiles of the Vetmeduni in
Vienna. The latter lineage was found in strigiform birds in China (4) [11] and western Russia (2) [117], in the biting midges Culicoides circumscriptus (2) and Culicoides submaritimus (1) from Turkey [118], and in Culicoides circumscriptus from Spain (1) [119]. Lineage hOTUSCO01 was found in Accipiter gularis (1), Circus cyaneus (1), and strigiform (6) and falconiform (3) birds in the Beijing Raptor Rescue Centre in China [11].

\section{Discussion}

This study aimed to summarize the $C y t B$ sequence data of haemosporidian lineages in accipitriform raptors and to show the patterns of geographic and host distribution of the parasites. This approach was also used to identify lineages, which have not been linked to morphospecies yet. The mitochondrial genomes of avian haemosporidians are highly conserved and some morphologically distinct species differ only in one or a few bp from each other in the $C y t B$ barcode section $[21,120]$. This is particularly problematic in parasites belonging to the genus Leucocytozoon because the number of morphological characters accessible for species description is limited, but the genetic diversity of these pathogens is comparable to the
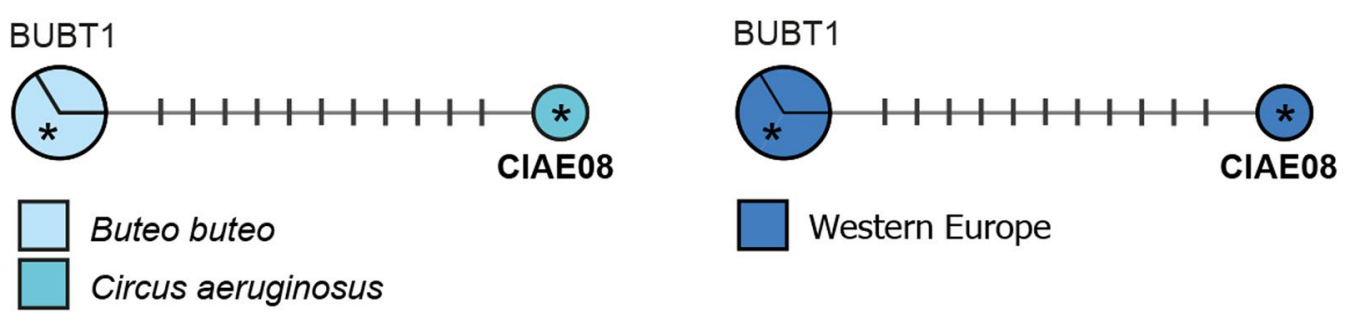

Western Europe

Fig. 11 Median-Joining DNA haplotype network of partial (474 bp) CytB sequences belonging to a Haemoproteus clade featuring lineage hBUBT1, currently linked to Haemoproteus elani. The left image indicates the number and frequency of host species, the right one the geographic origin according to the United Nations geoscheme. Asterisks mark haplotypes detected in the present study. New lineage names are indicated in bold letters. The original hBUBT1 sequences (FJ966924, FJ966926, FJ966927) and two similar but yet unnamed lineages (FJ966920, FJ966921) from six individuals of Buteo jamaicensis are not included in the network because they covered only $242 \mathrm{bp}$ of the CytB barcode region. In the $242 \mathrm{bp}$ section, FJ966921 is identical to hCIAE08 and FJ966920 differs in seven bp from hBUBT1
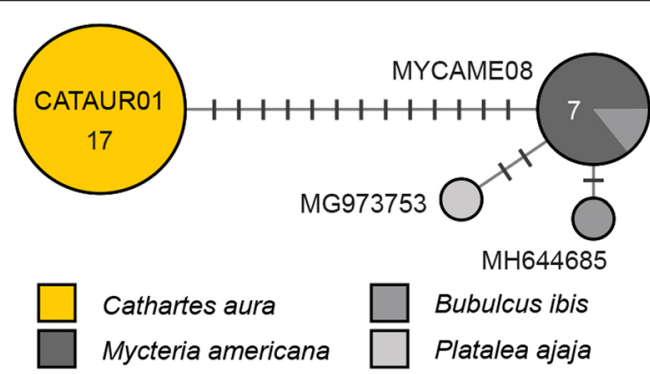

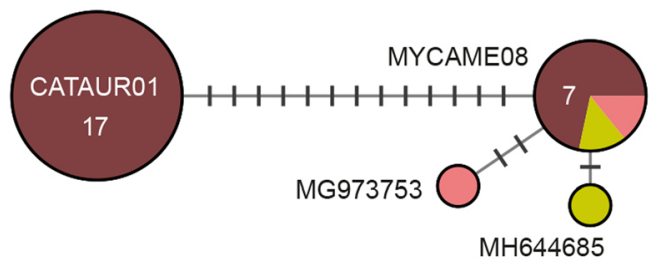

Northern America

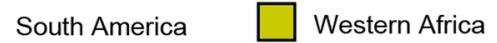

Fig. 12 Median-Joining DNA haplotype network of partial (474 bp) CytB sequences belonging to a Haemoproteus clade featuring lineage hCAT AUR01 linked to Haemoproteus cathartic. The left image indicates the number and frequency of host species, the right one the geographic origin according to the United Nations geoscheme 
diversity of the genus Plasmodium (MalAvi database; http://130.235.244.92/Malavi/). The blood stages (gametocytes) of the majority of described Leucocytozoon spp. parasitizing accipitriform birds are similar-sized roundish or oval bodies developing mainly in fusiform host cells with similar shape of nuclei, which is an important diagnostic character in Leucocytozoon spp. [3]. Gametocytes of Haemoproteus species and patterns of their development are also often similar in many species parasitizing accipitriform raptors. Plasmodium infections are common in birds belonging to the Accipitriformes birds but are often present in co-infections with Haemoproteus and Leucocytozoon spp. [3, 14]. Co-infections with haemosporidian parasites of the same and different genera are common and constitute a prominent obstacle in linking morphological data to sequence information [107, 121]. Another problem is that some groups of haemosporidian parasites specific to accipitriform raptors are not targeted by the standard primers of [6], which is the case for species of the L. toddi group [23] and probably most Haemoproteus parasites (G. Valkiūnas, pers. obs.). Specific primers have been developed already for the first group [23], but not for Haemoproteus lineages similar to Haemoproteus elani hBUBT1. The CytB sequence of the latter shares less than $87 \%$ identity with the $C y t B$ of other haemosporidians and might even be considered part of a separate subgenus or genus. These detection obstacles might explain the low prevalence of Haemoproteus lineages recorded in accipitriform birds so far compared to the other genera and should be considered in future studies screening this host group. Furthermore, morphological and molecular work on parasites found in accipitriform raptors has rarely been done in parallel, calling for a more integrative approach combining these techniques in future works. Therefore, at present, the available data should be treated with care. Accipitriformes are among the most endangered groups of birds, therefore investigations of haemosporidian infections are important regarding their health and preservation of biodiversity. This is particularly an alarming issue due to recent findings of damage caused by tissue stages of haemosporidian parasites in the internal organs of bird hosts $[23,122]$.

\section{Leucocytozoon parasites of accipitriform raptors}

The authors identified 57 Leucocytozoon lineages, which mostly belong to either the $L$. toddi group (48 lineages) or the $L$. californicus group (4 lineages).

All 10 Leucocytozoon species described from accipitriform birds belong to the $L$. toddi group (Table 1 ), but currently, only L. toddi, L. buteonis, and L. mathisi can be distinguished based on the available morphological features and knowledge on the biology of these parasites [29]. Due to the similarity of blood stages of these parasites, [17] synonymized L. mathisi, Leucocytozoon martyi, Leucocytozoon circaeti, and Leucocytozoon audieri with L. toddi, [18] did so with Leucocytozoon bacelari and Leucocytozoon franchini, and [19] and [20] did so with L. buteonis and Leucocytozoon muratovi. Sacchi \& Prigioni [123] speculated that $L$. mathisi and L. franchini might represent species distinct from L. toddi. According to [3], Leucocytozoon beaurepairei and $L$. franchini might be valid species, and other synonyms of $L$. toddi could be changed to valid names when more information on life cycles and DNA sequences is available. Validations and molecular characterisations of $L$. buteonis (a parasite of Buteo spp.) and L. mathisi (a parasite of Accipiter spp.) were conducted based on reported genetic differences and morphological features of their gametocytes and host cells. Particularly, fusiform processes of the infected blood cells are significantly longer in L. buteonis compared to L. mathisi [29]. However, the lineages linked to L. mathisi (1ACCOP01, lACNI04) differ from each other by $4.6 \%$ and those of L. buteonis (IBUBT2, lBUTJAM10, lBUTREG01) by $1.5-3.4 \%$, indicating that they might belong to several closely related cryptic species. Moreover, the parasite lineages found in the genera Buteo, Accipiter, and Circus cluster into several distinct subclades, indicating that each of the three raptor genera might host at least two different parasite species. Following the classification into sub-clades (Fig. 3), the currently known lineages of the $L$. toddi group might belong to about 20 distinct species. Considering that these lineages were obtained from 17 bird species only (less than $7 \%$ of 260 accipitriform species), the genetic diversity likely is much higher. Moreover, some molecular genetic studies including accipitriform birds did not detect parasites of the L. toddi species group [11, 14] because they used the standard PCR protocol by [6], which does not target the $C y t B$ of these parasites. Hanel et al. [12] also pointed out this problem and used the primers and PCR protocol of [72] to screen their samples more successfully. For the present study, the PCR protocol by [23] was used, which specifically targets the $C y t B$ of $L$. toddi group sequences. However, the latter primers also amplified the $C y t B$ of the lineages hBUBT1 and hCIAE08, which are currently attributed to Haemoproteus. The lineages of the L. toddi group were exclusively found in accipitriform raptors from Europe, Northern America, and Central Asia [8-10, 12]. There is one report of $L$. toddi from the falcon species Milvago chimango in southern Chile [124], but no illustrations of the parasites were provided. The parasite species might have been identified wrongly in the latter study because none of the $L$. toddi group lineages 
has been detected in falconiform birds so far. Still, no molecular genetic data is available on blood parasites of Kaupifalco monogrammicus, the type host of L. toddi.

Data on the exo-erythrocytic development of haemosporidian parasites in accipitriform raptors are absent. The present study features the first information about the exo-erythrocytic merogony of lineages attributed to L. buteonis. So far, meronts of Leucocytozoon spp. were only reported from Passeriformes, Anseriformes, Strigiformes, Podargiformes, and Sphenisciformes [3, 122], but not in diurnal raptors. The CISH analysis showed that both $L$. mathisi and L. buteonis preferably develop in renal tubular cells, which might indicate a typical pattern of exo-erythrocytic merogony in this species group. Although the number of meront infections was generally low in the investigated birds, higher parasite intensities could potentially damage kidneys, which should be taken into consideration in studies aiming at developing a treatment for accipitriform birds during leucocytozoonosis. Regarding blood stages of Leucocytozoon spp. detected with CISH, it was interesting to observe signals of elongate structures primarily in larger vessels of the heart and in lung capillaries. According to [3], gametocytes of $L$. toddi develop primarily in fusiform host cells but are exceptionally rarely observed in roundish host cells. Based on the shape of the CISH signals, the labelled parasite stages observed in larger vessels represent gametocytes in fusiform host cells. This is supported by the observation of gametocytes in histological preparations stained with haematoxylin-eosin (Fig. 1, c, i, l). Strikingly, numerous smaller roundish signals were also present but mainly observed in smaller capillaries. These stages might be young gametocytes. Valkiūnas [3] hypothesized, that gametocytes in roundish host cells might occur primarily during early parasitaemia. Although the phase of infection could not be determined for the birds investigated in this study, the birds could have died during early parasitaemia, which would explain the high numbers of small roundish signals as compared to elongated gametocytes in fusiform host cells. To confirm this hypothesis, experimental studies would be needed to clarify patterns of erythrocytic development in L. toddi group lineages.

The second Leucocytozoon clade containing multiple lineages from accipitriform raptors features $L$. californicus IFASPA02, which was recently described from Falco sparverius in California (USA) [31] and later found also in Falco columbarius in Italy [32]. However, the most common lineage in this clade is ICIAE02, which was detected in birds of ten different orders in Europe, Asia, and Africa. Half of the lCIAE02 records originate from accipitriform raptors of the genera Milvus, Circus, Accipiter, Buteo, and Aquila, and about one-third from seagulls Larus spp. Infections in birds of some orders might be abortive, i.e., sporozoites invade tissue cells leading to the formation of meronts but gametocytes do not develop. This is particularly probable in species of the genus Larus because in birds of this genus gametocytes of Leucocytozoon have been exceptionally rarely reported in blood films $[125,126]$. Such abortive infections are of particular concern because they have been associated with extensive parasite multiplication in tissues and the formation of megalomeronts, causing severe damage to organs and eventually death [127]. In particular, CIAE02 was reported to cause death in a captive cobalt-winged parakeet Brotogeris cyanoptera, demonstrating its pathogenic potential [23]. The clade features three additional lineages from accipitriform raptors (IACCTRI01, IBUTBUT01, ICIAE06), which also have not been linked to morphospecies yet. Due to its wide host range and the potential to cause severe haemosporidiosis, morphological characterization and experimental infection studies on ICIAE02 are highly recommended.

Five Leucocytozoon lineages were reported from a few individuals of accipitriform raptors and were mostly found in birds belonging to orders other than Accipitriformes. Most birds featuring these lineages were kept in rehabilitation facilities together with owls, falcons, and other birds, which might be the natural hosts. Lineage $\mathrm{IBT} 2$ belongs to a common parasite in passeriform birds [38, 45, 46] and lBUTBUT05 was mainly found in blood-fed black flies feeding on domestic chickens, while the natural hosts of lineages IBUBO01 and IASOT06 are probably owls. The detection of the latter lineages in accipitriform birds might therefore represent cases of abortive infections. Only the lineage IMILVUS02, which was found in single individuals of Milvus milvus, Haliaeetus albicilla, Buteo buteo, and Buteo lagopus in Europe [8, present study] was not found in birds of other orders.

\section{Plasmodium parasites of accipitriform raptors}

The diversity of Plasmodium lineages was lower (25 reported lineages) compared to that in Leucocytozoon. The most frequent lineages pTURDUS1 and pBT7 are linked to P. circumflexum. Apart from the two P. circumflexum lineages, only pORW1 was found in more than two individuals. The other lineages were each found in one or two individuals of accipitriform raptors but were mostly found in Passeriformes and birds of other orders. Most of these rare Plasmodium lineages were recorded in Eastern and South-Eastern Asia, which are rather poorly covered regarding molecular genetic studies on avian haemosporidians.

Plasmodium circumflexum, the type species of the subgenus Giovannolaia, was described from Turdus pilaris (Turdidae) in Germany. Morphologically similar parasites have since been reported from more than 100 
species of passeriform birds, but occasionally also from species of Accipitriformes, Anseriformes, Columbiformes, Coraciiformes, Charadriiformes, Falconiformes, Strigiformes, and Galliformes. According to the literature, $P$. circumflexum is particularly common in the Holarctic and was rarely recorded in South America and Australia [3, 125, 126]. Palinauskas et al. [54] linked the lineage pTURDUS1 to $P$. circumflexum and suggested that pBT7 belongs to the same species. Experimental infection studies showed that parasitaemia developed in Anas platyrhynchos, Carduelis spinus, and Loxia curvirostra after inoculation with pTURDUS1 positive blood, however, this lineage has not been detected in wild birds of the latter three species [128]. The main hosts of pTURDUS1 and pBT7 are the two Paridae species Cyanistes caeruleus and Parus major, but both lineages were also found in accipitriform raptors and birds of other orders. However, neither pTURDUS1 nor pBT7 have been detected in Falconiformes, Columbiformes, and Piciformes, which were also reported as host groups of $P$. circumflexum by [3]. In galliform birds, pBT7 was detected in about 31 individuals of Falcipennis canadensis, Tympanuchus phasianellus, and Bonasa umbellus in Alaska, USA [129] (data not included in Fig. 6 due to short sequence lengths of $425 \mathrm{bp}$ ). There is a discrepancy in host and geographic distribution between the two lineages. More than half of the pBT7 records originate from birds in the Americas, while pTURDUS1 was only found in Old World birds. Moreover, all or most pBT7 records from Anseriformes, Strigiformes, Charadriiformes, and the passeriform families Hirundinidae, Corvidae, and Turdidae originate from the Americas. The lineages in the network form a subclade within a larger clade featuring more than 30 lineages, which differ in less than 3\% from each other in the $C y t B$. Most of the other common lineages were found predominantly in passeriform birds, e.g., pGRW09, pNILSUN01, pSYBOR02, pPOMFER01, and pRFF1. Lineage pGRW09 was also reported from the European bee-eater Merops apiaster in Portugal and Germany, confirming the presence of a $P$. circumflexumrelated lineage in birds of the order Coraciiformes [86]. Lineage pSW5, which was also linked to $P$. circumflexum [130], was found mainly in Anseriformes and Gruiformes in the USA and Japan [59, 131, 132].

The second Plasmodium clade (Fig. 7) features the lineage pORW1, which was found mainly in passeriform birds, but also in the white-backed vulture Gyps bengalensis in India. Poharkar et al. [13] detected pORW1 in twelve dead and two living individuals of Gyps bengalensis in the Gadchiroli district in Maharashtra (central India). Blood film analysis (morphological data were not shown) and necropsy revealed the presence of erythrocytic meronts in the blood and tissue meronts in brain and liver sections, which were likely the cause of death for these birds [13]. Further investigations are necessary to characterise the morphology of the parasite and to test whether PORW 1 and similar lineages are also found in other raptor species. The lineage pACCTAC01 was found in one individual of the African goshawk Accipiter tachiro from Gabon [64], but mainly in Passeriformes and birds of other orders. In Europe, pACCTAC01 was found in the passeriform species Ficedula albicollis, Ficedula hypoleuca, Hirundo rustica, and the corncrake Crex crex (Additional file 3: Table S1). Transmission might take place in Africa because all of the latter species migrate to wintering sites in this region.

The third clade features the lineages pGYPTEN01, pGYPBEN01, pCIAE01, and pHALVOC01, which were found in single individuals of Gyps tenuirostris, Gyps bengalis, Circus aeruginosus, and Haliaeetus vocifer, respectively. The sequences in this clade are similar to Plasmodium parahexamerium pALEDIA02 (96.2\% identity), Plasmodium multivacuolaris pANLAT07 (95.4\% identity), and other Plasmodium lineages, which are particularly common in African birds [133]. The morphology of these five parasite lineages still needs to be assessed because the studies publishing them did not include blood film analyses.

Another 17 Plasmodium lineages covering the entire $C y t B$ barcode section were found in one or two accipitriform birds. In at least nine cases, the raptors were kept in zoos or rehabilitation centres together with birds of other orders featuring these parasite lineages [e.g., 85,97]. Hence, accipitriform raptors are probably not natural hosts of at least some of these lineages.

\section{Plasmodium species not yet linked to CytB lineages}

Plasmodium fallax was described from Strix woodfordii nuchalis (Strigiformes) in the Democratic Republic of the Congo (formerly Belgian Congo) and was reported also from the accipitriform Accipiter nisus, Aquila rapax, Aquila wahlbergi, Gyps africanus, the passeriform Emberiza tahapisi and Sylvia borin, and the helmeted guineafowl Numida meleagris. Experimental observations indicate that species of three different Culicidae genera can support sporogony and might be involved in the transmission of this parasite: Aedes aegypti, Aedes albopictus, Aedes atropalpus, Aedes triseriatus, Anopheles quadrimaculatus, Culex quinquefasciatus, and Culex tarsalis [3, 134]. Plasmodium fallax was recorded primarily in the Ethiopian and Oriental zoogeographical regions and adjacent territories of the Palearctic. The species morphologically resembles $P$. circumflexum, but its meronts and gametocytes do not encircle the host cell nucleus and are markedly vacuolated, the erythrocytic merogony is not synchronized, and it does not complete 
sporogony in vectors of the genera Culiseta and Mansonia [3]. Based on the present data, it is not possible to assign any lineage identified in accipitriform birds to $P$. fallax. The diversity of Plasmodium lineages detected in strigiform birds is low, and so far, no molecular genetic records have been published from the type host Strix woodfordii. Studies on haemosporidian parasites of African birds are still rare, and there is particularly a lack of combined morphological and molecular genetic studies, which would allow assigning lineages to morphospecies.

Plasmodium forresteri was described from the barred owl Strix varia in Georgia (USA). This parasite species was also reported from Buteo jamaicensis, Buteo lineatus, Buteo platypterus, and Haliaeetus leucocephalus in Florida and Georgia [53]. Experimental infection studies showed that sporozoites develop in Culex restuans but not in Culex nigripalpus, Culex erraticus, and $C$. quinquefasciatus. The Japanese quail Coturnix japonica and the mallard Anas platyrhynchos were susceptible experimental hosts. Morphologically, the attenuated gametocytes of $P$. forresteri, which belongs to the subgenus Novyella, resemble those of $P$. elongatum, which belongs to the subgenus Huffia [53], but the erythrocytic meronts of $P$. elongatum predominantly develop in young red blood cells, which is not the case in P. forresteri. Only a few Plasmodium lineages have been found in single specimens of the type host: Plasmodium aff. elongatum pPADOM11, Plasmodium aff. homopolare pLAIRI01, Plasmodium aff. cathemerium pSEIAUR01, Plasmodium sp. pSTVAR04, and P.circumflexum pSW5 [35, 135], whereas not even a single Plasmodium lineage has been reported from the four additional assumed natural hosts in North America. So far, $P$. cf. circumflexum pBT7 is the only Plasmodium lineage, which has been found in several species of accipitriform and strigiform raptors in Northern America, although not in the same host species as $P$. forresteri.

Three Plasmodium species were described from accipitriform raptors by [136] in Israel, $P$. accipiteris and $P$. alloelongatum from adult Accipiter brevipes, and $P$. buteonis from a juvenile Buteo buteo. The morphology of $P$. accipiteris erythrocytic meronts is reminiscent of Plasmodium tenuis and Plasmodium merulae, which are both considered subspecies of Plasmodium vaughani [3], but the gametocytes of $P$. accipiteris possess refractive globules, which is a distinct character indicating the validity of this species. However, $P$. alloelongatum is probably a synonym of $P$. elongatum, and $P$. buteonis needs redescription [16].

\section{Haemoproteus parasites of accipitriform raptors}

We identified 21 Haemoproteus lineages in accipitriform raptors, the majority of which was found in single individuals. Most of the lineages are part of one of the four clades shown as DNA haplotype networks.

The first Haemoproteus clade (Fig. 9) features 30 lineages, which were almost exclusively found in falconiform, strigiform, and accipitriform birds. Among those, only two lineages were linked to morphospecies, Haemoproteus brachiatus hLK03 and Haemoproteus tinnunculi hFALSUB01 from Falco tinnunculus [107]. Puech et al. [109] analysed a blood sample of Falco subbuteo from France featuring a mixed infection with $H$. brachiatus and a new species, Haemoproteus obainae, but they only retrieved a sequence of the lineage hBUBIBI01 by PCR and sequencing and could not assign it to either one of the two species. Based on the original description, Haemoproteus obainae might be a species inquirenda (a parasite of doubtful identity), and further data are needed to clarify its taxonomic validity. Ten of the lineages in this clade were detected in accipitriform raptors, among those eight in single individuals kept in the Beijing Raptor Rescue Centre in China [11]. Huang et al. [11] also prepared blood films from most of their samples, but no pictures are provided in the publication. Combined molecular genetic and morphological analyses of a broader sample of Eastern Asian raptors are required to confirm that these birds are natural hosts of these lineages. Alternatively, the source of infection could be falcons and owls kept in the same rehabilitation facility.

The second Haemoproteus clade (Fig. 10) features five similar lineages, which were exclusively reported from the accipitriform raptors Milvus migrans, Buteo rufinus, Buteo buteo, and Clanga pomarina (hMILANS01, pMILANS02, hMILANS03, hAFR048, and MG428418). No morphological data has been published for any of the five lineages so far. The sequences contained within this clade differ by more than $4 \%$ from other Haemoproteus lineages and seem to be specific to accipitriform birds. The lineages found in this clade are the only Haemoproteus sequences found in Milvus migrans and Buteo rufinus to date. Pérez-Rodríguez et al. [8] also screened more than 200 individuals of Milvus milvus in Spain and did not find any bird infected with Haemoproteus spp. In contrast to Milvus migrans, Milvus milvus is not native in sub-Saharan Africa. Since the European populations of the four raptors species hosting these parasite lineages have wintering sites in either Western or Eastern Africa, transmission probably takes place there and not in Europe. To clarify the taxonomic status of these parasites, morphological analyses of gametocytes of Milvus milvus are required.

Haemoproteus elani was described from the blackwinged kite Elanus caeruleus (Accipitriformes) in Daman, western India, and was reported from numerous other accipitriform raptors in North America, Europe, 
Africa, Middle East, and Asia [3, 111, 137]. Ishak et al. [112] identified lineage hBUBT1 from Buteo jamaicensis as H. elani. The linkage of hBUBT1 to Haemoproteus elani might be incorrect, because the type host Elanus caeruleus belongs to a different genus and inhabits Eurasia and Africa, but not the Americas. The lineage hBUBT1 and similar sequences form a unique clade and share less than $87 \%$ identity with the $C y t B$ of other haemosporidians, preventing the unequivocal assignment to any of the known genera. Further analyses are required to determine the generic position and biological features of these parasites. Haemoproteus elani was reported to be one of the most common Haemoproteus parasites in accipitriform raptors, but molecular genetic studies reported lineage hBUBT1 and related ones from a few bird species only. Both 'nest 2' reverse primers (HaemR2 and HaemR2L) of the standard PCR protocol by [6] feature four mismatches in the 3'-region to lineages of this group, which might explain the extremely scarce molecular genetic record in other studies. The sequences of the present study were obtained using the primers by [23], which were originally designed to target lineages of the $L$. toddi species group. Sequencing larger $C y t B$ sections would allow identifying better primer sites for this group of haemosporidians.

The systematic position of Haemoproteus catharti also needs to be addressed. Haemoproteus catharti was described from the New World vulture Cathartes aura in South Carolina (USA) by [113]. Yabsley et al. [114] linked hCATAUR01 and hCATAUR02 to Haemoproteus catharti. The latter lineages are part of the Plasmodium clade, but the parasite identified as Haemoproteus catharti did not feature erythrocytic meronts and therefore was considered a member of the genus Haemoproteus by [114]. However, the original description of Haemoproteus catharti was based on blood films featuring co-infections with at least two different Plasmodium species [113]. Although the description of Haemoproteus catharti is valid, the linked lineages hCATAUR01 and hCATAUR02 likely belong to a Plasmodium species present in co-infection.

Three other Haemoproteus lineages were detected in one or two individuals, hSTAL4 in Buteo buteo from Turkey (Simsek et al., unpublished; MF928778), hCIRCUM01 in Buteo buteo from Austria, and hOTUSCO01 in Accipiter gularis and Circus cyaneus from China [11]. The latter three lineages are part of a diverse Haemoproteus clade, which almost exclusively features lineages found in strigiform birds. All accipitriform raptors featuring these lineages were kept indoors close to owls, which presumably serve as reservoir hosts for Culicoides vectors. It is unclear if the parasites complete development and produce gametocytes in accipitriform birds.
Haemoproteus species not yet linked to $C y t B$ lineages Haemoproteus buteonis was described from Buteo buteo in Sweden. The parasite was reported from accipitriform birds in the Holarctic (mainly Palearctic), namely Accipiter cooperii, Accipiter nisus, Aquila nipalensis, Buteo platypterus, Circus aeruginosus, Pernis apivorus, and Pernis ptilorhynchus [3]. Peirce et al. [137] considered the parasite species a synonym of H. elani, but Valkiūnas [3] pointed out some morphological differences and suggested treating $H$. buteonis as a distinct species. Due to the morphological similarities and overlapping host ranges, $H$. buteonis might be related to $H$. elani. The parasite has not yet been characterized using molecular genetics, but $H$. buteonis might feature a lineage related to hBUBT1, which was attributed to $H$. elani by [112]. If $H$. buteonis is closely related to hBUBT1, which features unique $C y t B$ sequences not clustering with those of the other genera, it might not have been detected in studies using the standard primers by [6].

Haemoproteus janovyi was described from Gyps africanus in northwest Zimbabwe. The parasite is common in African vultures, and morphologically similar gametocytes were found throughout southern Africa in Necrosyrtes monachus, Torgos tracheliotus, Trigonoceps occipitalis. The gametocytes of $H$. janovyi resemble those of $H$. nisi and $H$. tinnunculi because they also might fully encircle the host nucleus $[3,138]$. So far, $H$. janovyi neither has been characterized using molecular genetics nor were any haemosporidian $C y t B$ sequences published from the vulture species reported to host this parasite. Blood samples of African vultures were collected extensively in recent ornithological studies [139-141], but no parasite screenings were performed.

Haemoproteus nisi was described from Accipiter nisus in Scotland, UK, and was found in numerous accipitriform hosts in the Holarctic, Ethiopian, and Oriental zoogeographical regions (Table 1) [3]. This parasite is certainly common in Accipiter nisus in Eurasia [142]. Due to the presence of circumnuclear fully-grown gametocytes, $H$. nisi resembles $H$. brachiatus, $H$. janovyi, and H. tinnunculi [3], but a molecular characterization is still missing. The lineages linked to H. brachiatus hLK03 and H. tinnunculi hFALSUB01 are part of a clade, which features almost 30 haemosporidian lineages of falconiform, strigiform, and accipitriform raptors (Fig. 9). This clade contains all Haemoproteus lineages found in Accipiter nisus so far, hACCNIS01, hACCNIS02, hACCNIS03, and hBUBIBI01. The first three lineages were found in single individuals of Accipiter nisus in China [11], while hBUBIBI01 was found also in Buteo buteo, Butastur indicus, Falco tinnunculus, Asio otus, Athene noctua, and Bubo bubo in China [11], and in Falco subbuteo and Falco eleonorae in Europe [109, 110]. Given that hBUBIBI01 
features a different host composition than proposed for $H$. nisi and that the other lineages were recorded only once in China, they are probably not associated with $H$. nisi, but might be abortive infections in this host. Blood film-positive samples of Accipiter nisus were negative in PCRs using the primers by [6], therefore $H$. nisi and related parasites might not be targeted by this PCR assay (G. Valkiūnas, pers. obs.).

\section{Taxonomic problems}

Despite the relatively small number of described haemosporidian species in Accipitriformes birds, only a few of them have been characterized using molecular genetics. These species are L. buteonis IBUBT2 (IBUTJAM10, lBUTREG01), L. mathisi lACCOP01 (lACNI04), and $H$. elani hBUBT1. The only other molecular genetically characterized species reported to be common in accipitriform birds, but first described from a different host group, is P. circumflexum pTURDUS1 (pBT7) (see also Table 1). However, the different lineages linked to L. buteonis and $L$. mathisi differ strongly in the $C y t B$ barcode region and were found in different host species, thus indicating they might belong to several cryptic species, and both parasite names might cover species groups, as is the case with the $L$. toddi group. This needs further research. The host distribution of the lineages in the $L$. toddi species group and the genetic distance between them support the presence of about 20 parasite species in this clade. Some of the known lineages might belong to other $L$. toddi group species, which were synonymized with $L$. toddi based on the similarity of their gametocytes and host cells [3], but the original descriptions of these species are incomplete and the type material is absent for all of them [29]. Moreover, most of these species were originally described from birds in Africa, which yet have not been screened for avian haemosporidians using molecular genetics. Valkiūnas et al. [29] and Sehgal et al. [9] suggested that $L$. toddi is likely a group of cryptic species, with different species or subspecies infecting Buteo spp. and Accipiter spp. However, adding the new data published by [12] and the present study shows a more complex picture. Both Buteo spp. and Accipiter spp. feature lineages in at least three separate sub-clades and Milvus spp. and Circus spp. in at least two. Some lineages were found in birds of different genera, but most seem specific to single bird species even. Characterizing the species diversity in this parasite group based on morphology is particularly complicated due to the low number of distinctive features and overlapping ranges of their morphometric characters. Analyses of exo-erythrocytic parasites stages in bird hosts and sporogonic stages in Simuliidae vectors might reveal additional morphological features for future taxonomic studies, which could facilitate species delimitation.
The problem with $H$. catharti hCATAUR01 is that the lineage clusters in the Plasmodium clade and probably originates from Plasmodium sp. present in the same samples. Another issue that needs to be addressed is that hBUBT1, the $C y t B$ lineage linked to $H$. elani by [112], does not cluster phylogenetically into the Haemoproteus clade. It shares less than $87 \%$ identity with lineages of the three main genera, not allowing a clear assignment to any known haemosporidian genus. Despite $H$. elani and the morphologically similar species $H$. buteonis having been reported frequently from accipitriform birds, the number of molecular genetic records is low. The fact that the standard DNA barcode primers by [6] generally do not allow amplification of the $C y t B$ in this group, might partially explain that it was rarely detected in molecular genetic parasite screenings. The development of new PCR assays specifically targeting these lineages would be highly recommended. Plasmodium circumflexum was also commonly reported from accipitriform raptors and the observation of gametocytes indicates that the parasite completes its life cycle in this host group (G. Valkiūnas, pers. obs.). However, the CISH conducted on tissue samples of five raptors (Accipiter nisus, Buteo buteo and Circus aeruginosus) infected with pTURDUS1 or pBT7 was negative and neither tissue meronts nor erythrocytic parasite stages were observed. The reason for the contrasting results between PCR and CISH remains unclear but might relate to a lower detection rate of CISH compared to sensitive PCR assays in case of low parasite intensities. Hanel et al. [12] detected pTURDUS1 in a single adult individual of Accipiter gentilis in Czechia by PCR and sequencing, but also did not observe parasites in the blood films. The latter might be cases of abortive infections in which sporozoites were present in the blood but host cells were not infected [143]. Gametocytes and erythrocytic meronts of $P$. circumflexum were observed in a wild-caught juvenile Accipiter badius in Thailand, however, the lineage detected was pACCBAD01, differing by $3.1 \%$ from pTURDUS1 in the $C y t B$ [144].

\section{Accidental infections and contaminations}

Most of the Leucocytozoon lineages detected in accipitriform raptors, particularly the lineages contained in the L. toddi clade, are specific to this host group. On the contrary, most Plasmodium lineages were found mainly in birds of other host orders, e.g., pACCTAC01, pBT7, pLINN1, pPLACAS02, pTURDUS1, pACCTAC01 in Passeriformes, pNYCNYC01 and pPESA01 in Anseriformes, pRTSR1 in Falconiformes, pACCNIS05 in Galliformes, and pACCBAD01 in Strigiformes. Some Haemoproteus lineages were also predominantly reported from other birds, e.g., hSTAL4, hCIRCUM01, and hOTUSCO01 from Strigiformes, hBUBIBI01 from Strigiformes and 
Falconiformes, and hLK03 from Falconiformes. Most accipitriform raptors featuring the latter lineages were kept in raptor rescue centres, zoos, or animal hospitals together with strigiform and falconiform birds as well as birds of other orders. Dipteran vectors then might transmit parasites between birds of different orders when they are kept in close proximity. Moreover, the birds might be exposed to dipteran vectors, which they do not or rarely encounter in their natural habitats, facilitating accidental infections in untypical host species. Parasites featuring some of these lineages might not complete their life cycles in accipitriform raptors, but the sporozoites injected by blood-feeding vectors still might be detected for a certain period using sensitive PCR assays. For example, living sporozoites of Leucocytozoon spp. were observed in the blood of experimentally infected birds for up to 11 days post infection [143, 145]. Valkiūnas et al. [133] found that several yellow-whiskered greenbuls Andropadus latirostris from Ghana were positive for Leucocytozoon spp. using the nested PCR protocol by [6], however, microscopic analysis of the blood films showed only sporozoites in the blood. Valkiūnas et al. [143] suggested that sensitive PCR-screenings potentially also detect the presence of haemosporidian sporozoites in the hosts' blood. Therefore, the detection of these lineages in molecular genetic parasite screenings does not necessarily prove that accipitriform raptors are susceptible hosts. Unless blood stages visualization confirms the presence of gametocytes, accipitriform raptors should be treated as provisional hosts of these lineages. Abortive development has been documented in haemosporidians. In this case, tissue stages might develop partly and produce templates for PCR amplification, but tissue merozoites either do not develop or are incapable to infect blood cells [23, 127].

Another explanation for the detection of unusual haemosporidian lineages in birds is contamination. Bensch et al. [146] recently discussed some cases in avian haemosporidian parasite screenings. Common causes of unusual haemosporidian reports might be contaminations of laboratory chemicals (e.g., PCR reagents and extraction buffers) with PCR products or DNA from positive controls, and the confusion of samples [146]. Some of the lineages found in accipitriform raptors, particularly those belonging to Plasmodium spp., might result from contaminations because they were rarely reported in raptors and mostly found in other bird groups.

\section{Conclusion}

The present study summarizes and discusses information on $C y t B$ sequences of haemosporidian parasites detected in accipitriform raptors worldwide. So far, only five of the 21 haemosporidian parasites described from or reported to occur in Accipitriformes birds have been characterized molecular genetically, and there are numerous taxonomic questions, which deserve attention. The total number of $C y t B$ lineages recorded in accipitriform birds was 57 for Leucocytozoon, 25 for Plasmodium, and 21 for Haemoproteus. The DNA haplotype networks visualize the geographic and host distribution of most lineages and suggest directions for taxonomy research. They allowed identifying numerous distinct groups of lineages, which have not been linked to morphospecies yet, and many of them likely belong to yet undescribed parasite species. Whereas the majority of Leucocytozoon and Haemoproteus lineages are specific to this host group, most Plasmodium lineages were predominantly found in birds of other orders. Some of these lineages are common in owls and other birds, which are often kept at the same facilities as accipitriform raptors (raptor rescue centres and zoos), suggesting local transmission and probably abortive infections of accipitriform raptors with owl parasites. Several taxonomic and systematic problems could not be resolved in the present study. To clarify these issues, combined morphological and molecular genetic analyses on a wider range of accipitriform host species, including the examination of type hosts, are recommended. Some general primers commonly used in haemosporidian research do not allow the detection of many Haemoproteus and Leucocytozoon lineages specific to accipitriform hosts. This calls for the development of new PCR protocols for the detection of haemosporidians in this bird group.

\section{Abbreviations}

B.-H.: Bosnia-Herzegovina; BI: Bayesian inference; bp: Base pair/s; CISH: Chromogenic in situ hybridization; CytB: Cytochrome b; ML: Maximum likelihood; rpm: Rotations per minute.

\section{Supplementary Information}

The online version contains supplementary material available at https://doi. org/10.1186/s12936-021-04019-z.

Additional file 1: Fig. S1. An intramuscular parasite cyst (arrow) detected in a hematoxylin-eosin stained section of the heart of a western marsh harrier Circus aeruginosus co-infected with Leucocytozoon sp. ICIAE03 and P. circumflexum PTURDUS1. The morphology resembles tissue cysts of parasites belonging to the family Sarcocystidae (Conoidasida, Apicomplexa). Scale bar is $50 \mu \mathrm{m}$.

Additional file 2: Fig. S2. Bayesian inference tree of CytB lineages (474 bp) belonging to the genus Leucocytozoon, except for the sequences belonging to the Leuocytozoon toddi species group, which are shown in Fig. 2. Bayesian posterior probabilities and Maximum likelihood bootstrap values are indicated at most nodes. A sequence of L. buteonis (belonging to the L. toddi species group) was used as outgroup. The scale bars indicate the expected number of substitutions per site according to the model of sequence evolution applied. Lineage names in bold letters were found in accipitriform raptors. Species names indicate that the lineages were already linked to the respective morphospecies. 
Additional file 3: Table S1. CytB sequences used in the present study (including GenBank accession numbers, MalAvi lineage names, localities, host species, and references).

Additional file 4: Fig. S3. Bayesian inference tree of CytB lineages (474 bp) belonging to the genus Plasmodium. Bayesian posterior probabilities and Maximum likelihood bootstrap values are indicated at most nodes. A sequence of Haemoproteus tinnunculi was used as outggroup. The scale bars indicate the expected number of substitutions per site according to the model of sequence evolution applied. Lineage names in bold letters were found in accipitriform raptors. Species names indicate that the lineages were already linked to the respective morphospecies.

Additional file 5: Fig. S4. Bayesian inference tree of CytB lineages (474 bp) belonging to the genus Haemoproteus. Bayesian posterior probabilities and Maximum likelihood bootstrap values are indicated at most nodes. The sequences of the H. elani clade were used to root the tree. The scale bars indicate the expected number of substitutions per site according to the model of sequence evolution applied. Lineage names in bold letters were found in accipitriform raptors. Species names indicate that the lineages were already linked to the respective morphospecies.

\section{Acknowledgements}

We want to thank Staffan Bensch for his support concerning the MalAvi database.

\section{Authors' contributions}

$J \mathrm{H}, \mathrm{HW}$, TH: study conception and design; JH: drafting the manuscript, sequence analyses, data analyses, preparation of data sets and figures for the DNA analyses; $\mathrm{TH}$ : chromogenic in situ hybridization, data analysis, and drafting the corresponding methods, results, and discussion sections; GV, MI: contributing to the taxonomic sections and the discussion; NN, JM: chromogenic in situ hybridization lab work; AK, AA: sample collection and pathological analyses; CK blood sample collection. All authors read and approved the final manuscript.

\section{Funding}

This study was funded by the Austrian Science Fund FWF (Grant P 29628).

\section{Availability of data and materials}

The dataset supporting the conclusions of this article is included within the article and its additional files.

\section{Declarations}

\section{Ethics approval and consent to participate}

The collection of blood samples from living birds was approved by the institutional ethics and animal welfare committee and the national authority according to $\S \S 26 f f$. of Animal Experiments Acts, Tierversuchsgesetz TVG 2012, Austria (BMWFW- 68.205/0036-WFN/3b/2017). The samples collected by the Research Institute of Wildlife Ecology (University of Veterinary Medicine Vienna) and the Faculty of Veterinary Medicine (University of Sarajevo) were taken from carcasses submitted for routine pathological examinations. No birds were killed for the present study.

\section{Consent for publication}

Not applicable.

\section{Competing interests}

The authors declare that they have no competing interests.

\section{Author details}

${ }^{1}$ Institute of Pathology, Department of Pathobiology, University of Veterinary Medicine Vienna, Veterinaerplatz 1, 1210 Vienna, Austria. ${ }^{2}$ Nature Research Centre, Akademijos 2, 08412 Vilnius, Lithuania. ${ }^{3}$ Research Institute of Wildlife Ecology, Department of Integrative Biology and Evolution, University of Veterinary Medicine Vienna, Savoyenstraße 1, 1160 Vienna, Austria. ${ }^{4}$ Department of Pathology, Faculty of Veterinary Medicine, University of Sarajevo, Zmaja od Bosne 90, 71000 Sarajevo, Bosnia and Herzegovina. ${ }^{5}$ Service for Birds and Reptiles, Clinic for Small Animal Internal Medicine, Department for Companion
Animals and Horses, University of Veterinary Medicine Vienna, Veterinaerplatz 1, 1210 Vienna, Austria.

Received: 12 October 2021 Accepted: 9 December 2021

Published online: 05 January 2022

\section{References}

1. Himmel T, Harl J, Pfanner S, Nedorost N, Nowotny N, Weissenböck H. Haemosporidioses in wild Eurasian blackbirds (Turdus merula) and song thrushes (T. philomelos): an in situ hybridization study with emphasis on exo-erythrocytic parasite burden. Malar J. 2020;19:69.

2. Dinhopl N, Nedorost N, Mostegl MM, Weissenbacher-Lang C, Weissenböck H. In situ hybridization and sequence analysis reveal an association of Plasmodium spp. with mortalities in wild passerine birds in Austria. Parasitol Res. 2015;114:1455-62.

3. Valkiūnas G. Avian malaria parasites and other haemosporidia. CRC press. 2005. https://doi.org/10.1201/9780203643792

4. Harl J, Himmel T, Valkiūnas G, Ilgūnas M, Bakonyi T, Weissenböck H. Geographic and host distribution of haemosporidian parasite lineages from birds of the family Turdidae. Malar J. 2020;19:335.

5. Bensch S, Stjernman M, Hasselquist D, Örjan Ö, Hannson B, Westerdahl $\mathrm{H}$, et al. Host specificity in avian blood parasites: a study of Plasmodium and Haemoproteus mitochondrial DNA amplified from birds. Proc Biol Sci. 2000;267:1583-9.

6. Hellgren O, Waldenström J, Bensch S. A new PCR assay for simultaneous studies of Leucocytozoon, Plasmodium, and Haemoproteus from avian blood. J Parasitol. 2004;90:797-802.

7. Bensch S, Hellgren O, Pérez-Tris J. MalAvi: a public database of malaria parasites and related haemosporidians in avian hosts based on mitochondrial cytochrome b lineages. Mol Ecol Resour. 2009;9:1353-8.

8. Pérez-Rodríguez A, de la Puente J, Onrubia A, Pérez-Tris J. Molecular characterization of haemosporidian parasites from kites of the genus Milvus (Aves: Accipitridae). Int J Parasitol. 2013:43:381-7.

9. Sehgal RNM, Hull AC, Anderson NL, Valkiūnas G, Markovets MJ, Kawamura S, et al. Evidence for cryptic speciation of Leucocytozoon spp. (Haemosporida, Leucocytozoidae) in diurnal raptors. J Parasitol. 2006;92:375-9.

10. Jasper MA, Hull JM, Hull AC, Sehgal RNM. Widespread lineage diversity of Leucocytozoon blood parasites in distinct populations of western Red-tailed Hawks. J Ornithol. 2014;155:767-75.

11. Huang $X$, Huang D, Liang $Y$, Zhang L, Yang G, Liu B, et al. A new protocol for absolute quantification of haemosporidian parasites in raptors and comparison with current assays. Parasit Vectors. 2020;13:354.

12. Hanel J, Doležalová J, Stehlíková Š, Modrý D, Chudoba J, Synek P, et al. Blood parasites in northern goshawk (Accipiter gentilis) with an emphasis to Leucocytozoon toddi. Parasitol Res. 2016;115:263-70.

13. Poharkar A, Reddy PA, Gadge VA, Kolte S, Kurkure N, Shivaji S. Is malaria the cause for decline in the wild population of the Indian White-backed vulture (Gyps bengalensis)? Curr Sci. 2009;96:553-8.

14. Krone $\mathrm{O}$, Waldenström J, Valkiūnas G, Lessow O, Müller K, lezhova TA, et al. Haemosporidian blood parasites in European birds of prey and owls. J Parasitol. 2008;94:709-15.

15. Ciloglu A, Yildirim A, Duzlu O, Onder Z, Dogan Z, Inci A. Investigation of avian haemosporidian parasites from raptor birds in Turkey, with molecular characterisation and microscopic confirmation. Folia Parasitol (Praha). 2016;63:1-8.

16. Valkiūnas $\mathrm{G}$, lezhova TA. Keys to the avian malaria parasites. Malar J. 2018;17:212.

17. Hsu C, Campbell GR, Levine ND. A check-list of the species of the genus Leucocytozoon (Apicomplexa, Plasmodiidae). J Protozool. 1973;20:195-203.

18. Greiner EC, Kocan AA. Leucocytozoon (Haemosporida; Leucocytozoidae) of the Falconiformes. Can J Zool. 1977;55:761-70.

19. Valkiūnas G. Parasitic Protozoa of the blood of birds in the USSR.(3. Leucocytozoidae of Passeriformes, Strigiformes, Anseriformes and Falconiformes) Lietuvos TSR MA darbai. C Ser. 1988;2:114-31.

20. Valkiūnas G. Occurrence and morphology of two types of Leucocytozoon toddi gametocytes in some palearctic Falconiformes. Parazitologiya. 1989;4:46-50. 
21. Nilsson E, Taubert H, Hellgren O, Huang X, Palinauskas V, Markovets MY, et al. Multiple cryptic species of sympatric generalists within the avian blood parasite Haemoproteus majoris. J Evol Biol. 2016;29:1812-26.

22. Galen SC, Nunes R, Sweet PR, Perkins SL. Integrating coalescent species delimitation with analysis of host specificity reveals extensive cryptic diversity despite minimal mitochondrial divergence in the malaria parasite genus Leucocytozoon. BMC Evol Biol. 2018;18:128.

23. Himmel T, Harl J, Kübber-Heiss A, Konicek C, Juan-Sallés C, Ilgūnas M, et al. Molecular probes for the identification of avian Haemoproteus and Leucocytozoon parasites in tissue sections by chromogenic in situ hybridization. Parasit Vectors. 2019;12:282.

24. Hall TA. BioEdit: a user-friendly biological sequences alignment editor and analysis program for Windows 95/98/NT. Nucleic Acids Symp Ser. 1999:41:95-8.

25. Rozas J, Ferrer-Mata A, Sánchez-DelBarrio JC, Guirao-Rico S, Librado P, Ramos-Onsins SE, et al. DnaSP 6: DNA sequence polymorphism analysis of large data sets. Mol Biol Evol. 2017;34:3299-302.

26. Katoh K, Standley DM. MAFFT multiple sequence alignment software version 7: improvements in performance and usability. Mol Biol Evol. 2013:30:772-80

27. Trifinopoulos J, Nguyen L-T, von Haeseler A, Minh BQ. W-IQ-TREE: a fast online phylogenetic tool for maximum likelihood analysis. Nucleic Acids Res. 2016;44:232-5.

28. Ronquist F, Teslenko M, Van Der Mark P, Ayres DL, Darling A, Höhna S, et al. MrBayes 3.2: efficient Bayesian phylogenetic inference and model choice across a large model space. Syst Biol. 2012;61:539-42.

29. Valkiūnas G, Sehgal RNM, lezhova TA, Hull AC. Identification of Leucocytozoon toddi group (Haemosporida: Leucocytozoidae), with remarks on the species taxonomy of leucocytozoids. J Parasitol. 2010;96:170-7.

30. Musa S, Mackenstedt U, Woog F, Dinkel A. Avian malaria on Madagascar: prevalence, biodiversity and specialization of haemosporidian parasites. Int J Parasitol. 2019;49:199-210.

31. Walther E, Valkiūnas G, Wommack EA, Bowie RCK, lezhova TA, Sehgal RNM. Description and molecular characterization of a new Leucocytozoon parasite (Haemosporida: Leucocytozoidae), Leucocytozoon californicus sp. Nov., found in American kestrels (Falco sparverius sparverius). Parasitol Res. 2016;1 15:1853-62.

32. Nardoni S, Parisi F, Rocchigiani G, Ceccherelli R, Mancianti F, Poli A. Haemoproteus spp. and Leucocytozoon californicus Coinfection in a Merlin (Falco colombarius). Pathogens. 2020;9:263.

33. Pornpanom P, Salakij C, Prasopsom P, Lertwatcharasarakul P, Kasorndorkbua C, Santavakul M. Morphological and molecular characterization of avian trypanosomes in raptors from Thailand. Parasitol Res. 2019;118:2419-29.

34. Carlson ML, Proudfoot GA, Gentile K, Dispoto J, Weckstein JD. Haemosporidian prevalence in northern saw-whet owls Aegolius acadicus is predicted by host age and average annual temperature at breeding grounds. J Avian Biol. 2018;49:1-11.

35. Ishak HD, Dumbacher JP, Anderson NL, Keane JJ, Valkiūnas G, Haig SM et al. Blood parasites in owls with conservation implications for the spotted owl (Strix occidentalis). PLoS ONE. 2008;3:e2304.

36. Tanaka K, Sumiyama D, Kanazawa T, Sato Y, Murata K. Prevalence and molecular phylogeny of avian malaria parasites in Columbiformes in Japan. Japanese J Zoo Wildl Med. 2019;24:65-71.

37. Drovetski SV, Aghayan SA, Mata VA, Lopes RJ, Mode NA, Harvey JA et al. Does the niche breadth or trade-off hypothesis explain the abundance-occupancy relationship in avian Haemosporidia? Mol Ecol. 2014:23:3322-9.

38. Ellis VA, Huang $X$, Westerdahl $H$, Jönsson J, Hasselquist D, Neto JM, et al. Explaining prevalence, diversity and host specificity in a community of avian haemosporidian parasites. Oikos. 2020;129:1314-29.

39. Scaglione FE, Pregel P, Cannizzo FT, Pérez-Rodríguez AD, Ferroglio E, Bollo E. Prevalence of new and known species of haemoparasites in feral pigeons in northwest Italy. Malar J. 2015;14:99.

40. Dunn JC, Stockdale JE, Bradford EL, Mccubbin A, Morris AJ, Grice PV, et al. High rates of infection by blood parasites during the nestling phase in UK Columbids with notes on ecological associations. Parasitology. 2017;144:622-8.

41. Lertwatcharasarakul P, Salakij C, Prasopsom P, Kasorndorkbua C, Jakthong P, Santavakul M, et al. Molecular and morphological analyses of Leucocytozoon parasites (Haemosporida: Leucocytozoidae) in raptors from Thailand. Acta Parasitol. 2021;66:1406-16.

42. Villar Couto CM, Cumming GS, Lacorte GA, Congrains C, Izbicki R, Braga $\mathrm{EM}$, et al. Avian haemosporidians in the cattle egret (Bubulcus ibis) from central-western and southern Africa: high diversity and prevalence. PLOS ONE. 2019;14:e0212425.

43. Jiang Y, Brice B, Nguyen M, Loh R, Greay T, Adlard R, et al. Further characterisation of Leucocytozoon podargii in wild tawny frogmouths (Podargus strigoides) in Western Australia. Parasitol Res. 2019;118:1833-40.

44. Tanigawa M, Sato Y, Ejiri H, Imura T, Chiba R, Yamamoto H, et al. Molecular identification of avian haemosporidia in wild birds and mosquitoes on Tsushima Island. Japan J Vet Med Sci. 2013;75:319-26.

45. Hellgren O, Wood MJ, Waldenström J, Hasselquist D, Ottosson U, Stervander M, et al. Circannual variation in blood parasitism in a sub-Saharan migrant passerine bird, the garden warbler. J Evol Biol. 2013;26:1047-59.

46. Liu B, Deng Z, Huang W, Dong L, Zhang Y. High prevalence and narrow host range of haemosporidian parasites in Godlewski's bunting (Emberiza godlewskii) in northern China. Parasitol Int. 2019;69:121-5.

47. Synek P, Popelková A, Koubínová D, Štastný K, Langrová I, Votýpka J, et al. Haemosporidian infections in the Tengmalm's Owl (Aegolius funereus) and potential insect vectors of their transmission. Parasitol Res. 2016;115:291-8.

48. Pramual P, Thaijarern J, Tangkawanit U, Wongpakam K. Molecular identification of blood meal sources in black flies (Diptera: Simuliidae) suspected as Leucocytozoon vectors. Acta Trop. 2020;205:105383.

49. Jumpato W, Tangkawanit U, Wongpakam K, Pramual P. Molecular detection of Leucocytozoon (Apicomplexa: Haemosporida) in black flies (Diptera: Simuliidae) from Thailand. Acta Trop. 2019;190:228-34.

50. Razmyar J, Razmi GR, Mirzazadeh A. Microscopy and PCR-based detection of Leucocytozoon spp. in Iranian birds of prey. Sci Parasitol. 2016;17:1-6.

51. Ortego J, Cordero PJ. PCR-based detection and genotyping of haematozoa (Protozoa) parasitizing eagle owls, Bubo bubo. Parasitol Res. 2009;104:467-70.

52. Fecchio A, Bell JA, Bosholn M, Vaughan JA, Tkach W, Lutz HL, et al. An inverse latitudinal gradient in infection probability and phylogenetic diversity for Leucocytozoon blood parasites in New World birds. J Anim Ecol. 2020;89:423-35.

53. Telford SR, Nayar JK, Foster GW, Knight JW. Plasmodium forresteri n. sp., from raptors in Florida and southern Georgia: Its distinction from Plasmodium elongatum morphologically within and among host species and by vector susceptibility. J Parasitol. 1997;83:932-7.

54. Palinauskas V, Kosarev V, Shapoval A, Bensch S, Valkiūnas G. Comparison of mitochondrial cytochrome $b$ lineages and morphospecies of two avian malaria parasites of the subgenera Haemamoeba and Giovannolaia (Haemosporida: Plasmodiidae). Zootaxa. 2007;1626:39-50.

55. Dubiec A, Podmokła E, Zagalska-Neubauer M, Drobniak SM, Arct A, Gustafsson L, et al. Differential prevalence and diversity of haemosporidian parasites in two sympatric closely related non-migratory passerines. Parasitology. 2016;143:1320-9.

56. Hellgren O, Waldenström J, Peréz-Tris J, Szöll E, Si Ö, Hasselquist D, et al. Detecting shifts of transmission areas in avian blood parasites - a phylogenetic approach. Mol Ecol. 2007;16:1281-90.

57. Pérez-Tris J, Hellgren O, Križanauskienė A, Waldenström J, Secondi J, Bonneaud C, et al. Within-host speciation of malaria parasites. PLoS ONE. 2007:2:e235

58. Martinsen ES, Perkins SL, Schall JJ. A three-genome phylogeny of malaria parasites (Plasmodium and closely related genera): evolution of life-history traits and host switches. Mol Phylogenet Evol. 2008;47:261-73.

59. Ramey AM, Reed JA, Walther P, Link P, Schmutz JA, Douglas DC, et al. Evidence for the exchange of blood parasites between North America and the Neotropics in blue-winged teal (Anas discors). Parasitol Res. 2016;115:3923-39.

60. Dodge M, Guers SL, Sekercioğlu ÇH, Sehgal RNM. North American transmission of hemosporidian parasites in the Swainson's thrush (Catharus ustulatus), a migratory songbird. J Parasitol. 2013;99:548-54.

61. Pulgarín P, Gómez C, Bayly NJ, Bensch S, FitzGerald AM, Starkloff N, et al. Migratory birds as vehicles for parasite dispersal? Infection by 
avian haemosporidians over the year and throughout the range of a long-distance migrant. J Biogeogr. 2019;46:83-96.

62. Fecchio A, Bell JA, Pinheiro RBP, Cueto VR, Gorosito CA, Lutz HL, et al. Avian host composition, local speciation and dispersal drive the regional assembly of avian malaria parasites in South American birds. Mol Ecol. 2019;28:2681-93.

63. Tasci G, Olmez N, Aydin PN, Akca A, Sari B, Arslan M, et al. Prevalence and molecular characterization of haemosporidians in domestic geese: a new focus of haemosporidian parasites, kars province, northeastern Turkey. Isr J Vet Med. 2018;73:33-42.

64. Beadell JS, Covas R, Gebhard C, Ishtiaq F, Melo M, Schmidt BK, et al. Host associations and evolutionary relationships of avian blood parasites from West Africa. Int J Parasitol. 2009:39:257-66.

65. Bonneaud C, Pérez-Tris J, Federici P, Chastel O, Sorci G. Major histocompatibility alleles associated with local resistance to malaria in a passerine. Evolution. 2006;60:383-9.

66. Njabo KY, Cornel AJ, Bonneaud C, Toffelmier E, Sehgal RNM, Valkiūnas $\mathrm{G}$, et al. Nonspecific patterns of vector, host and avian malaria parasite associations in a central African rainforest. Mol Ecol. 2011:20:1049-61.

67. Martinsen ES, Waite JL, Schall JJ. Morphologically defined subgenera of Plasmodium from avian hosts: test of monophyly by phylogenetic analysis of two mitochondrial genes. Parasitology. 2007;134:483-90.

68. Salakij C, Kasorndorkbua C, Salakij J, Suwannasaeng P, Jakthong P. Quantitative and qualitative morphologic, cytochemical and ultrastructural characteristics of blood cells in the Crested Serpent eagle and Shikra. Jpn J Vet Res. 2015;63:95-105.

69. Pornpanom P, Chagas CRF, Lertwatcharasarakul P, Kasorndorkbua C, Valkiūnas G, Salakij C. Molecular prevalence and phylogenetic relationship of Haemoproteus and Plasmodium parasites of owls in Thailand: Data from a rehabilitation centre. Int J Parasitol Parasites Wildl. 2019;9:248-57.

70. Chagas $C R$, Valkiūnas G, de Oliveira GL, Ferreira Monteiro E, Vaz Guida FJ, França Simões R, et al. Diversity and distribution of avian malaria and related haemosporidian parasites in captive birds from a Brazilian megalopolis. Malar J. 2017;16:83.

71. Lacorte GA, Felix GMF, Pinheiro RRB, Chaves AV, Almeida-Neto G, Neves FS, et al. Exploring the diversity and distribution of neotropical avian malaria parasites-a molecular survey from Southeast Brazil. PLOS ONE. 2013:8:e57770.

72. Perkins SL, Schall J. A molecular phylogeny of malarial parasites recovered from cytochrome b gene sequences. J Parasitol. 2002;88:972-8.

73. Morel AP, Webster A, Prusch F, Anicet M, Marsicano G, Trainini G, et al. Molecular detection and phylogenetic relationship of Haemosporida parasites in free-ranging wild raptors from Brazil. Vet Parasitol Reg Stud Rep. 2021;23:100521.

74. Yoshimura A, Koketsu M, Bando H, Saiki E, Suzuki M, Watanabe Y, et al. Phylogenetic comparison of avian haemosporidian parasites from resident and migratory birds in northern Japan. J Wildl Dis. 2014;50:235-42.

75. Ishtiaq F, Gering E, Rappole JH, Rahmani AR, Jhala YV, Dove CJ, et al. Prevalence and diversity of avian hematozoan parasites in Asia: a regional survey. J Wild Dis. 2007:43:382-98.

76. Huang X, Dong L, Zhang C, Zhang Y. Genetic diversity, temporal dynamics, and host specificity in blood parasites of passerines in north China. Parasitol Res. 2015;114:4513-20.

77. Ilgūnas M, Palinauskas V, lezhova TA, Valkiūnas G. Molecular and morphological characterization of two avian malaria parasites (Haemosporida: Plasmodiidae), with description of Plasmodium homonucleophilum n. sp. Zootaxa. 2013;3666:49-61.

78. Santiago-Alarcon D, Outlaw DC, Ricklefs RE, Parker PG. Phylogenetic relationships of haemosporidian parasites in New World Columbiformes, with emphasis on the endemic Galapagos dove. Int J Parasitol. 2010:40:463-70

79. Mendes L, Pardal S, Morais J, Antunes S, Ramos JA, Perez-Tris J, et al. Hidden haemosporidian infections in Ruffs (Philomachus pugnax) staging in Northwest Europe en route from Africa to Arctic Europe. Parasitol Res. 2013;112:2037-43.

80. Lauron EJ, Loiseau C, Bowie RCK, Spicer GS, Smith TB, Melo M, et al. Coevolutionary patterns and diversification of avian malaria parasites in African sunbirds (Family Nectariniidae). Parasitology. 2015;142:635-47.
81. Chasar A, Loiseau C, Valkiūnas G, lezhova T, Smith TB, Sehgal RNM. Prevalence and diversity patterns of avian blood parasites in degraded African rainforest habitats. Mol Ecol. 2009:18:4121-33.

82. Loiseau C, Melo M, Lobato E, Beadell JS, Fleischer RC, Reis S, et al. Insularity effects on the assemblage of the blood parasite community of the birds from the Gulf of Guinea. J Biogeogr. 2017;44:2607-17.

83. Ferreira FC, Rodrigues RA, Sato Y, Borges MAZ, Braga ÉM. Searching for putative avian malaria vectors in a seasonally dry tropical forest in Brazil. Parasit Vectors. 2016:9:587.

84. Fecchio A, Wells K, Bell JA, Tkach VV, Lutz HL, Weckstein JD, et al. Climate variation influences host specificity in avian malaria parasites. Ecol Lett. 2019:22:547-57.

85. Schumm YR, Bakaloudis D, Barboutis C, Cecere JG, Eraud C, Fischer $D$, et al. Prevalence and genetic diversity of avian haemosporidian parasites in wild bird species of the order Columbiformes. Parasitol Res. 2021:120:1405-20.

86. Emmenegger T, Alves JA, Rocha AD, Costa JS, Schmid R, Schulze M, et al. Population-and age-specific patterns of haemosporidian assemblages and infection levels in European bee-eaters (Merops apiaster). Int J Parasitol. 2020;50:1125-31.

87. Chagas C, de Oliveira GL, Ferreira Monteiro E, Valkiūnas G, Viana Katayama M, Santos SV, et al. Hemosporidian parasites of free-living birds in the São Paulo Zoo. Brazil Parasitol Res. 2016;115:1443-52.

88. Tostes R, Pedroso Dias RJ, Martinele I, Xavier Senra MV, D'Agosto M, Massard CL. Multidisciplinary re-description of Plasmodium (Novyella) paranucleophilum in Brazilian wild birds of the Atlantic Forest kept in captivity. Parasitol Res. 2017;116:1887-97.

89. Villar CM, Bryan AL Jr, Lance SL, Braga EM, Congrains C, Del Lama SN. Blood parasites in nestlings of wood stork populations from three regions of the American continent. J Parasitol. 2013;99:522-7.

90. Crosby GT. Spread of the cattle egret in the Western Hemisphere. BirdBanding. 1972;43:205-12.

91. Manwell RD, Sessler GJ. Plasmodium paranucleophilum n. sp. from a South American tanager. J Protozool. 1971;18:629-32.

92. Salakij C, Kasorndorkbua C, Lertwatcharasarakul P, Salakij J. Ultra-structure of blood cells and molecular characteristics of Haemoproteus sp. in Blyth's hawk eagle. Comp Clin Path. 2015;24:1293-9.

93. Fecchio A, Pinheiro R, Felix G, Faria IP, Pinho JB, Lacorte GA, et al. Host community similarity and geography shape the diversity and distribution of haemosporidian parasites in Amazonian birds. Ecography (Cop). 2017:41:505-15.

94. Smith JD, Gill SA, Baker KM, Vonhof MJ. Prevalence and diversity of avian Haemosporida infecting songbirds in southwest Michigan. Parasitol Res. 2018;117:471-89.

95. Lutz HL, Hochachka WM, Engel Jl, Bell JA, Tkach WV, Bates JM, et al. Parasite prevalence corresponds to host life history in a diverse assemblage of Afrotropical birds and haemosporidian parasites. PLOS ONE. 2015;10:e0121254.

96. Ortego J, Calabuig G, Cordero PJ, Aparicio JM. Genetic characterization of avian malaria (Protozoa) in the endangered lesser kestrel Falco naumanni. Parasitol Res. 2007:101:1153-6.

97. Fourcade Y, Keišs O, Richardson DS, Secondi J. Continental-scale patterns of pathogen prevalence: a case study on the corncrake. Evol Appl. 2014;7:1043-55

98. Kulma K, Low M, Bensch S, Qvarnström A. Malaria infections reinforce competitive asymmetry between two Ficedula flycatchers in a recent contact zone. Mol Ecol. 2013;22:4591-601.

99. Jones W, Kulma K, Bensch S, Cichoń M, Kerimov A, Krist M, et al. Interspecific transfer of parasites following a range-shift in Ficedula flycatchers. Ecol Evol. 2018:8:12183-92.

100. Pacheco MA, Escalante AA, Garner MM, Bradley GA, Aguilar RF. Haemosporidian infection in captive masked bobwhite quail (Colinus virginianus ridgwayi), an endangered subspecies of the northern bobwhite quail. Vet Parasitol. 2011;182:113-20.

101. Beadell JS, Fleischer RC. A restriction enzyme-based assay to distinguish between avian hemosporidians. J Parasitol. 2005:91:683-5.

102. Pedro R, Claudio N, Elena C, Claudio V. Low occurrence of hemosporidian parasites in the Neotropic cormorant (Phalacrocorax brasilianus) in Chile. Parasitol Res. 2019;118:325-33.

103. Ham-Dueñas JG, Chapa-Vargas L, Stracey CM, Huber-Sannwald E. Haemosporidian prevalence and parasitaemia in the Black-throated 
sparrow (Amphispiza bilineata) in central-Mexican dryland habitats. Parasitol Res. 2017;116:2527-37.

104. Marzal A, Ricklefs RE, Valkiūnas G, Albayrak T, Arriero E, Bonneaud C, et al. Diversity, loss, and gain of malaria parasites in a globally invasive bird. PLOS ONE. 2011;6:e21905.

105. Beadell JS, Gering E, Austin J, Dumbacher JP, Peirce MA, Pratt TK, et al. Prevalence and differential host-specificity of two avian blood parasite genera in the Australo-Papuan region. Mol Ecol. 2004;13:3829-44.

106. Ferreira-Junior FC, de Angeli DD, Silveira P, Pacheco RC, Witter R, de Souza Ramos DG, et al. A new pathogen spillover from domestic to wild animals: Plasmodium juxtanucleare infects free-living passerines in Brazil. Parasitology. 2018;145:1949-58.

107. Valkiūnas $G$, llgūnas $M$, Bukauskaitè $D$, Chagas CRF, Bernotienè R, Himmel T, et al. Molecular characterization of six widespread avian haemoproteids, with description of three new Haemoproteus species. Acta Trop. 2019;197:1-17.

108. Gangoso L, Gutiérrez-López R, Martínez-de la Puente J, Figuerola J. Genetic colour polymorphism is associated with avian malarial infections. Biol Lett. 2016;12:20160839.

109. Puech M-P, Chavatte J-M, Landau I, Karadjian G. Haemoparasites of falcons in France: a 2-year survey in the Cevennes, with description of two new Haemoproteid species from poly-parasitised birds. J Nat Hist. 2019:53:2023-37.

110. Gutiérrez-López R, Gangoso L, Martínez-De La Puente J, Fric J, LópezLópez P, Mailleux M, et al. Low prevalence of blood parasites in a long-distance migratory raptor: the importance of host habitat. Parasit Vectors. 2015;8:189.

111. de Mello IF. New haemoproteids of some Indian birds. Proc Indian Acad Sci B. 1935:2:469-75.

112. Ishak HD, Loiseau C, Hull AC, Sehgal RNM. Prevalence of blood parasites in migrating and wintering California hawks. J Raptor Res. 2010;44:215-23.

113. Greiner EC, Fedynich AM, Webb SL, DeVault TL, Rhodes OE. Hematozoa and a new haemoproteid species from Cathartidae (New World Vulture) in South Carolina. J Parasitol. 2011:97:1137-40.

114. Yabsley MJ, Vanstreels RET, Martinsen ES, Wickson AG, Holland AE, Hernandez SM, et al. Parasitaemia data and molecular characterization of Haemoproteus catharti from New World vultures (Cathartidae) reveals a novel clade of Haemosporida. Malar J. 2018;17:12

115. Chahad-Ehlers S, Fushita AT, Lacorte GA, de Assis PCP, Del Lama SN. Effects of habitat suitability for vectors, environmental factors and host characteristics on the spatial distribution of the diversity and prevalence of haemosporidians in waterbirds from three Brazilian wetlands. Parasit Vectors. 2018;11:276.

116. Yildirim A, Aysul N, Bayramli G, Inci A, Eren H, Aypak S, et al. Detection and molecular characterization of a Haemoproteus lineage in a Tawny Owl (Strix aluco) in Turkey. Vet J Ankara Univ. 2013;69:179-83.

117. Bukauskaitè D, Žiegytè R, Palinauskas V, lezhova TA, Dimitrov D, Ilgūnas $M$, et al. Biting midges (Culicoides, Diptera) transmit Haemoproteus parasites of owls: evidence from sporogony and molecular phylogeny. Parasit Vectors. 2015:8:303.

118. Ciloglu A, Ergen AG, Inci A, Dik B, Duzlu O, Onder Z, et al. Prevalence and genetic diversity of avian haemosporidian parasites at an intersection point of bird migration routes: Sultan Marshes National Park. Turkey Acta Trop. 2020;210:105465.

119. Ferraguti M, Martínez-de la Puente J, Ruiz S, Soriguer R, Figuerola J. On the study of the transmission networks of blood parasites from SW Spain: diversity of avian haemosporidians in the biting midge Culicoides circumscriptus and wild birds. Parasit Vectors. 2013;6:208.

120. Valkiūnas $G$, Ilgūnas M, Bukauskaitè D, Duc M, lezhova TA. Description of Haemoproteus asymmetricus n. sp. (Haemoproteidae), with remarks on predictability of the DNA haplotype networks in haemosporidian parasite taxonomy research. Acta Trop. 2021;218:105905.

121. Valkiūnas G, lezhova TA, Shapoval AP. High prevalence of blood parasites in hawfinch Coccothraustes coccothraustes. J Nat Hist. 2003:37:2647-52

122. Valkiūnas $\mathrm{G}$, lezhova TA. Exo-erythrocytic development of avian malaria and related haemosporidian parasites. Malar J. 2017;16:101.

123. Sacchi L, Prigioni C. A Leucocytozoon of Buzzard (Buteo buteo (L), Accipitridae) from Northen Italy. Ann Parasitol Hum Comp. 1982:57:203-8.
124. Forrester DJ, Foster GW, Morrison JL. Leucocytozoon toddi and Haemoproteus tinnunculi (Protozoa: Haemosporina) in the Chimango caracara (Milvago chimango) in Southern Chile. Mem Inst Oswaldo Cruz. 2001;96:1023-4.

125. Bennett GF, Whiteway M, Woodworth-Lynas C. A host-parasite catalogue of the Avian Haematozoa. Canada: Memorial University of Newfoundland; 1982

126. Bishop MA, Bennett GF. Host-parasite catalogue of the avian haematozoa: supplement 1, and Bibliography of the avian blood-inhabiting haematozoa. Meml Univ Newfoundl Occas Pap Biol. 1992;15:1-243.

127. Ortiz-Catedral L, Brunton D, Stidworthy MF, Elsheikha HM, Pennycott T, Schulze C, et al. Haemoproteus minutus is highly virulent for Australasian and South American parrots. Parasit Vectors. 2019;12:1-10.

128. Dimitrov $D$, Palinauskas $V$, lezhova TA, Bernotienè $R$, llgūnas $M$, Bukauskaitè D, et al. Plasmodium spp.: an experimental study on vertebrate host susceptibility to avian malaria. Exp Parasitol. 2015;148:1-16.

129. Smith MM, Van Hemert C, Merizon R. Haemosporidian parasite infections in grouse and ptarmigan: prevalence and genetic diversity of blood parasites in resident Alaskan birds. Int J Parasitol Parasites Wildl. 2016:5:229-39.

130. Valkiūnas G, Palinauskas V, Ilgūnas M, Bukauskaitè D, Dimitrov D, Bernotiené $\mathrm{R}$, et al. Molecular characterization of five widespread avian haemosporidian parasites (Haemosporida), with perspectives on the PCR-based detection of haemosporidians in wildlife. Parasitol Res. 2014;113:2251-63.

131. Inumaru M, Murata K, Sato Y. Prevalence of avian haemosporidia among injured wild birds in Tokyo and environs, Japan. Int J Parasitol Parasites Wildl. 2017;6:299-309.

132. Bertram MR, Hamer GL, Hartup BK, Snowden KF, Medeiros MC, Hamer SA. Haemosporida prevalence and diversity are similar in endangered wild whooping cranes (Grus americana) and sympatric sandhill cranes (Grus canadensis). Parasitology. 2017;144:629-40.

133. Valkiūnas G, lezhova TA, Loiseau C, Smith TB, Sehgal RNM. New malaria parasites of the subgenus Novyella in African rainforest birds, with remarks on their high prevalence, classification and diagnostics. Parasitol Res. 2009;104:1061.

134. Garnham PCC. Malaria parasites and other Haemosporidia. Oxford: Blackwell; 1966.

135. Lewicki KE, Huyvaert KP, Piaggio AJ, Diller LV, Franklin AB. Effects of barred owl (Strix varia) range expansion on Haemoproteus parasite assemblage dynamics and transmission in barred and northern spotted owls (Strix occidentalis caurina). Biol Invasions. 2015;17:1713-27.

136. Paperna I, Yosef R, Landau I. Plasmodium spp. in raptors on the EurasianAfrican migration route. Parasite. 2007;14:313-22.

137. Peirce MA, Bennett GF, Bishop M. The haemoproteids of the avian order Falconiformes. J Nat Hist. 1990;24:1091-100.

138. Greiner EC, Mundy PJ. Hematozoa from southern African vultures, with a description of Haemoproteus janovyi sp. N. J Parasitol. 1979:65:147-53.

139. Thompson LJ, Barber DR, Bechard MJ, Botha AJ, Wolter K, Neser W, et al. Variation in monthly sizes of home-ranges of Hooded Vultures Necrosyrtes monachus in western, eastern and southern Africa. Ibis. 2020;162:1324-38.

140. Reading RP, Bradley J, Hancock P, Garbett R, Selebatso M, Maude G. Home-range size and movement patterns of Hooded Vultures Necrosyrtes monachus in southern Africa. Ostrich. 2019;90:73-7.

141. Garbett R, Maude G, Hancock P, Kenny D, Reading R, Amar A. Association between hunting and elevated blood lead levels in the critically endangered African white-backed vulture Gyps africanus. Sci Total Environ. 2018:630:1654-65.

142. Valkiūnas $G$, lezhova T. [The peculiarities of infection of sparrowhawks from West-European and Indian-Asiatic flyways with haemosporidians (Sporozoa: Haemosporidia)](in Russian). Parazitol (St Petersburg). 1990;24:113-20.

143. Valkiūnas G, lezhova TA, Loiseau C, Sehgal RNM. Nested cytochrome b polymerase chain reaction diagnostics detect sporozoites of hemosporidian parasites in peripheral blood of naturally infected birds. J Parasitol. 2009;95:1512-5.

144. Salakij J, Lertwatcharasarakul P, Kasorndorkbua C, Salakij C. Plasmodium circumflexum in a Shikra (Accipiter badius): phylogeny and ultra-structure of the haematozoa. Jpn J Vet Res. 2012:60:105-9. 
145. Khan RA, Desser SS, Fallis AM. Survival of sporozoites of Leucocytozoon in birds for 11 days. Can J Zool J Zool. 1969;47:347-50.

146. Bensch S, Inumaru M, Sato Y, Lee Cruz L, Cunningham AA, Goodman $\mathrm{SJ}$, et al. Contaminations contaminate common databases. Mol Ecol Resour. 2021:21:355-62.

147. Sehgal RNM, Valkiūnas G, lezhova TA, Smith TB. Blood parasites of chickens in Uganda and Cameroon with molecular descriptions of Leucocytozoon schoutedeni and Trypanosoma gallinarum. J Parasitol. 2006;92:1336-43.

\section{Publisher's Note}

Springer Nature remains neutral with regard to jurisdictional claims in published maps and institutional affiliations.

- fast, convenient online submission

- thorough peer review by experienced researchers in your field

- rapid publication on acceptance

- support for research data, including large and complex data types

- gold Open Access which fosters wider collaboration and increased citations

- maximum visibility for your research: over $100 \mathrm{M}$ website views per year

At BMC, research is always in progress.

Learn more biomedcentral.com/submissions 